\title{
RECUPERAÇÃO ESTRUTURAL DE EDIFICAÇÕES HISTÓRICAS UTILIZANDO PERFIS FORMADOS A FRIO
}

\section{MARCOS LEOPOLDO BORGES}

Dissertação apresentada à Escola de Engenharia de São Carlos, da Universidade de São Paulo, como parte dos requisitos para obtenção do título de Mestre em Engenharia de Estruturas

ORIENTADOR: Prof. Dr. José Jairo de Sáles

São Carlos

2001 
À Renata, companheira e amiga de todos os momentos e ao Rafael fruto do nosso amor, inspiração para novos sonhos... 


\section{AGRADECIMENTOS}

Ao agradecer àqueles que contribuíram para que este trabalho viesse a se concretizar, sei estar correndo risco de cometer alguma omissão. Mal maior, porém, seria o silêncio.

Muitas pessoas foram imprescindíveis para que esta Dissertação de Mestrado fosse gestada e enfim se concretizasse. Serei sempre grato aos meus pais, Leopoldino e Elza, pelo incentivo permanente, manifesto em palavras e em gestos concretos, à minha sogra, Abadia, que é mãe para mim, por todo apoio à minha família, nas minhas constantes ausências em razão dos afazeres acadêmicos, aos funcionários da biblioteca central e bibliotecária do departamento de Estruturas da Escola de Engenharia de São Carlos - USP, dentre os quais destaco a Maria Nadir, que sempre me atendeu com especial deferência, e por fim, registro meu sincero agradecimento ao meu orientador, Prof. Dr. José Jairo de Sáles, pelas oportunas e seguras intervenções pedagógicas, neste processo em que fui o grande beneficiário. Soli Dio Gloria! 


\section{SUMÁRIO}

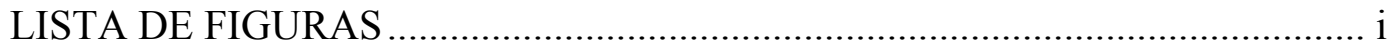

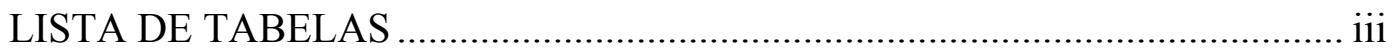

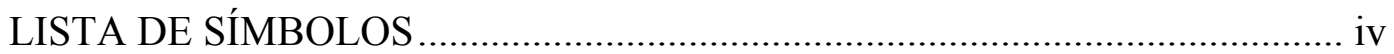

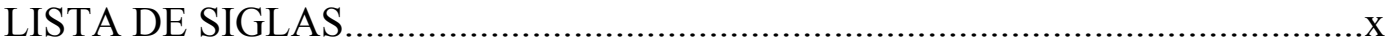

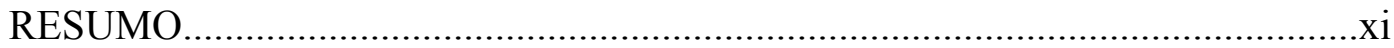

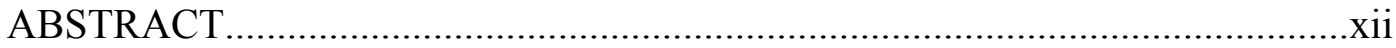

1. INTRODUÇÃ

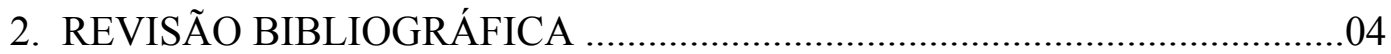

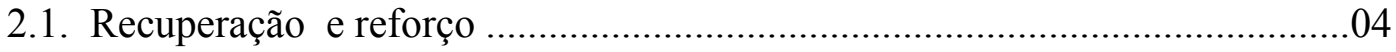

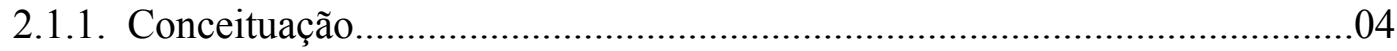

2.1.2. Procedimentos de recuperação e reforço.....................................................05

2.1.3. Recuperação de elementos estruturais de madeira......................................11

2.1.4.Recuperação de edifícios com a utilização de estruturas de aço....................16

2.2. Metodologia para a recuperação de obras históricas....................................23

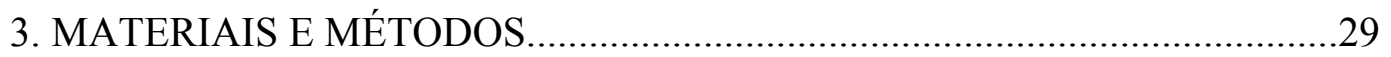


3.1.1.Histórico do município onde está situada a edificação..................................29

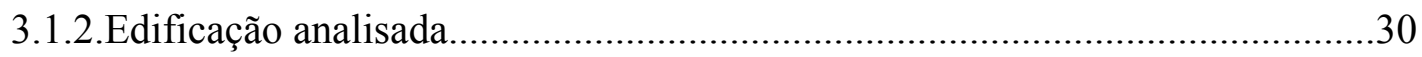

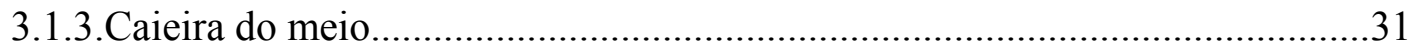

3.2. Elementos estruturais em aço formados a frio..................................................3

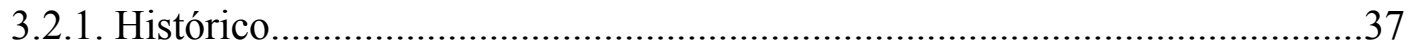

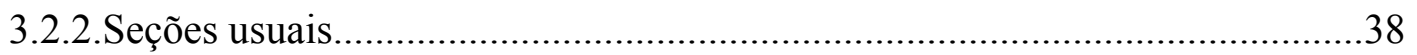

3.2..3.Materiais empregados em perfis de chapa dobrada....................................39

3.3. Dimensionamento das peças a serem substituídas........................................43

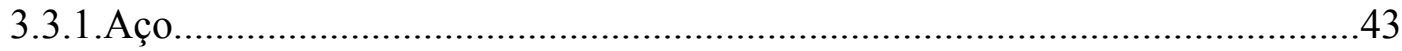

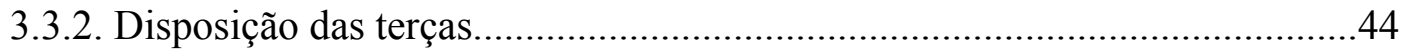

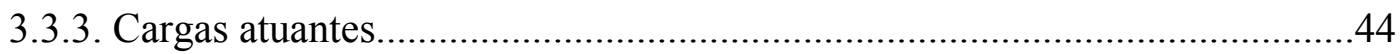

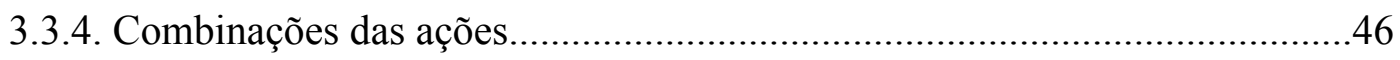

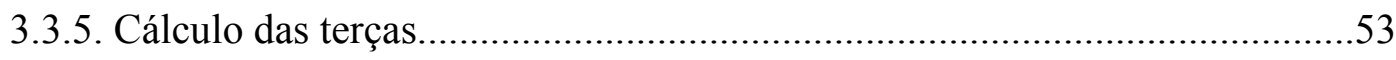

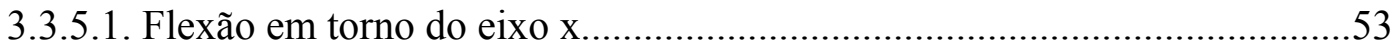

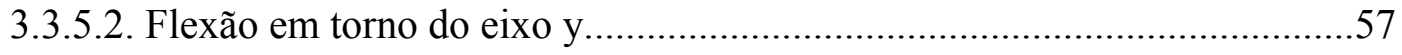

3.3.5.3. Verificação dos deslocamentos limites......................................................58

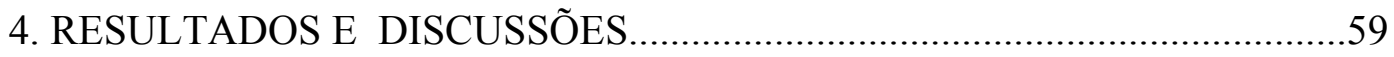

5. CONSIDERAÇÕES FINAIS E CONCLUSÕES..........................................62

ANEXO

REFERÊNCIAS BIBLIOGRAFICAS...................................................... 101 


\section{LISTA DE FIGURAS}

FIGURA 1.1 Trabalhos internos da restauração no Palazzo Ducale........................02

FIGURA 2.1 Fluxograma de atuação para resolução de problema patológico........10

FIGURA 2.2 Cobertura do pavilhão de exposição - Uberaba-MG - Ataques

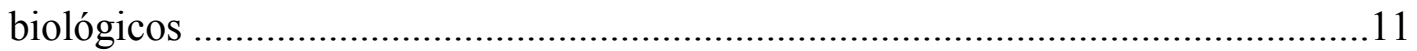

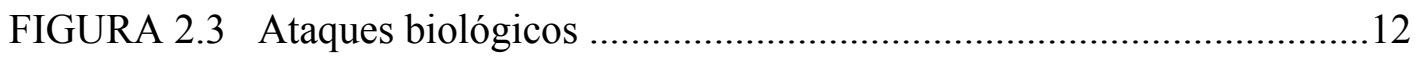

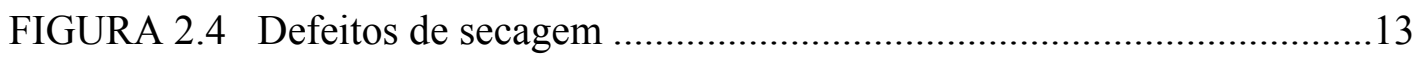

FIGURA 2.5 Defeitos de processamento da madeira ............................................13

FIGURA 2.6 Estrutura de madeira “ Galpão Criolo “- Florianópolis-SC...............15

FIGURA 2.7 Detalhe do reforço das barras inclinadas........................................15

FIGURA 2.8 Fachada da Igreja São Cristóvão......................................................16

FIGURA 2.9 Detalhe da recuperação da cúpula...................................................17

FIGURA 2.10 Igreja São Cristóvão. Pilar de aço embutido no arco........................17

FIGURA 2.11 Detalhe da recuperação da cobertura da Igreja Matriz de Conquista-

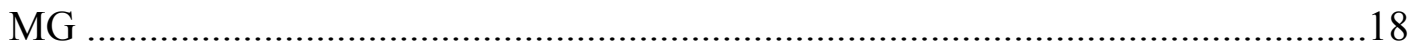

FIGURA 2.12 Igreja São Francisco - Recuperação do arco cruzeiro......................19

FIGURA 2.13 Detalhe de vigas metálicas sustentando piso de madeira.................20

FIGURA 2.14 Cobertura em estrutura metálica - Mercado público ......................21

FIGURA 2.15 Execução da cobertura - Mercado público.....................................21

FIGURA 2.16 Fluxograma - Passos a serem seguidos na recuperação de uma

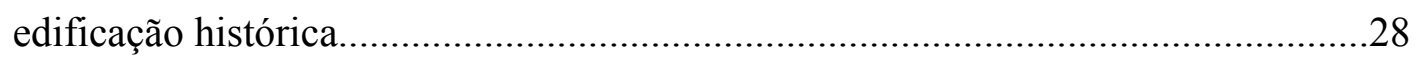

FIGURA 3.1 Mapa indicando entorno da Caieira do Meio.................................32

FIGURA 3.2 Detalhe do galpão dos fornos com carretão......................................32

FIGURA 3.3 Corte esquemático da edificação dos fornos...................................33 
FIGURA 3.4 Planta dos fornos - Caieira do Meio...............................................33

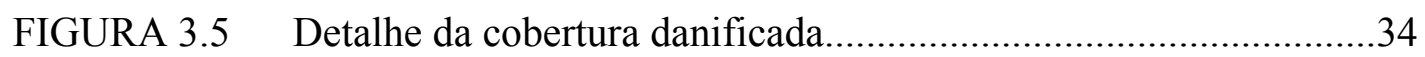

FIGURA 3.6 Visão geral da cobertura danificada............................................ 34

FIGURA 3.7 Vista geral - Edificação 2 - Caieira do Meio.....................................35

FIGURA 3.8 Edificação 2 - Caieira do Meio. Corte esquemático.........................35

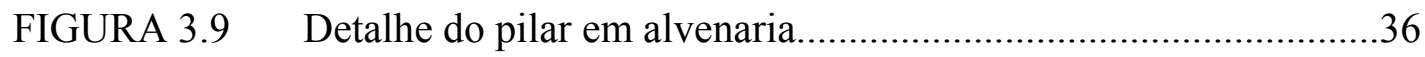

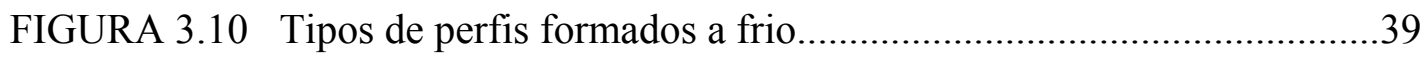

FIGURA 3.10 Esquema de carregamento das terças...........................................49

FIGURA 4.1 Detalhe da ligação aço/madeira................................................61 
TABELA 3.1 Principais aços estruturais ASTM e sua utilização...........................40

TABELA 3.2 Coeficientes de ponderação das ações..........................................47

TABELA 3.3 Fatores de combinação e fatores de utilização...............................47

TABELA 3.4 Deslocamentos limites recomendados...........................................50 


\section{LISTA DE SIGLAS}

ABNT Associação Brasileira de Normas Técnicas

AISI Norma Americana de chapa dobrada (American Iron Steel Institute)

CODEMPHAU Conselho Deliberativo Municipal do Patrimônio Histórico e Artístico de Uberaba.

CONDEPHAAT Conselho de Defesa do Patrimônio Artístico, Arqueológico e Turístico do Estado de São Paulo

IPHAN - Instituto do Patrimônio Histórico e Artístico Nacional 


\section{LISTA DE SÍMBOLOS}

\section{Romanos maiúsculos}

A - área bruta da seção transversal da barra

- área estabelecida para cálculo de enrijecedores transversais

$\mathrm{A}_{\mathrm{d}} \quad$ - área bruta da mesa comprimida e do respectivo enrijecedor de borda

$\mathrm{A}_{\mathrm{ef}} \quad$ - área efetiva da seção transversal da barra

- área efetiva do enrijecedor intermediário ou de borda

$\mathrm{A}_{\mathrm{s}} \quad$ - área reduzida do enrijecedor intermediário ou de borda

- área da seção transversal do enrijecedor de alma

$\mathrm{A}_{\mathrm{st}} \quad$ - área da seção do enrijecedor de borda ou intermediário excluindo qualquer parte de elementos adjacentes

$\mathrm{C}_{\mathrm{b}} \quad$ - coeficiente de equivalência de momentos na flexão

$\mathrm{C}_{\mathrm{m}} \quad$ - coeficiente de equivalência de momentos na flexão composta

$\mathrm{C}_{\mathrm{mx}}$ - valor de $\mathrm{C}_{\mathrm{m}}$ para flexão em relação ao eixo principal $\mathrm{x}$

$\mathrm{C}_{\mathrm{my}}$ - valor de $\mathrm{C}_{\mathrm{m}}$ para flexão em relação ao eixo principal y

$\mathrm{C}_{\mathrm{w}} \quad$ - constante de empenamento da seção

D - largura nominal do enrijecedor de borda

E - módulo de elasticidade do aço (205 $000 \mathrm{MPa})$

$\mathrm{F}_{\mathrm{G}} \quad$ - ação permanente

$\mathrm{F}_{\mathrm{Q}} \quad$ - ação variável

$\mathrm{F}_{\mathrm{Q}, \mathrm{exc}}$ - ação excepcional;

$\mathrm{F}_{\mathrm{Rd}} \quad$ - força resistente de cálculo, em geral 
$\mathrm{F}_{\mathrm{Sd}} \quad$ - força solicitante de cálculo, em geral

$\mathrm{G} \quad$ - módulo de elasticidade transversal do aço $(0,385 \mathrm{E}=78925 \mathrm{MPa})$

$\mathrm{I}_{\mathrm{a}} \quad$ - momento de inércia de referência do enrijecedor intermediário ou de borda

$I_{\min } \quad$ - momento de inércia mínimo do enrijecedor intermediário

$\mathrm{I}_{\mathrm{S}} \quad$ - momento de inércia da seção bruta do enrijecedor, em torno do seu próprio eixo baricêntrico paralelo ao elemento a ser enrijecido. Para enrijecedor de borda, a parte curva entre o enrijecedor e o elemento a ser enrijecido não deve ser considerada

$I_{s, m i n}$ - momento de inércia mínimo do enrijecedor em relação ao plano médio da alma

$I_{\mathrm{sf}} \quad$ - momento de inércia da seção bruta do elemento com enrijecedores intermediários (incluindo os enrijecedores intermediários) em relação ao seu próprio eixo principal

$\mathrm{I}_{\mathrm{x}} ; \mathrm{I}_{\mathrm{y}}$ - momentos de inércia da seção bruta em relação aos eixos principais $x$ e $y$, respectivamente

$\mathrm{I}_{\mathrm{t}} \quad$ - momento de inércia à torção uniforme

$\mathrm{K}_{\mathrm{x}} \mathrm{L}_{\mathrm{x}}$ - comprimento efetivo de flambagem da barra em relação ao eixo $\mathrm{x}$

$\mathrm{K}_{\mathrm{y}} \mathrm{L}_{\mathrm{y}}$ - comprimento efetivo de flambagem da barra em relação ao eixo y

$\mathrm{K}_{t} \mathrm{~L}_{\mathrm{t}} \quad$ - comprimento efetivo de flambagem da barra por torção

L - distância entre pontos travados lateralmente da barra

- comprimento da barra

$\mathrm{L}_{\mathrm{d}} \quad$ - comprimento da meia onda longitudinal associada à tensão convencional de flambagem elástica por distorção

$\mathrm{M}_{\mathrm{A}} \quad$ - momento fletor solicitante, em módulo, no $1^{\mathrm{o}}$. quarto do segmento analisado para FLT

$\mathrm{M}_{\mathrm{B}} \quad$ - momento fletor solicitante, em módulo, no centro do segmento analisado para FLT

$\mathrm{M}_{\mathrm{C}} \quad$ - momento fletor solicitante, em módulo, no $3^{\circ}$. quarto do segmento analisado para FLT 
$\mathrm{M}_{\text {dist }}$ - momento fletor de flambagem por distorção

$\mathrm{M}_{\mathrm{e}} \quad$ - momento fletor de flambagem elástica

$\mathrm{M}_{\text {máx }}$ - momento fletor solicitante máximo, em módulo, no segmento analisado para FLT

$\mathrm{M}_{\mathrm{Rd}} \quad$ - momento fletor resistente de cálculo

$\mathrm{M}_{\mathrm{x}, \mathrm{Rd}} ; \mathrm{M}_{\mathrm{y}, \mathrm{Rd}}$ - momentos fletores resistentes de cálculo em relação aos eixos principais $x$ e $y$, respectivamente

$\mathrm{M}_{\mathrm{Sd}} \quad$ - momento fletor solicitante de cálculo

$\mathrm{M}_{\mathrm{x}, \mathrm{Sd}} ; \mathrm{M}_{\mathrm{y}, \mathrm{Sd}}$ - momentos fletores solicitantes de cálculo em relação aos eixos principais $x$ e $y$, respectivamente

$\mathrm{M}_{\mathrm{xt}, \mathrm{Rd}} ; \mathrm{M}_{\mathrm{yt}, \mathrm{Rd}}$ - momentos fletores resistentes de cálculo, na seção considerada, em relação aos eixos $x$ e $y$, respectivamente, calculados com base no escoamento da fibra tracionada da seção bruta

$\mathrm{M}_{\mathrm{y}} \quad$ - momento fletor correspondente ao início de escoamento na seção

$\mathrm{M}_{0, \mathrm{Rd}}$ - momento fletor resistente de cálculo, obtido com base no início de escoamento da seção efetiva, conforme 7.8.1.1

$\mathrm{M}_{1} ; \mathrm{M}_{2}$ - menor e maior momento fletor de extremidade da barra, respectivamente

$\mathrm{N}_{\mathrm{c}, \mathrm{Rd}}$ - força normal de compressão resistente de cálculo

$\mathrm{N}_{\mathrm{c}, \mathrm{Sd}}$ - força normal de compressão solicitante de cálculo

$\mathrm{N}_{\mathrm{e}} \quad$ - força normal de flambagem elástica

$\mathrm{N}_{\mathrm{ex}} ; \mathrm{N}_{\mathrm{ey}}$ - forças normais de flambagem elástica por flexão em relação aos eixos $x \mathrm{e}$

$y$, respectivamente

$\mathrm{N}_{\mathrm{et}} \quad$ - força normal de flambagem elástica por torção

$\mathrm{N}_{\mathrm{ext}}$ - força normal de flambagem elástica por flexo-torção

$\mathrm{N}_{\mathrm{s}, \mathrm{Rd}}$ - força normal de compressão resistente de cálculo do enrijecedor de alma

$\mathrm{N}_{0, R d}$ - força normal de compressão resistente de cálculo, conforme 7.7, admitindo $\rho=1,0$ 
$\mathrm{W}_{\mathrm{c}} \quad$ - módulo de resistência elástico da seção bruta em relação à fibra comprimida

$\mathrm{W}_{\mathrm{c}, \text { ef }}$ - módulo de resistência elástico da seção efetiva em relação à fibra comprimida, referente à flambagem lateral com torção

$\mathrm{W}_{\text {ef }}$ - módulo de resistência elástico da seção efetiva referente ao início de escoamento da seção efetiva

$\mathrm{W}_{\mathrm{xt}} ; \mathrm{W}_{\mathrm{yt}}$ - módulos de resistência elásticos da seção bruta em relação aos eixos $x$ e $y$, respectivamente, referentes à fibra tracionada;

\section{Romanos minúsculos}

b - largura do elemento, é a dimensão plana do elemento sem incluir dobras

$b_{\text {ef }} \quad$ - largura efetiva

$\mathrm{b}_{\mathrm{ef}, 1} ; \mathrm{b}_{\mathrm{ef}, 2}$ - larguras efetivas

$b_{\text {ef,r }} \quad$ - largura efetiva reduzida do subelemento

$b_{\mathrm{f}} \quad$ - largura nominal da mesa ou do conjunto mesa - enrijecedores de borda

$b_{\mathrm{w}} \quad$ - largura nominal da alma

$b_{0} \quad$ - largura de um elemento com enrijecedor(es) intermediário(s)

$d_{\text {ef }} \quad$ - largura efetiva do enrijecedor de borda

$d_{s} \quad$ - largura efetiva reduzida do enrijecedor de borda

$\mathrm{d}_{1} \quad$ - deslocamento referente à combinação de todas as ações

$\mathrm{d}_{2} \quad$ - deslocamento referente à combinação das ações variáveis

$f_{u} \quad$ - resistência à ruptura do aço na tração

$\mathrm{f}_{\mathrm{y}} \quad$ - resistência ao escoamento do aço

h $\quad$ - largura da alma (altura da parte plana da alma)

$\mathrm{h}_{\mathrm{x}} ; \mathrm{h}_{\mathrm{y}}$ - coordenadas $x$ e $y$, respectivamente, do apoio da seção constituída pela mesa

e enrijecedores de borda em relação ao seu centróide

$\mathrm{k} \quad$ - coeficiente de flambagem local 
$\mathrm{k}_{\mathrm{a}} \quad$ - parâmetro empregado no cálculo do coeficiente de flambagem local $k$ de elementos uniformemente comprimidos com enrijecedor de borda

$\mathrm{k}_{\phi} \quad$ - constante de rigidez à rotação empregada no cálculo da tensão convencional de flambagem elástica por distorção

q - valor de cálculo da força uniformemente distribuída de referência empregada no dimensionamento das ligações de barras compostas submetidas à flexão

r $\quad$ - raio de giração da seção bruta

$\mathrm{r}_{\mathrm{o}} \quad$ - raio de giração polar da seção bruta em relação ao centro de torção

$r_{x} \quad$ - raio de giração da seção bruta em relação ao eixo principal $x$

$\mathrm{r}_{\mathrm{y}} \quad$ - raio de giração da seção bruta em relação ao eixo principal y

t $\quad$ - espessura da chapa ou do elemento

$t_{\text {eq }} \quad$ - espessura equivalente do elemento com enrijecedores intermediários

$t_{s} \quad-$ espessura do enrijecedor transversal

$\mathrm{x}_{\mathrm{o}} ; \mathrm{y}_{\mathrm{o}}$ - coordenadas do centro de torção na direção dos eixos $x$ e $y$, respectivamente, em relação ao centróide da seção

\section{Gregos minúsculos}

$\alpha \quad$ - fator de imperfeição inicial

$\alpha_{1} ; \alpha_{2} ; \alpha_{3}$ - parâmetros empregados no cálculo da tensão convencional de flambagem elástica por distorção

$\beta$ - parâmetro empregado no cálculo do fator de redução associado à flambagem $\rho$

$\beta_{1}$ a $\beta_{4}$ - parâmetros empregados no cálculo da tensão convencional de flambagem elástica por distorção

$\gamma \quad$ - coeficiente de ponderação das ações ou das resistências, em geral 
$\gamma_{\mathrm{g}} ; \gamma_{\mathrm{q}}$ - coeficientes de ponderação das ações permanentes e variáveis, respectivamente

$\eta \quad$ - parâmetro empregado no cálculo da tensão convencional de flambagem elástica por distorção

$\lambda_{\text {dist }} \quad$ - índice de esbeltez reduzido referente à flambagem por distorção

$\lambda_{\mathrm{p}} \quad$ - índice de esbeltez reduzido do elemento

$\lambda_{\mathrm{pd}} \quad$ - índice de esbeltez reduzido do elemento calculado com a tensão $\sigma_{\mathrm{n}}$

$\lambda_{\mathrm{p} 0} \quad$ - valor de referência do índice de esbeltez reduzido do elemento

$\lambda_{0} \quad$ - índice de esbeltez reduzido da barra

$\theta$ - ângulo entre o plano da mesa e o plano do enrijecedor de borda simples

$\rho \quad$ - fator de redução associado à flambagem da barra

$\rho_{\mathrm{FLT}} \quad$ - fator de redução associado à flambagem lateral com torção da barra

$\sigma \quad$ - tensão normal, em geral

$\sigma_{\text {dist }}$ - tensão convencional de flambagem elástica por distorção

$\sigma_{\mathrm{n}} \quad$ - tensão normal de compressão calculada com base nas combinações de ações para os estados limites de utilização

$\Psi \quad$ - relação $\sigma_{2} / \sigma_{1}$ empregada no cálculo do coeficiente de flambagem local $\mathrm{k}$

$\psi_{0} \quad$ - fator de combinação para as combinações últimas das ações

$\psi_{0, \text { ef }} \quad$ - fator de combinação efetivo para as combinações últimas das ações

$\psi_{1} ; \psi_{2}$ - fatores de utilização para as combinações de utilização das ações 
BORGES, M. L. (2001). Recuperação estrutural de edificações históricas utilizando perfis formados a frio. São Carlos, 2001. 120 p. Dissertação ( Mestrado) - Escola de Engenharia de São Carlos, Universidade de São Paulo.

Este trabalho apresenta a proposta de recuperação estrutural de uma edificação histórica no Município de Uberaba por meio de perfis formados a frio. Para o dimensionamento e cálculo dos elementos estruturais foi utilizado o projeto de Norma Brasileira de Dimensionamento de Estruturas de Aço Constituídas por Perfis formados a Frio. São apresentados os critérios e procedimentos para a recuperação de estruturas em geral e especificamente para as edificações antigas ou históricas. É feita uma análise da viabilidade técnica, da utilização de perfís formados a frio na recuperação estrutural de obras históricas.

Palavras-chave: recuperação estrutural; edificações históricas; perfis formados a frio. 
BORGES, M. L. (2001). Structural recovery of a historical construction by means of cold-formed sections. São Carlos, 2001. 120 p. Dissertação ( Mestrado) - Escola de Engenharia de São Carlos, Universidade de São Paulo.

This work presents the proposal of structural recovery of a historical construction in Uberaba City, by means of cold-formed sections. It was used the Steel Structures Increasing Brazilian Norm Project, composed of cold-formed sections. It is presented the criteria and procedures for the general structural recovery to the old or historical constructions. It is also made an analysis of technical viability of cold-formed sections utilization in structural recovery of historical works.

Keywords: structural recovery; historical construction; cold-formed sections. 


\section{INTRODUCẼ̃O}

A intervenção na parte estrutural de edificações históricas deve ser feita de maneira a preservar, ao máximo, as características originais. Segundo PUCCIONI (1997), deve-se estudar o máximo, para intervir o mínimo com eficiência e segurança. Devese observar e avaliar quais são realmente as características originais dessas edificações, já que várias delas passaram por processos de descaracterização. Tais processos podem advir de transformações de caráter histórico, ou realmente de deformações impostas ao longo do tempo, comprometendo às vezes sua autenticidade e sua originalidade.

Para intervir em obras históricas exige-se uma pesquisa minuciosa e a definição de critérios específicos a fim de se obter um resultado satisfatório em nível de partido arquitetônico. Segundo um dos precursores da teoria do restauro o arquiteto francês VIOLET LE DUC (1868) "Restaurar um edifício não é mantê-lo, repará-lo ou refazê-lo: é restabelecê-lo num estado completo que pode não haver existido em um momento determinado". No reforço e recuperação da estrutura propriamente dita é necessário obter informações detalhadas por meio de projetos, na maioria inexistentes, ou por investigação no local. Essa investigação pode ser feita por meio de uma inspeção visual detalhada da estrutura, verificando o tipo de esquema estrutural, o sistema de ligação - geometria e disposição - deslocamentos excessivos nos elementos estruturais, corrosão, entre outros.

Independentemente dos materiais estruturais utilizados, de acordo com PIZZI \&. GUEVARA (1997) as etapas de investigação da estrutura de uma edificação são as seguintes: a) Relatório Dimensional b) Relatório de danos Estruturais c) Reavaliação 
das degradações envolvidas d) estimativa de cálculo das ações mediante análise computacional. Tais etapas de investigação permitem a elaboração de um projeto viável sob o ponto de vista técnico, para recuperação dos elementos de uma estrutura.

Dentre os materiais existentes para reforço e/ou recuperação de estruturas das edificações, tem-se o aço. A estrutura de aço se adapta muito bem a outros materiais como o concreto armado e a madeira. Segundo SANTOS apud REIS (1996) estruturas metálicas empregadas para reforço e recuperação de edificações advém da época do renascimento. Em 1523, as cúpulas de São Marcos, em Veneza, datadas de 976 a 1071, foram envolvidas em anéis de ferro para eliminar os problemas estruturais caracterizados pelas fendas nelas existentes na ocasião. O Palazzo Ducale,

em Gênova, Itália, datado do século XI, foi transformado em Palácio da Cultura em 1980, sendo que o aço foi utilizado na restauração das escadas principal e secundária, no anfiteatro (Figura 1.1) e na cúpula sonora da sala de reuniões.

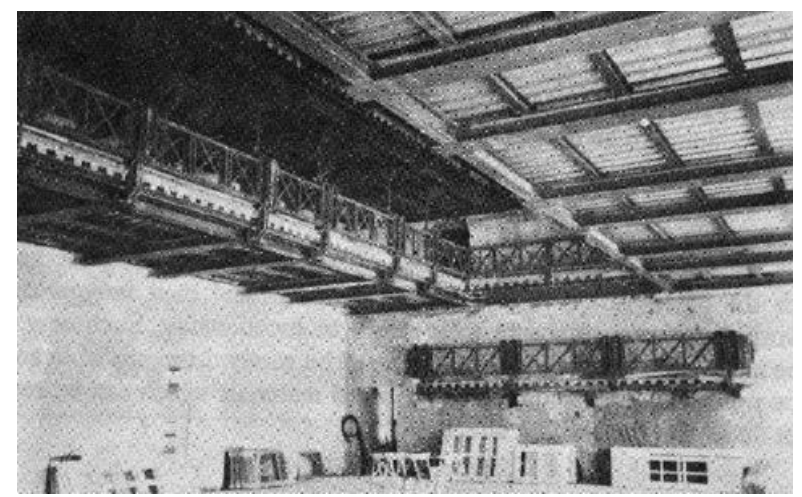

Figura 1.1 - Trabalhos internos da restauração no Palazzo Ducale - Gênova - Itália fonte: MAZZOLANI, 1996 
No Brasil, também se utiliza tal material para recuperação e reforço de edificações, mas ainda em proporções menores quando comparado com outros países, talvez em parte pela cultura do concreto armado. Os elementos em aço utilizados para a recuperação das edificações em geral podem ser perfis laminados, soldados e formados a frio bem como chapas e barras.

A norma brasileira de cálculo de estruturas de aço constituídas por perfis leves, já se tornou há tempos ultrapassada, acarretando constante consulta, pelos projetistas, a normas estrangeiras. A elaboração de uma norma atualizada já se fazia necessário, a fim de que projetistas e calculistas dispusessem de um documento técnico mais próximo da realidade brasileira, ajustada com outras normas, permitindo critérios mais uniformes. $\mathrm{O}$ texto base da norma brasileira dedicada ao projeto de estruturas utilizando perfis formados a frio encontra-se em fase final de aprovação na Associação Brasileira de Normas Técnicas (ABNT).

O objetivo deste trabalho é apresentar uma proposta de recuperação estrutural de uma edificação histórica no município de Uberaba-MG, utilizando perfis formados a frio, verificando-se a viabilidade técnica de sua adoção.

Para os cálculos dos elementos foi utilizado o projeto da norma brasileira de dimensionamento e cálculo de perfis formados a frio, que se encontra em fase final para publicação. 


\section{REVISÃO BIBLIOGRÁFICA}

\subsection{RECUPERAÇÃO E REFORÇO}

\subsubsection{CONCEITUAÇÃO}

Segundo CALAVERA et al. (1987) reforço é todo trabalho que visa aumentar a capacidade portante da estrutura eliminando-se possíveis deficiências de resistência e recuperação é repará-la para uma nova vida útil, eliminando-se os efeitos dos danos e da deterioração. Afirmam que existem dois tipos de reforços, definidos a partir do momento em que os novos elementos incorporados à estrutura entram em carga. São eles:

- Ativos - aqueles que sua colaboração à resistência se alcança desde o momento da entrada em serviço da estrutura.

- Passivos - São aqueles que exercem sua colaboração partindo do estado neutro em condições iniciais e entrando em carga, bem antes das condições específicas do material que originalmente forma a estrutura (fluência, retração, etc) e de sua falha.

Pode-se dizer que os reforços ativos são adequados para aliviar situações de segurança precária em elementos originais nos quais o material de base presente na estrutura original não é capaz, mediante a reologia, deformabilidade, plasticidade, de mobilizar a capacidade resistente do reforço. 
Os reforços passivos são geralmente adequados para elevar os níveis de segurança ante situações em que exista o risco de ruína e se quer melhorar a garantia de um comportamento estrutural.

Precisa-se conhecer, principalmente no caso da seleção de um reforço passivo, uma série de características do material da estrutura (propriedades físicas e mecânicas), e da própria estrutura em geral, para saber se a mesma pode condicionar-se bem a dimensão do reforço.

\subsubsection{PROCEDIMENTOS PARA RECUPERAÇÃO E REFORÇO.}

Os processos de recuperação e/ou reforço de qualquer edificação dependem de etapas investigativas básicas, independentemente da estrutura a ser analisada. Essas se dividem em três etapas diferenciadas, a saber: informações sobre a estrutura existente, estimativa da sua capacidade de carga e desenho do reforço e dos detalhes de recuperação.

Ao se investigar uma estrutura deve-se observar diferenças, visando à escolha ideal do processo de intervenção ao qual deverá ser submetida à edificação. Conforme observado por Pizzi \& Guevara (1997) essas etapas básicas devem conter relatórios dimensionais, de danos estruturais, reavaliação da degradação envolvida e simular ações de interferência. Considerando-se essas etapas convém, porém, observar algumas variáveis de acordo com o tipo de material utilizado na execução da estrutura: concreto armado, aço, madeira, entre outros.

Para intervir em uma edificação em concreto armado, ao se fazer uma investigação inicial no local existe a necessidade de se extrair corpos de provas, pois visualmente não se é possível saber nada do concreto, muito menos sobre a armadura. No caso de estrutura metálica, ela é mais explícita, mais à vista, sendo mais fácil de intervir sem 
conhecer o projeto. A estrutura de madeira apresenta situações de recuperação ligada muita das vezes ao efeito de biodegradação do material por agentes biológicos. Daí a necessidade do conhecimento dos materiais envolvidos na execução da estrutura, para a escolha correta do procedimento a ser tomado para o reforço ou recuperação.

CALAVERA et al. (1987) observam que a recuperação de um edifício consiste geralmente em um processo de substituição de componentes ou agregação de outros a fim de que a estrutura possa funcionar de novo. Afirmam que se planeja a recuperação ou reabilitação de um edifício após um estudo cuidadoso e crítico observando principalmente as seguintes características:

a) Segurança - Alguns elementos estruturais apresentam sintomas de movimentações, deformações, fissuras, entre outros, que possibilitarão prever se a ruína se manifestara a curto ou médio prazo.

b) Adequação - As características funcionais e estéticas são antiquadas e podem não corresponder as atuais exigências da sociedade.

c) Conforto - Os elementos de proteção e acabamento do edifício e instalações têm que funcionar.

Segundo CALAVERA et al. (1987), em qualquer situação será sempre preciso uma inspeção preliminar da estrutura, que permitirá a adoção de um plano de atuação detalhado. Tal plano deve conter normalmente o programa de atuação necessário para definir a estrutura ou parte da estrutura que será necessário estudar e seu estado de conservação. Pode-se definir os seguintes tipos de atuação:

a) Inspeção visual detalhada, visando o estabelecimento de procedimentos adequados:

- $\quad$ Esquema estrutural: Seções, tipologias dos elementos estruturais, sistemas de apoio.

Sistemas de união: geometria e disposição e controle dimensional de alguns elementos. 
- Possíveis defeitos: Deformações nos elementos estruturais, inspeção de ligações soldadas e parafusadas, corrosão, deterioração, fissuras, entre outros.

b) Tomada de amostras e ensaios destrutivos: ensaios mecânicos de qualificação do material, ensaios químicos.

c) Ensaios não destrutivos: ensaios de soldas (radiografias, líquidos penetrantes, ultra-som), comprovação de perda de espessura, ensaios de carga.

A partir destes procedimentos poderão ser definidos os parâmetros necessários para o cálculo estrutural dos elementos afetados a fim de se iniciar o processo de reabilitação do elemento ou sistema estrutural danificado.

Durante a inspeção visual dos elementos de união observam CALAVERA et al. (1987), que é possível verificar como é executada a união entre as peças e simultaneamente se fazer à comprovação do estado de conservação e possíveis defeitos da ligação.

Para poder recalcular os elementos afetados, será preciso definí-los geometricamente, comparando com a documentação disponível. Existe a necessidade de se obter dados que possam definir vãos, apoios, tipologias e seções, entre outros. Em edificações mais recentes, em geral, tais dados são mais fáceis de serem obtidos, já que a possibilidade de existência de projetos estruturais da edificação é maior.

Segundo LICHTENSTEIN (1986) o método a ser utilizado para a resolução de um problema patológico em uma edificação é formado basicamente por três partes distintas:

a) Levantamento de subsídios

b) Diagnóstico da situação

c) Definição da conduta a ser seguida 
No levantamento dos subsídios deve-se acumular e organizar as informações necessárias e suficientes para o entendimento completo dos fenômenos. Essas informações podem ser obtidas por meio de vistoria no local, o levantamento da história do problema e do edifício e o resultado de análises e ensaios complementares.

De acordo com LICHTENSTEIN (1986) dentro da fase de levantamento de subsídios, a vistoria no local consiste no processo em que o profissional se aproxima fisicamente do edifício. Essa vistoria pode seguir os seguintes passos para atingir um resultado satisfatório:

a) Determinação da existência e da gravidade do problema patológico.

b) Definição da extensão e do alcance do exame.

c) Caracterização dos materiais e das patologias:

- Utilização dos sentidos humanos

- Utilização de instrumentos

d) Registro de resultados

O procedimento geral a ser seguido a partir da queixa do usuário, quanto ao desempenho da edificação e por profissional encarregado da inspeção periódica da mesma, inicia-se pela fase do levantamento do maior número de informações que possam ajudar a diagnosticar e posteriormente resolver o problema.

O diagnóstico da situação é o entendimento dos fenômenos em termos da identificação das múltiplas relações de causa e efeito que normalmente caracterizam um problema patológico.

$\mathrm{Na}$ definição da conduta prescreve-se o trabalho a ser executado para resolver o problema, definição sobre os meios e a previsão das conseqüências em relação ao desempenho final. Ainda, de acordo com LICHTENSTEIN (1986), para definir a conduta, inicialmente é feito o prognóstico da situação, ou seja, são levantadas as 
hipóteses da tendência de evolução futura do problema e as alternativas de intervenção acompanhadas dos respectivos prognósticos.

Segundo LICHTENSTEIN (1986) a definição da conduta é feita levando-se em conta três parâmetros básicos :

a) Grau de incerteza sobre os efeitos

A probabilidade da intervenção não atingir o resultado esperado esta ligada diretamente a incerteza de correção do diagnóstico e com a eficiência demonstrada em casos semelhantes anteriores. A divulgação de casos reais permite uma base mais segura para escolha da mais adequada conduta.

b) Relação custo/benefício

As alternativas de intervenção devem ser avaliadas pelos custos envolvido e desempenho do edifício ao longo do tempo propiciado por cada uma delas. Essa comparação é necessária a fim de se optar pela melhor conduta a ser tomada.

c) Disponibilidade de tecnologia para execução dos serviços

Faz-se necessário um levantamento dos recursos tecnológicos envolvidos na execução das intervenções para cada uma das alternativas. Tais recursos estão relacionados a técnica requerida pelo responsável pela execução e os materiais e equipamentos necessários.

LICHTENSTEIN (1986) apresenta um fluxograma de atuação para resolução de problemas patológicos (figura 2.1), independentemente do material utilizado na edificação, visando a adoção da melhor conduta a ser seguida, não intervir, ou intervir reparando, protegendo ou restringindo o uso. 


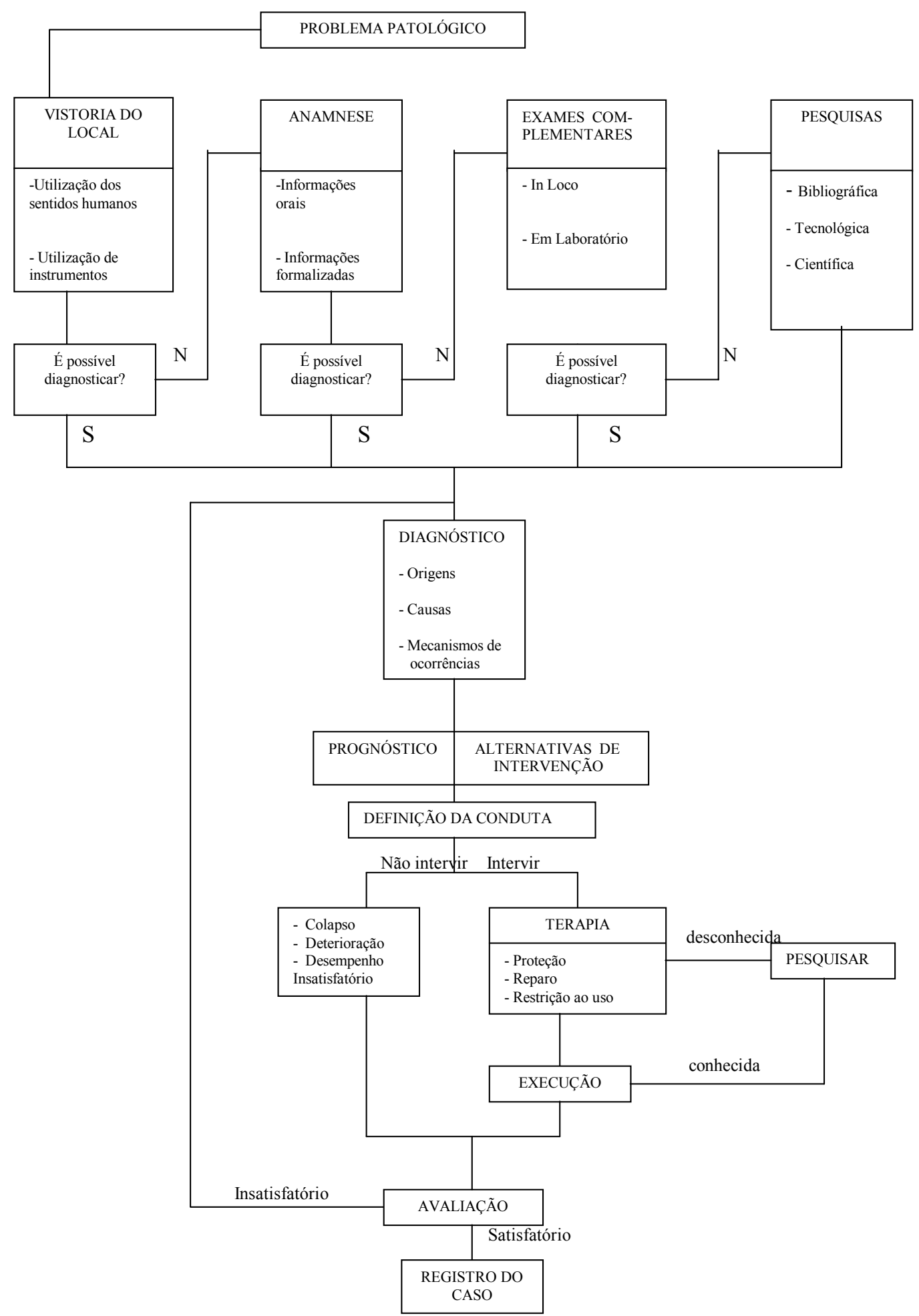

Figura 2.1 - Fluxograma de atuação para a resolução dos problemas patológicos fonte: LICHTENSTEIN , 1986 


\subsubsection{RECUPERAÇÃO DE ELEMENTOS ESTRUTURAIS DE MADEIRA}

Para a recuperação de elementos estruturais de madeira é importante o conhecimento prévio das patologias mais comuns que a afetam, pois grande parte dos problemas estruturais neste material são provenientes de problemas tais como ataques biológicos, defeitos de secagem e defeitos de secagem.

CALIL JR et al. (1998) apresentam alguns defeitos comuns na madeira que podem propiciar a ruptura do elemento estrutural:

- Defeitos por ataques biológicos:

Surgem dos ataques provenientes de fungos ou insetos (brocas, cupins entre outros), Os insetos causam perfurações que podem ser pequenas ou grandes, conforme podese observar na figura 2.2. Os fungos podem causar manchas azuladas e podridões (clara ou parda), conforme figura 2.3.

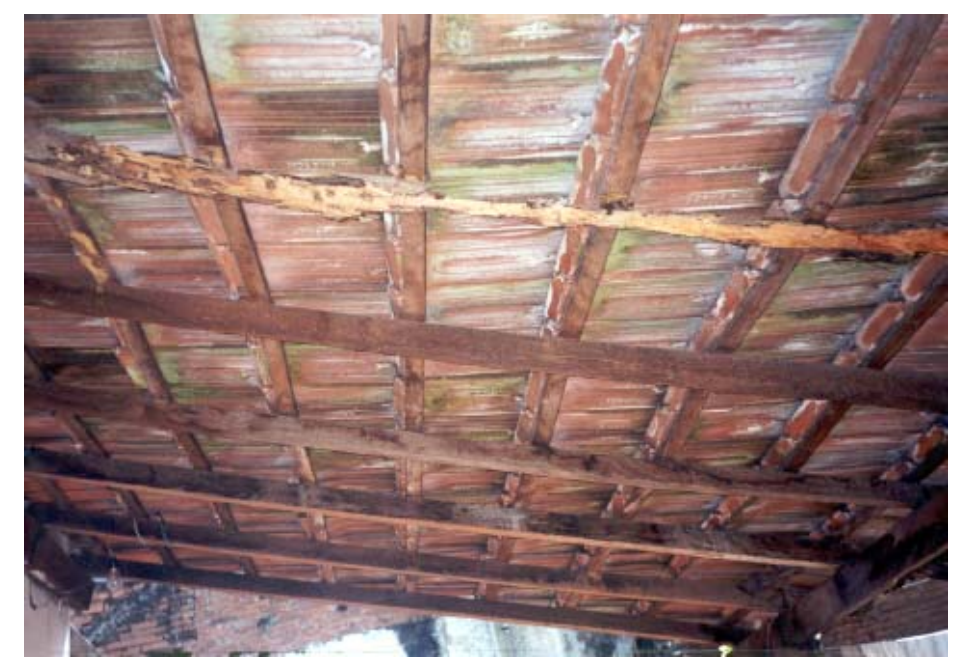

Figura 2.2 - Cobertura do Pavilhão de Exposição - Uberaba-MGAtaques biológicos. 


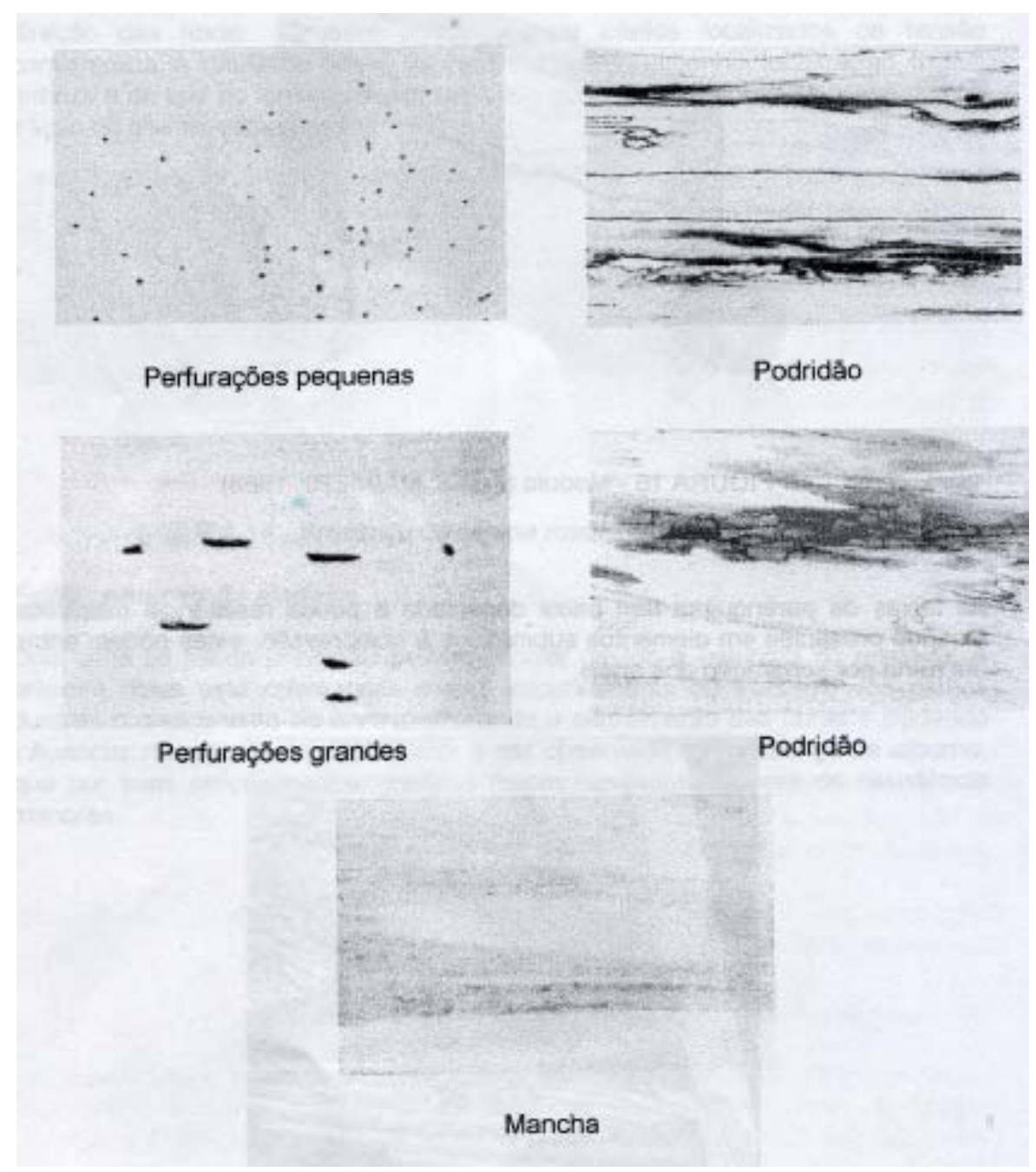

Figura 2.3 - Ataques biológicos fonte: CARLITO,1999

- Defeitos de secagem

Originados pela deficiência dos sistemas de secagem e armazenamento das peças. Podem ser: encanoamento, arqueamento, encurvamento e torcimento, conforme figura 2.4 . 


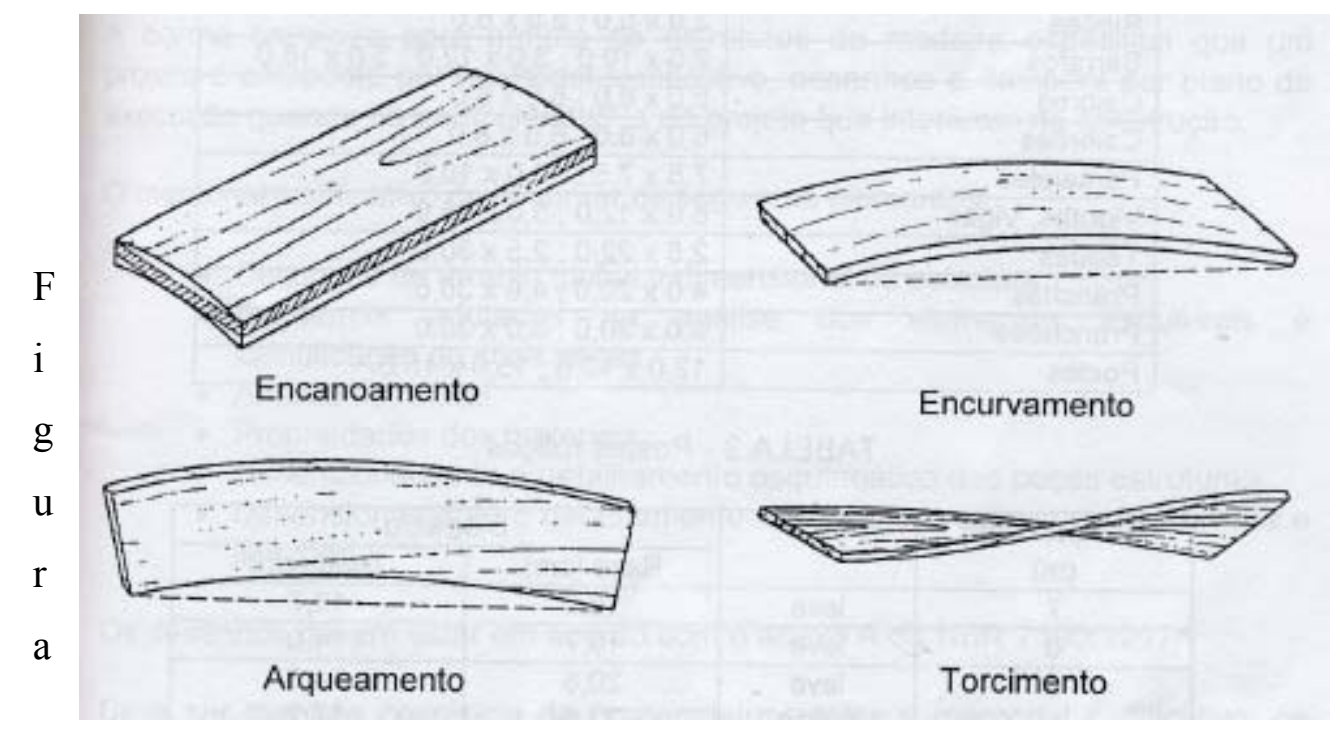

2.4 - Defeitos de secagem

fonte: CARLITO, 1999

- $\quad$ Defeitos de processamento da madeira

São originados na manipulação, transporte, armazenamento e desdobro da madeira.

São eles: as arestas quebradas e a variação da seção transversal, conforme figura 2.5.

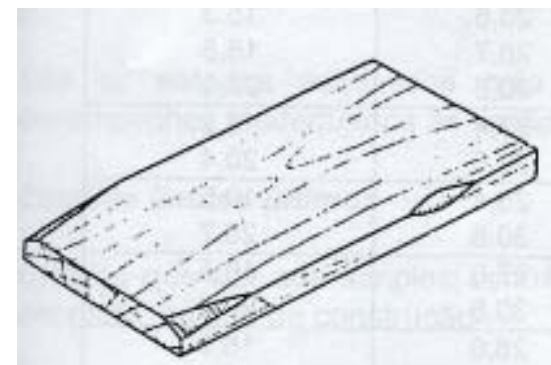

Arestas quebradas

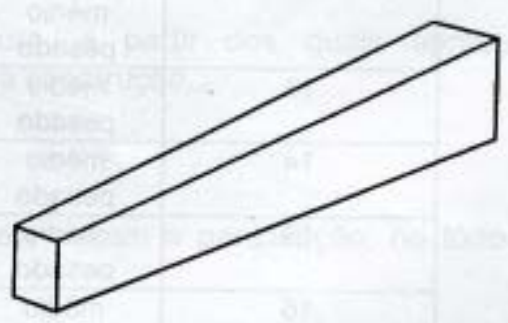

Variaçăo da seçāo transversal
Figu

ra

$2.5-$

Defe itos

de processamento da madeira

fonte: CARLITO, 1999. 
Além disto podem existir falhas naturais da madeira (presença de alburno, presença de medula, faixas de parênquima) e ações de sobrecargas e vento não previstas que também podem acarretar problemas nos elementos estruturais.

$\mathrm{Na}$ recuperação da estrutura de madeira pode ser necessária a substituição de todo o elemento ou apenas a composição com outros elementos. Neste caso convém atentar para os meios de ligações e formas de adaptação a outros elementos com o aço e o concreto armado. Deve-se elaborar um plano de execução viável para a recuperação da edificação em madeira. Faz-se necessário uma análise inicial das possíveis soluções a serem empregadas no reforço ou recuperação.

CORDOVIL \& LORIGGIO (1992) apresentaram depois da caracterização dos problemas patológicos e análise das possíveis soluções para recuperação da estrutura de madeira do "Galpão Criolo" (figura 2.6), da Associação Bamerindus em Florianópolis, um plano de execução de reforço conforme a seguir:

$1^{\mathrm{a}}$ etapa: escoramentos com postes de eucalipto;

$2^{\text {a }}$ etapa: retiradas das telhas de cobertura;

$3^{\text {a }}$ etapa: suspensão dos pontos da cumeeira do prédio;

$4^{\mathrm{a}}$ etapa: colocação de tirantes, aperto e ajustes de prumo e rosqueamento forçado; colocação dos reforços nas peças inclinadas; (figura 2.7).

$5^{\text {a }}$ etapa: reparos e recondicionamentos das peças de madeira (pilares);

$6^{\mathrm{a}}$ etapa: vistoria geral e outros serviços que se fizeram necessários, nas peças de aço e madeira;

$7^{\text {a }}$ etapa: recolocação das telhas; 


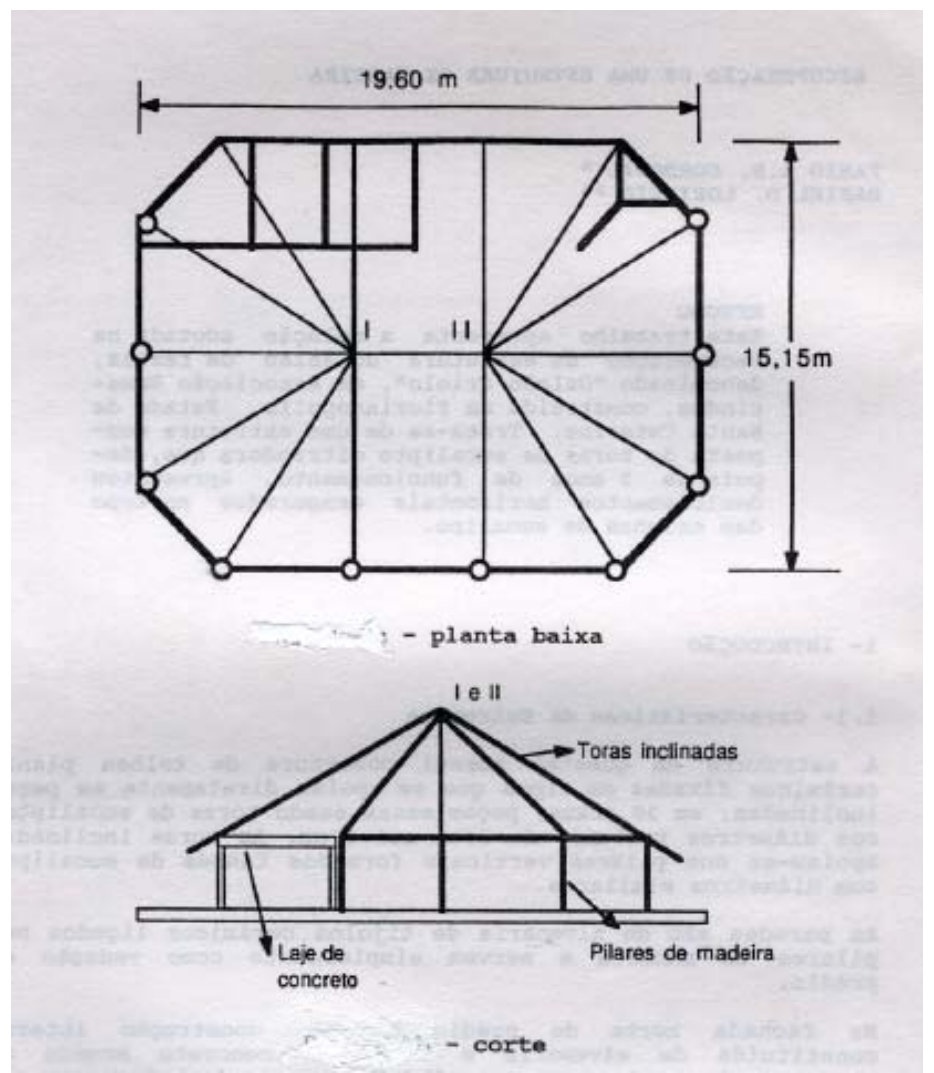

Figura 2.6. - Estrutura de madeira "Galpão Criolo" - Florianópolis -SC fonte: CORDOVIL \& LORIGGIO, 1992.

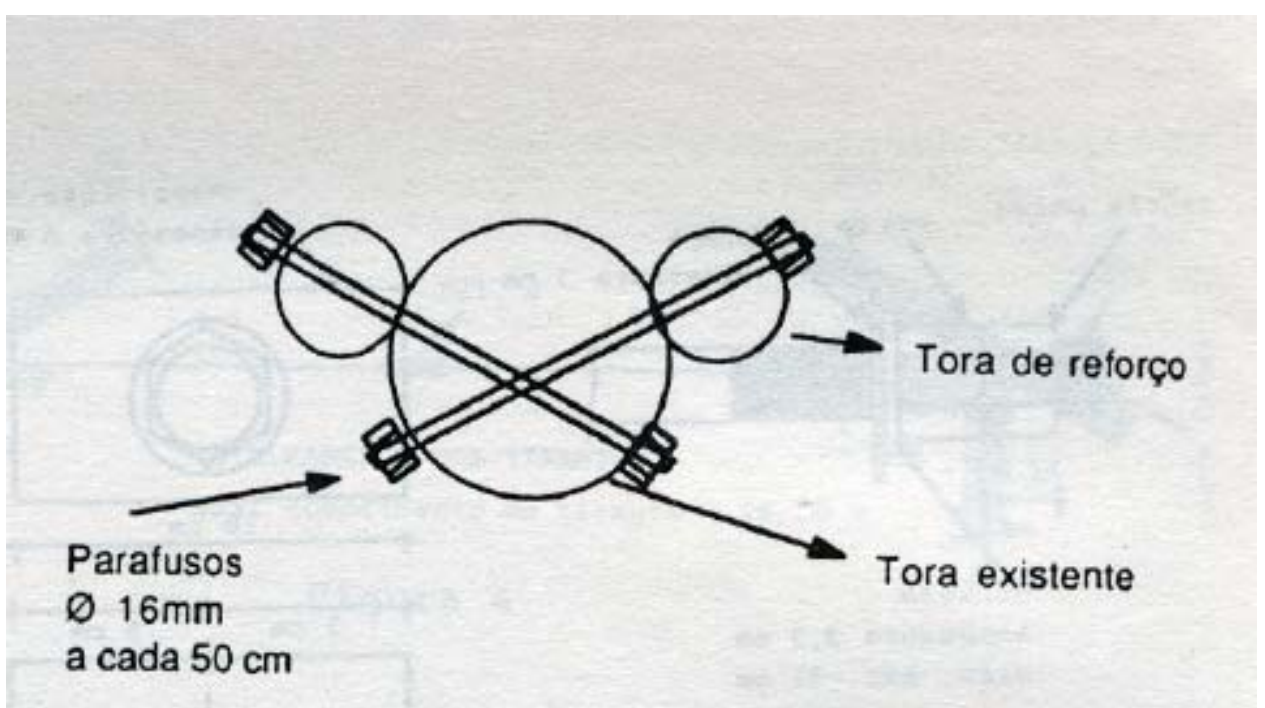

Figura 2.7. - Detalhe do reforço das barras inclinadas fonte: CORDOVIL \& LORIGGIO, 1992. 
De acordo com o plano apresentado acima se observa que além de se caracterizar o estado de deterioração da edificação e propor soluções para recuperá-la é necessário também apresentar a maneira como será executada a recuperação, visto que tal procedimento propiciará a correta aplicação da intervenção.

\subsubsection{RECUPERAÇÃO DE EDIFÍCIOS COM A UTILIZAÇÃO DE ESTRUTURAS DE AÇO}

A recuperação de elementos estruturais de edifícios pode ser feita com a utilização de perfis e/ou barras metálicas. Pela sua versatilidade e resistência, o aço pode ser viável na recuperação de elementos de concreto armado e de madeira. As técnicas utilizadas devem ser sistematizadas, já que cada caso é único. A seguir, são apresentadas algumas edificações nas quais foram feitas recuperações e/ou reforços estruturais e reabilitação, utilizando perfis metálicos:

- $\quad$ Igreja de São Cristóvão - São Paulo (Figura 2.8)

Essa igreja foi erguida para ser sede do primeiro seminário de São Paulo em 1856. Foi tombada pelo Condephaat (Conselho de Defesa do Patrimônio Artístico, Arqueológico e Turístico do Estado de São Paulo).

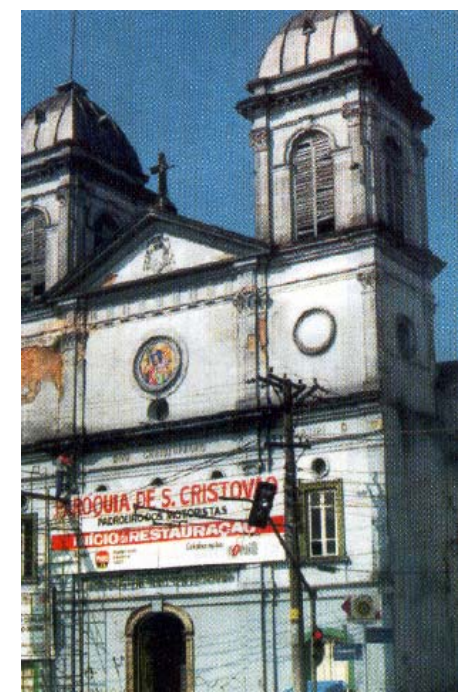

Figura 2.8 - Fachada da Igreja São Cristóvão - São Paulo antes da recuperação. fonte: Revista Téchne, Nov/Dez 99. 
$\mathrm{O}$ estado de degradação de grande parte da estrutura impossibilitou a simples substituição de materiais. As patologias mais graves foram causadas por cupins e infiltração de água. A cúpula bastante afetada por patologias foi recuperada pela substituição da madeira por uma nova estrutura em aço, conforme figura 2.9. Pilares de aço foram embutidos no arco do piso superior cuja estrutura foi atacada por cupins, conforme figura 2.10 .

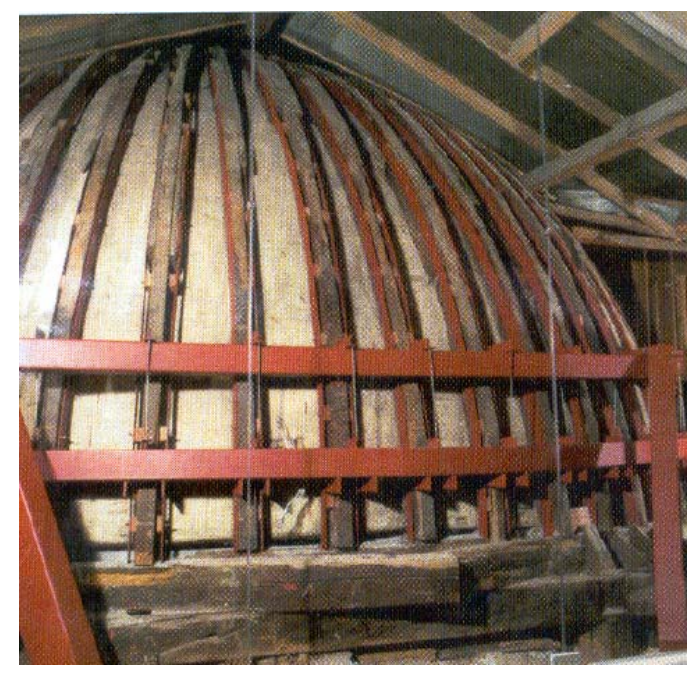

Figura 2.9. - Detalhe da recuperação da Cúpula. fonte: Revista Téchne, Nov/Dez 99.

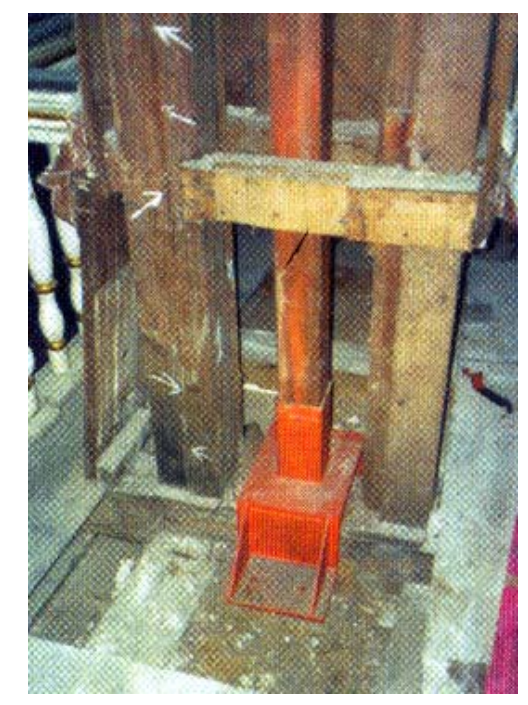

Figura 2.10. - Igreja São Cristóvão. Detalhe de Pilar de aço embutido no arcofonte: Revista Téchne, Nov/Dez 99. 
- $\quad$ Igreja Matriz de Conquista - MG

A igreja matriz de Conquista-MG passou em 1999 por um processo de restauração, sendo que a torre em estrutura de madeira se apresentava toda deteriorada, não suportando mais o peso da cruz. Por meio de trabalhos investigativos feitos pelo engenheiro civil Gilberto Dib e chegou-se a conclusão que o material mais recomendado para sua recuperação seria o aço, pela rapidez de execução, leveza e resistência. Os trabalhos de recuperação da torre foram executados pela empresa Irmãos Fernandes de Uberaba-MG. O madeiramento foi substituído por perfis cantoneiras laminadas, fixadas por solda e revestida com chapa de latão. Foi feito um tratamento com jateamento de areia SA2,5, com posterior aplicação de primer e acabamento em esmalte sintético.

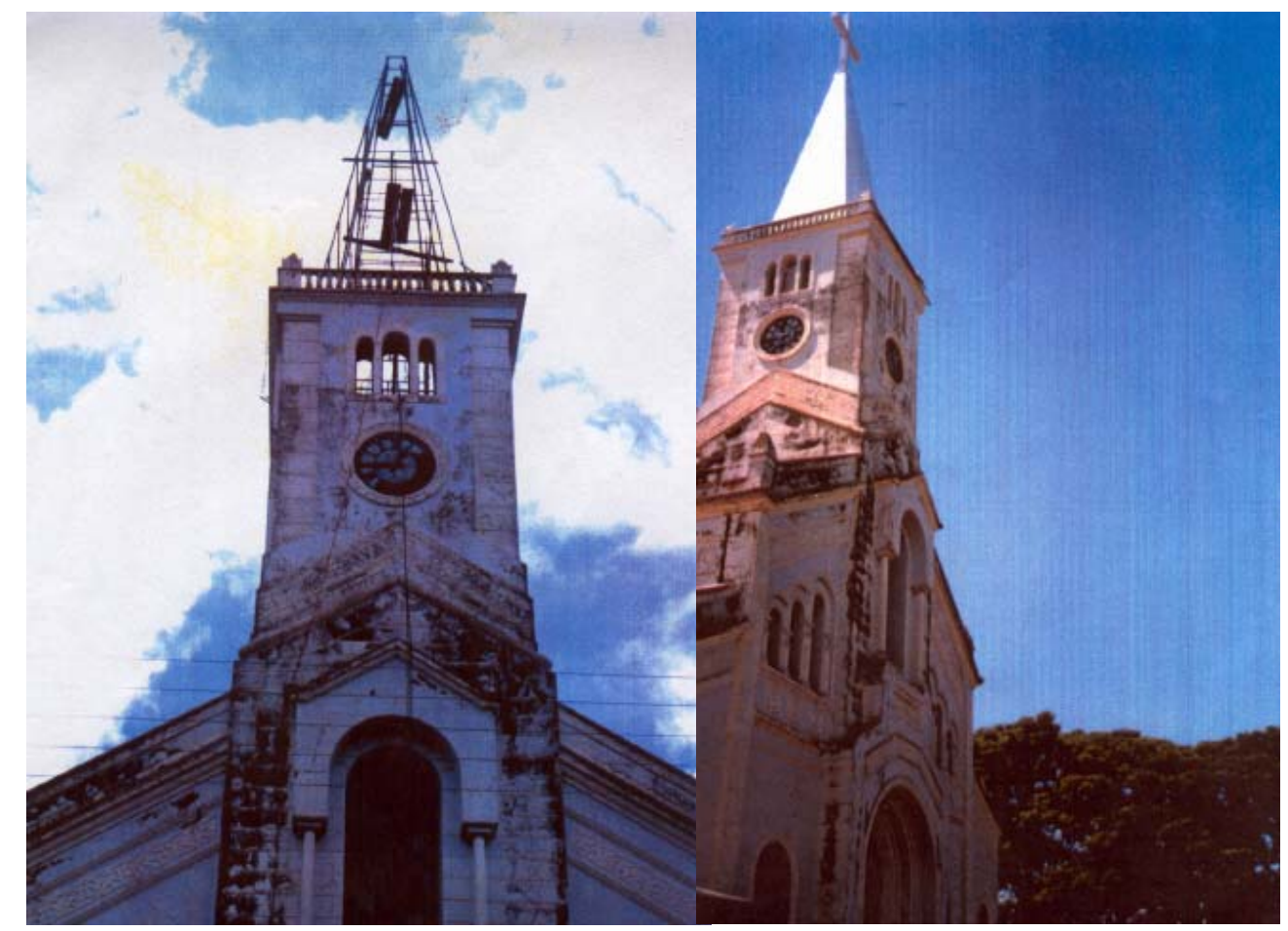

Figura 2.11 - Detalhe da recuperação da cobertura da Igreja Matriz de Conquista 
Além da torre, as paredes laterais da igreja apresentavam, segundo relatório do engenheiro Gilberto Dib, várias fissuras que provocariam a queda eminente das paredes para o interior da igreja. Foi proposto e executado neste caso treliças de banzos paralelos de $800 \mathrm{~mm}$ de altura com cantoneiras duplas, para travar as paredes laterais.

- $\quad$ Igreja de São Francisco de Assis - Ouro Preto-MG

A igreja São Francisco de Assis de Ouro Preto foi construída quase inteira por Aleijadinho em 1693. Essa igreja não possui muito ouro, pois na época ainda não era usado nas grandes construções. É interessante notar que o lustre da igreja, que normalmente fica próximo do teto, aqui está mais baixo indicativo que o ser humano está abaixo de Deus. Atualmente essa igreja passa por processo de restauração sendo que seu arco cruzeiro que apresentava trincas foi restaurado usando vigas metálicas, conforme figura 2.12, para eliminar os problemas estruturais caracterizados por fissuras diversas.

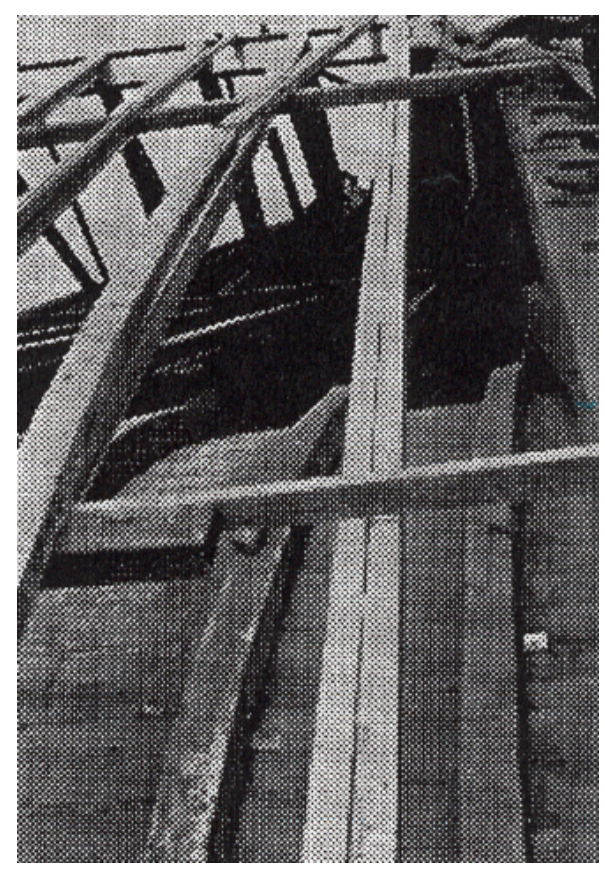

Figura 2.12 - Igreja São Francisco de Assis -- Recuperação do Arco cruzeiro fonte: SPHAN 
Assim como diversos casarões e bares de Ouro Preto-MG, essa edificação antiga passou por um processo de recuperação/reforço, sendo que o apoio para o segundo piso em madeira recebeu suporte de viga metálica de perfil I. Tal reforço permitiu que o andar superior pudesse receber cargas maiores que as previstas inicialmente, conforme comunicação pessoal. A figura 2.13 apresenta o detalhe do piso que recebeu suporte da viga metálica.

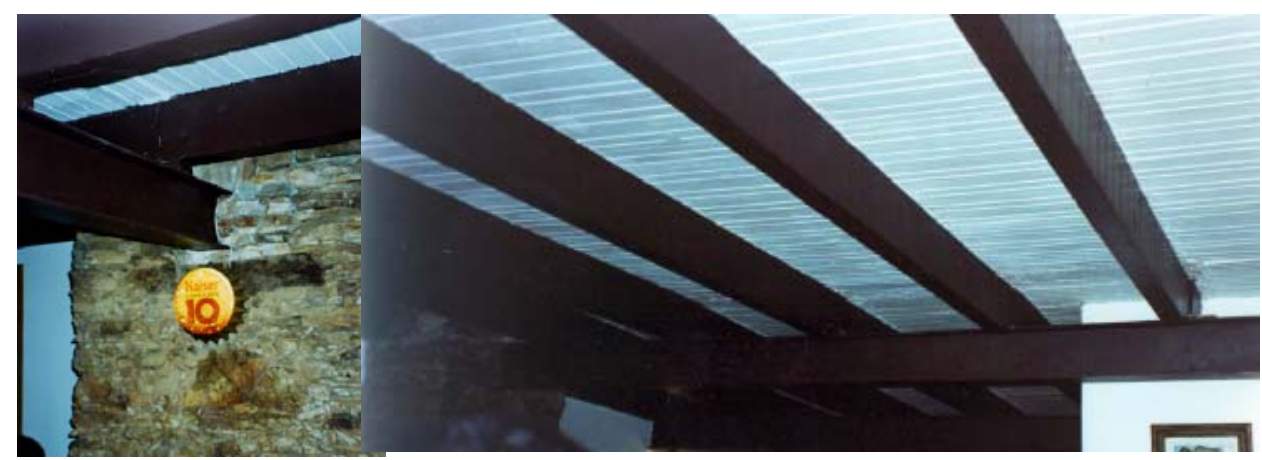

Figura 2.13 - Detalhe de vigas metálicas sustentando piso de madeira

- $\quad$ Mercado Popular de Porto Alegre-RS.

O Mercado Público de Porto Alegre foi construído em 1869, e desde então é um ponto de referência dos porto-alegrenses. $\mathrm{O}$ estilo de sua construção é neoclássico. Tinha originalmente apenas um andar. No ínicio do século XX foi acrescido o segundo andar, obra que foi concluída em 1913. A última restauração promoveu a retirada do antigo telhado e o mercado ganhou uma cobertura nova, conforme pode ser observado na figuras 2.14 e 2.15. Com isso, o segundo e o primeiro piso ficaram integrados e a sensação de amplitude aumentou consideravelmente. 


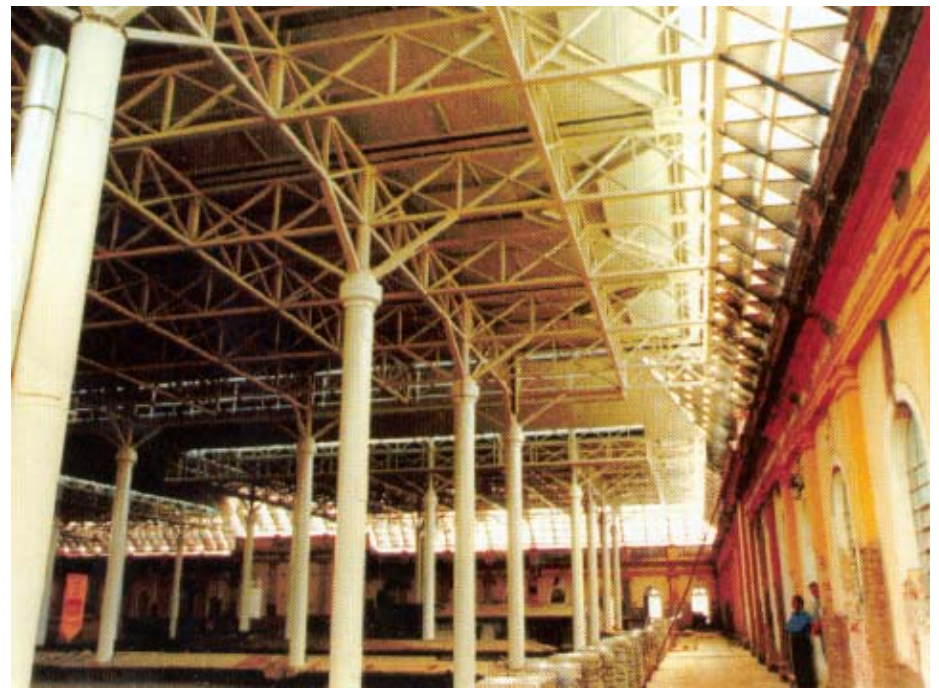

Figura 2.14 - Cobertura em Estrutura Metálica - Mercado Público fonte: Revista Construção Metálica MAI/JUN 97

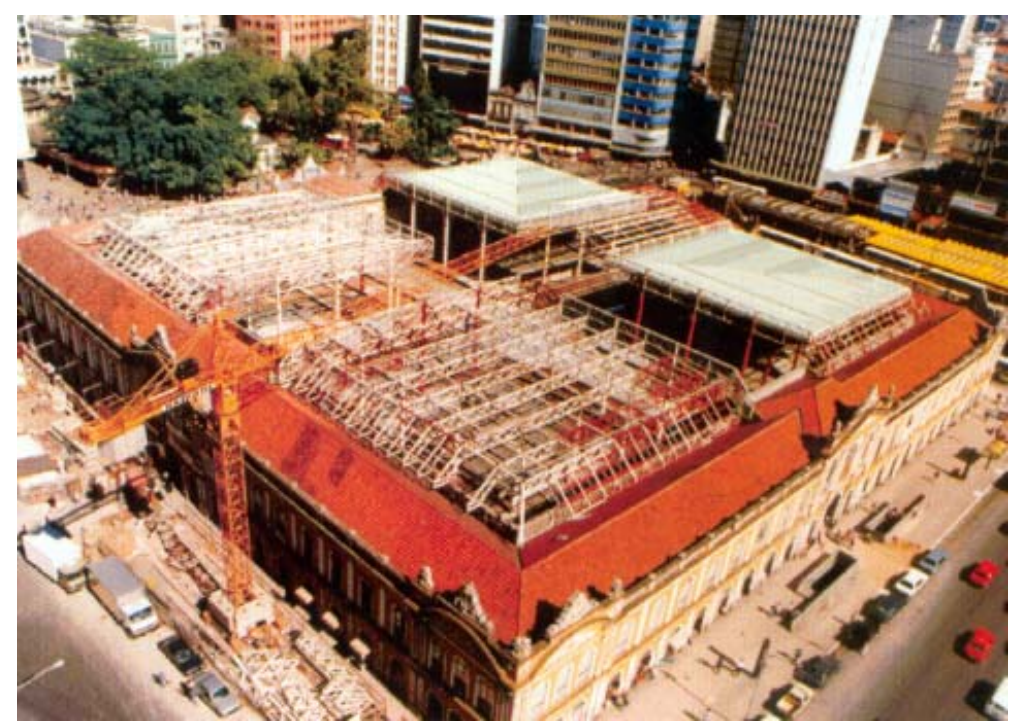

Figura 2.15 - Execução da cobertura - Mercado Público fonte: Revista Construção Metálica MAI/JUN 97

- $\quad$ Casa França-Brasil-RJ 
O edifício da Casa França-Brasil constitui um patrimônio cultural para o país. Foi construído em 1820, é em estilo neoclássico, sendo de grande valor artístico, histórico e arquitetônico. Inicialmente projetado para ser a primeira Praça do Comércio do Rio de Janeiro, posteriormente transformou-se em Alfândega da cidade. Tombado pelo IPHAN (Instituto do Patrimônio Histórico e Artístico Nacional) em 1938, foi restaurado no final da década de 80, passando a denominar-se Casa FrançaBrasil.

Segundo RIBEIRO (1997) ao se realizar a prospecção do local verificou-se que a estrutura da cúpula em madeira estava quase que totalmente destruída pela ação de cupins, que encontraram no local, o ambiente ideal para o seu desenvolvimento. Local escuro, quente, úmido, com temperatura em torno de $25^{\circ} \mathrm{C}$ e umidade relativa do ar em torno de $70 \%$. Foi necessária a substituição total da estrutura de madeira já que não existia mais nenhuma possibilidade de tratamento do material.

RIBEIRO (1997) constata que após vários estudos de viabilidade técnica, o parecer de uma empresa de projeto estrutural com experiência em obras de restauração, concluiu que:

- $\quad$ "a substituição das estruturas de madeira por outras desse mesmo material seria onerosa” (devido às grandes dimensões das peças) “e exigiria tratamento rigoroso e manutenção eficiente;

- $\quad$ estruturas de concreto, no caso, embora de custo mais baixo, aumentaria bastante o peso suportado pelos pilares e fundações já existentes, além de implicarem em obra de maior prazo e de execução, mais difícil, face aos reduzidos locais para canteiro de obra;

- a estrutura mais adequada é a de aço. Seria mais leve, e o trabalho de campo mais limpo. No caso de restauração tem mais semelhança com a obra original, sendo mantido o partido estrutural “.

Optou-se então pela substituição do madeiramento da cúpula por aço, sendo utilizado o aço ASTM A36, revestido com pintura epóxi. 


\subsection{METODOLOGIA PARA A RECUPERAÇÃO DE OBRAS HISTÓRICAS}

Segundo KLEIN et al. (1999), a importância de se seguir uma metodologia correta para a reabilitação ou reparo de uma edificação histórica, é que ela permite:

- Avaliar o valor histórico da edificação

- Verificar os diferentes usos que o prédio apresentou

- Conhecer as condições atuais de conservação da obra - condições de segurança

- Conhecer as causas de sua degradação

- Identificar a concepção estrutural utilizada na sua construção e os materiais usados

- Utiliza-la adequadamente

- Poder formular um projeto adequado de recuperação ou restauração, evitando erros de execução e conseqüente desperdícios de recursos.

Para a recuperação de edificações antigas, são obviamente válidos os mesmos princípios da física e química, bem como a boa técnica construtiva das instalações como nos prédios novos. Porém, as edificações antigas impõem restrições ao uso de materiais, técnicas construtivas e detalhes pela incompatibilidade com materiais e técnicas antigas. Isso é valido também para edificações históricas, porém com um agravante que pode modificar todas as hierarquias e as restrições: manutenção do valor histórico, isto significa resguardar o existente. É proibido na recuperação de obras históricos a livre escolha de variáveis possíveis, se existirem outros métodos de recuperação com menor ingerência. As leis que regulamentam a preservação do acervo histórico não proíbem a adaptação da edificação histórica às necessidades atuais pelo menos na prática. As habitações devem ser atendidas com as necessidades de hoje sem interferir na edificação histórica.

A Carta Internacional para a Conservação e Restauração de Monumentos e Sítios Carta de Veneza (1964) preconiza nos seus artigos $9^{\circ}, 10^{\circ}, 11^{\circ}, 12^{\circ}$ e $13^{\circ}$ os seguintes critérios de restauração: 
Art. $9^{\circ}$ - A restauração, uma operação que deve se manter em caráter excepcional tem por finalidade conservar e revelar os valores estéticos e históricos do monumento, fundamentando-se no respeito à substância antiga e na autenticidade dos documentos. Deve deter-se onde começa a hipótese, e no plano das reconstituições conjunturais, o trabalho complementar, considerado indispensável por razões estéticas ou técnicas, deverá se destacar da composição arquitetônica, levando consigo a marca de nosso tempo.

A restauração, sempre será precedida e acompanhada de estudo arqueológico e histórico do monumento.

Art. $\mathbf{1 0}^{\mathbf{0}}$ - Quando as técnicas tradicionais se revelarem inadequadas, a consolidação de um monumento será assegurada, com o recurso de todas as técnicas modernas de conservação e de construção, cuja eficácia tenha comprovação cientifica e garantia firmada pela experiência.

Art. $1^{\circ}$ - Os acréscimos à construção de um monumento são marcas respeitáveis de todas as épocas, e devem permanecer, uma vez que a unidade do estilo não constitui a meta final da restauração. Quando em um edifício vários acréscimos se superpõem, o resgate de um estágio subjacente não se justifica, senão excepcionalmente, e, sob a condição de que os elementos retirados não sejam representativos, a composição descoberta deve constituir testemunho de grande valor histórico, arqueológico ou estético, e seu estado de conservação considerado suficiente. O julgamento sobre o valor dos elementos em questão e a decisão das eliminações a operar não poderão depender somente do autor do projeto.

Art. $1^{\circ}$ - Os elementos destinados a substituir as falhas existentes devem integrar-se harmoniosamente ao conjunto, distinguindo-se nitidamente das partes originais, para que a restauração não falsifique o documento de arte e história. 
Art. $1^{\circ}$ - Os acréscimos não serão tolerados, a não ser que diga respeito a todas as partes do edifício, sua área envoltória, o equilíbrio de sua composição e suas relações com o meio ambiente.

Deve-se, portanto, de acordo com a Carta de Veneza (1964) seguir-se as seguintes fases para chegar as intervenções:

a) Levantamento, diagnóstico e monitoramento:

- Levantamento da geometria da edificação e levantamento ou reconhecimento das suas propriedades físicas e estruturais.

- Diagnóstico do estado de deterioração da construção, suas causas e mecanismos.

- Monitoramento da evolução do comportamento estrutural quer para diagnóstico, quer para avaliação dos efeitos das medidas corretivas.

O levantamento, o diagnóstico e o monitoramento pressupõem a realização na construção de determinadas observações, quer sobre amostras dela retiradas para estudo laboratorial, quer por meio de ensaios feitos "in situ".

Pode-se dizer, portanto, que de acordo com a da Carta de Veneza (1964), a preservação da autenticidade arquitetônica da construção deve ser extensiva à preservação da sua autenticidade estrutural, sendo que a introdução de materiais e de elementos estruturais diferentes deve ser cuidadosamente analisada e dosada. Ao recorrer-se exclusivamente a técnicas antigas e aos materiais originais, pode-se incorrer em maiores custos e prazos.

Há então, às vezes, a necessidade de utilizar materiais e tecnologias mais avançadas, desde que respeitem o caráter original da construção antiga e ajudem a corrigir, de forma mais rápida e econômica, as anomalias e deficiências estruturais existentes.

Segundo KLEIN et al. (1999) para conhecer a edificação a ser reabilitada deve-se fazer um levantamento do que existe. Faz-se necessário o levantamento cadastral e técnico do existente. 
- Levantamento Cadastral do Existente (corresponde a todas atividades desenvolvidas inicialmente fora da edificação):

a) Nos Arquivos Públicos

- plantas históricas (originais), plantas de alterações efetuadas durante o uso do prédio, informações sobre os diferentes usos da edificação;

b) Nos órgãos de Patrimônio Histórico

- valor histórico do prédio e seu tombamento como patrimônio;

c) Em Arquivos Históricos e Literatura

- $\quad$ sobre o desenvolvimento urbano do entorno da edificação obtendo dados de transformação do meio ambiente envolvente e sobre o histórico da edificação;

d) Em Institutos Meteorológicos

- condições climáticas que envolvem o prédio;

- Levantamento Técnico do Existente (realizado na obra)

a) Levantamento Dimensional

- produzir dados para elaboração de plantas baixas e cortes (caso não exista) e para confrontar com plantas originais históricas;

b) Identificação do Tipo de Construção

- $\quad$ sistemas construtivos;

c) Identificação do Sistema Estrutural

- é fundamental para avaliar a estabilidade atual e definir algum reforço estrutural para adequação do prédio;

d) Identificação do tipo de fundação

- muitas das vezes o estado precário das fundações é que acarreta falhas em obras históricas, a estabilidade deve ser verificada antes e após a execução da recuperação da edificação; 
e) Tipos de Materiais Empregados

- identificação correta dos materiais empregados é fundamental para avaliar a estabilidade da obra e proceder corretamente quando houver necessidade de reforço estrutural;

f) Levantamento das Patologias com Documentação Fotográfica

- mostrará o estado de conservação que a edificação encontra-se e apontará suas causas;

g) Coleta de Amostras e Ensaios de Campo

- para determinação das características dos materiais componentes da edificação;

h) Levantamentos Complementares

- fornecerá dados para recuperação do prédio a fim de evitar-se transtornos nos serviços de revitalização da edificação;

O fluxograma da figura 2.16 apresenta os passos a serem seguidos, segundo KLEIN et al. (1999), na recuperação de uma edificação histórica.

O diagnóstico poderá ser elaborado após a análise das condições de conservação da edificação histórica, podendo ser de acordo com KLEIN et al. (1999): pessimista ou otimista. No caso de pessimista a recuperação da edificação se torna inviável técnica e economicamente devendo-se na maioria dos casos deixar de ser executada. No caso contrário, passa-se a elaboração dos projetos de recuperação e reforço, o que denominamos terapia.

KLEIN et al. (1999) afirmam que a escolha da terapia adequada para uma edificação histórica depende sempre do trabalho conjunto de engenheiros especialistas, arquitetos restauradores e arqueólogos. Os problemas apresentados em uma edificação deste tipo são complexos e exigem um diagnóstico preciso sobre as condições do imóvel.

Para KLEIN et al. ( 1999) a recuperação de uma edificação histórica compreende vários projetos, tais como : reforço estrutural, reforço de fundações, recuperação de 
elementos estruturais e projetos afins. Todas as intervenções resultam em custos que devem ser detalhadamente especificados, já que nestes casos o custos são normalmente elevados. Tais intervenções deverão estar relacionadas com o projeto de restauração que procura resgatar as características originais da edificação.

A utilização de um metodologia adequada para a recuperação de edificações históricas propiciará uma melhor adequação dos trabalhos de intervenção às normas de restauro e recuperação.

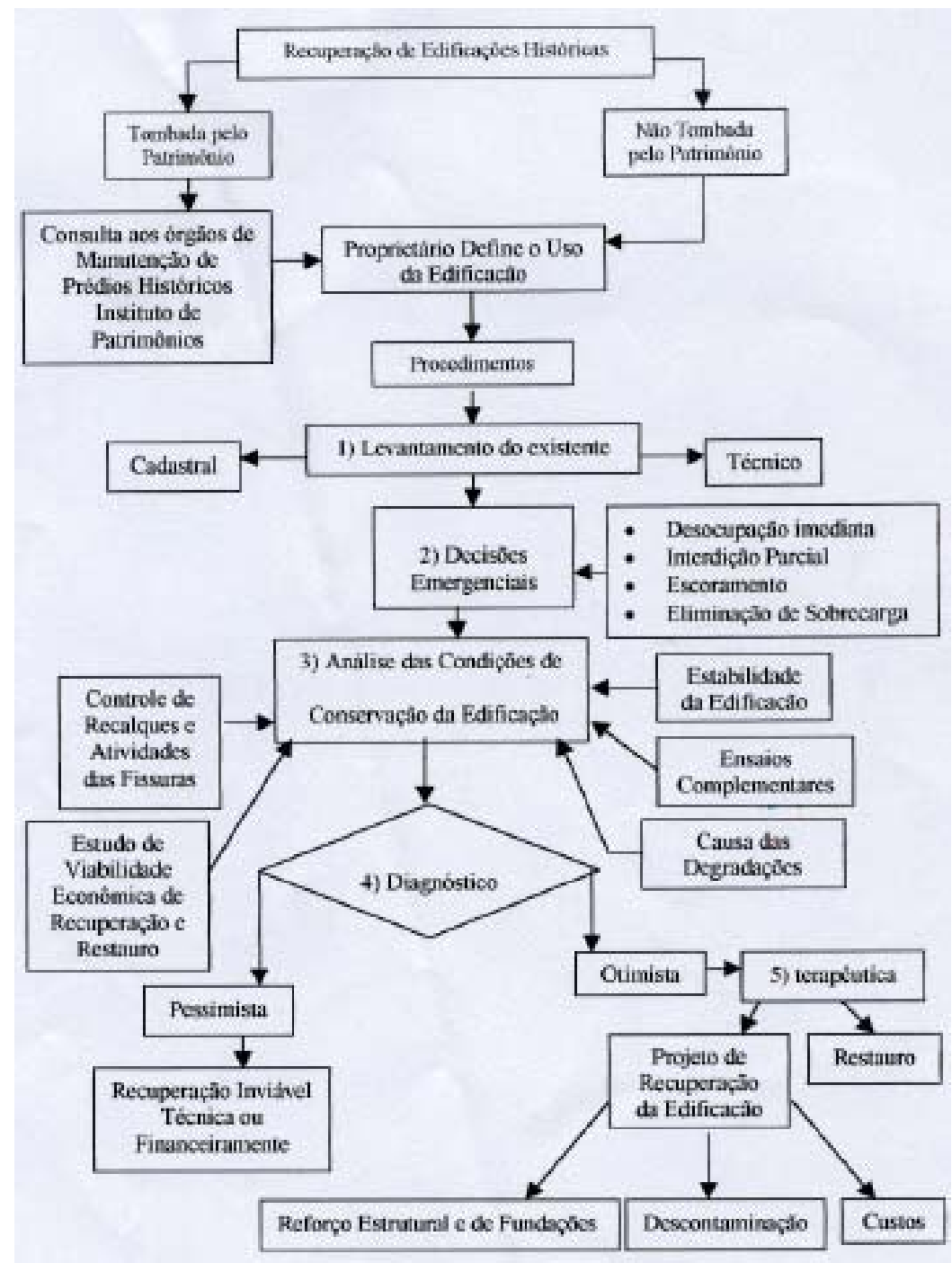

Figura 2.16 - Fluxograma - Passos a serem seguidos na recuperação de uma edificação histórica. fonte: KLEIN, 1999. 


\section{MATERIAIS E MÉTODOS}

Inicialmente foi feito um levantamento de obras históricas nas quais foram executados reforços ou recuperação, utilizando-se de consultas ao IPHAN ( Instituto do Patrimônio Histórico e Artístico Nacional), e a Internet em sites de empresas que trabalham com recuperação de estruturas para dar embasamento teórico-prático ao desenvolvimento do trabalho. A seguir, iniciou-se o levantamento de edificações históricas e antigas representativas para o município de Uberaba-MG, por meio de consultas ao Arquivo Público da cidade, entrevistas com pessoal técnico ligado a recuperação de edificações históricas e CODEMPHAU ( Conselho Deliberativo Municipal do Patrimônio Histórico e Artístico de Uberaba), possibilitando a seleção de uma delas dentre várias ( Prefeitura Municipal, Vila dos Eucaliptos, Prédio da estação Ferroviária). Foi escolhida para estudo e proposta de recuperação a Caeira do Meio, por seu valor histórico e por estar localizada em uma região que já foi parcialmente tombada pelo Patrimônio Histórico e Artístico de Uberaba.

\subsection{PESQUISA HISTÓRICA DO EDIFÍCIO}

\subsubsection{HISTÓRICO DO MUNICÍPIO ONDE ESTÁ SITUADA A EDIFICAÇÃO}

A edificação em estudo está localizada no município de Uberaba. Esse município situa-se na Micro-Região do Triângulo Mineiro, estado de Minas Gerais, com

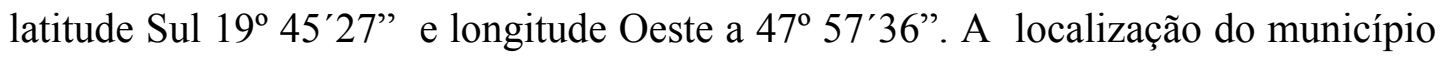
do ponto de vista geo-econômico é altamente estratégica em função da eqüidistância média de $500 \mathrm{Km}$, de Belo Horizonte, São Paulo, Brasília e Goiânia . Ocupa uma 
área física total de $4.524 \mathrm{Km}^{2}$, sendo que $256 \mathrm{Km}^{2}$ são ocupados pelo perímetro urbano, estando a sede do município a $764 \mathrm{~m}$ de altitude.

A colonização da região onde se formou Uberaba, se deu a partir dos primeiros anos do século XIX , quando garimpeiros do Desemboque começaram a se expandir por estes sertões, em razão do esgotamento das minas de ouro que exploravam A fundação se deveu ao Sargento-Mor Antônio Eustáquio de Oliveira, sendo nomeado Regente Geral e curador dos índios da região, em 1811, saiu do Desemboque e veio estabelecer-se onde hoje está a cidade, às margens da Estrada Toque Anhanguera, construída para extrair ouro em Goiás, e na cabeceira do Córrego das Lages.

No dia $1^{\circ}$ de dezembro de 1818 , foi benzida a primeira capela dedicada a Santo Antônio e São Sebastião. O então Arraial de Santo Antônio da Farinha Podre foi elevado a condição de Freguesia em 02 de março de 1820 . Em 22 de fevereiro de 1836 com a instalação da Câmara Municipal, completou-se a organização administrativa, surgindo a Vila de Uberaba, e posteriormente em 1856 elevou-se à vila a condição de Cidade. Segundo o censo realizado pelo IBGE/2000, a população do município é de 247.000 habitantes.

\subsubsection{EDIFICAÇÃO ANALISADA}

Dentre as várias edificações históricas existentes no município de Uberaba, foi selecionada uma delas, para estudo e análise. Tal edificação de acordo com o arquivo público se encontra em processo de tombamento como patrimônio histórico municipal, através do CODEMPHAU. Já existe parecer favorável ao tombamento deste bem imóvel. A seguir é apresentado na integra esse parecer, assinado pelo presidente do CODEMPHAU, Prof. José Thomaz da Silva Sobrinho.

Parecer de Tombamento - Caieira do Meio:

“O tombamento da Caieira do Meio, Fábrica de Cal anterior aos anos de 1892, reveste-se de muitos significados, arquitetônicos e históricos. A edificação dos 
fornos, remonta à uma técnica usada na França e sua colônia Argélia, onde os imigrantes que se fixaram no atual Distrito de Peirópolis - Flamínio Fantini, e mais tarde, Maximino Alonso, prestaram serviço na Legião Estrangeira. A industrialização do final do século XIX, com a expansão da Era da Estrada de Ferro, atingiram favoravelmente Uberaba. As fábricas de Cal são também um testemunho do crédito no progresso industrial com base no transporte da Companhia Mogiana de Estrada de Ferro. Ao valor histórico e arquitetônico, acrescenta-se o valor utilitário, que é a ampliação do espaço de visitação do conjunto Arquitetônico e Paisagístico de Peirópolis, já tombado em parte.”

\subsubsection{CAIEIRA DO MEIO}

De acordo com dados fornecidos pelo Arquivo Público Municipal a edificação está localizada, próxima a Peirópolis (4 Km), Município de Uberaba, BR262, Km 776 conforme mapa representativo indicado na figura 3.1.

Sua construção data aproximadamente de 1896. O primeiro forno da Caieira do Meio foi construído por volta de 1900 por Flamínio Fantini. Comprada por Maximino Alonso em 1917, foi ampliando e crescendo sua produção, sendo desativado em 1960, após ser vendido para a Cia de Cimento Portland. No galpão dos fornos estão guardados os carretões tal com estavam (figura 3.2), sendo que o pavilhão inferior serviu de moradia.

O complexo está distribuído em dois patamares. O primeiro edifício é um galpão de $29,55 \times 7,8 \mathrm{~m}^{2}$ e $6,73 \mathrm{~m}$ de altura, com cobertura em duas águas, com cumeeira sustentada por três esteios, coberta com telhas de zinco, sendo os caibros de aroeira e bálsamo, apoiados por esteios de aroeira . Do lado externo da cobertura, um esteio de aroeira apóia uma peça de madeira que segura um dos cabos laterais, certamente uma intervenção posterior. Este galpão foi construído junto ao corte da colina de forma que o barranco vertical servisse de abrigo aos fornos de calcinação. A cada um 
dos três fornos, de tamanhos diferentes, corresponde um acesso por um túnel, com uma entrada em arco de meio ponto, de tijolos (Figura 3.3 e 3.4).

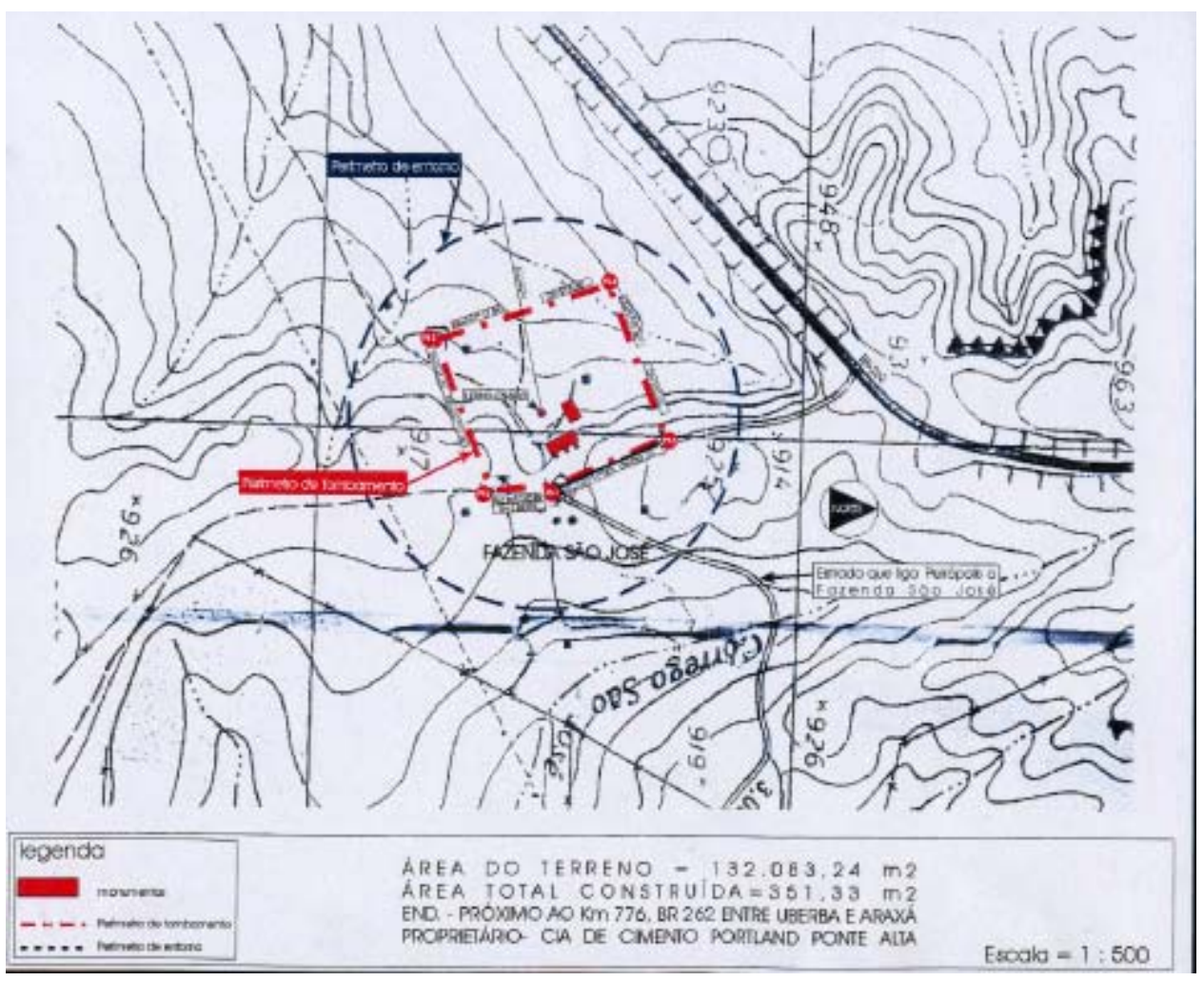

Figura 3.1 - Mapa indicando entorno da Caieira do Meio fonte: Arquivo Público Municipal, 1999

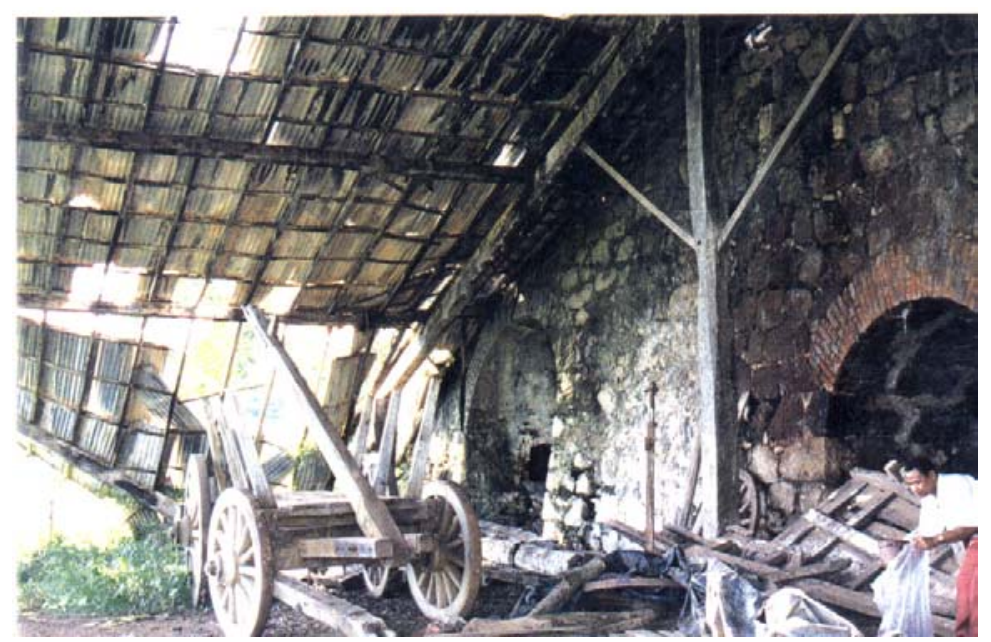

Figura 3.2 - Detalhe do galpão dos fornos com Carretão fonte: Arquivo Púbico Municipal , 1999 


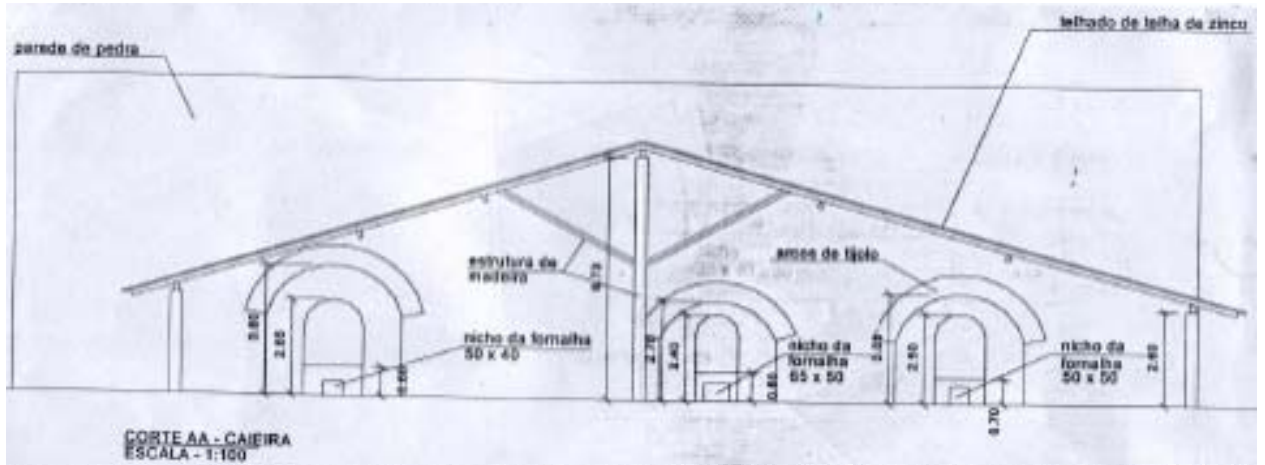

Figura 3.3 - Corte esquemático da edificação dos fornos fonte: Arquivo Público Municipal, 1999

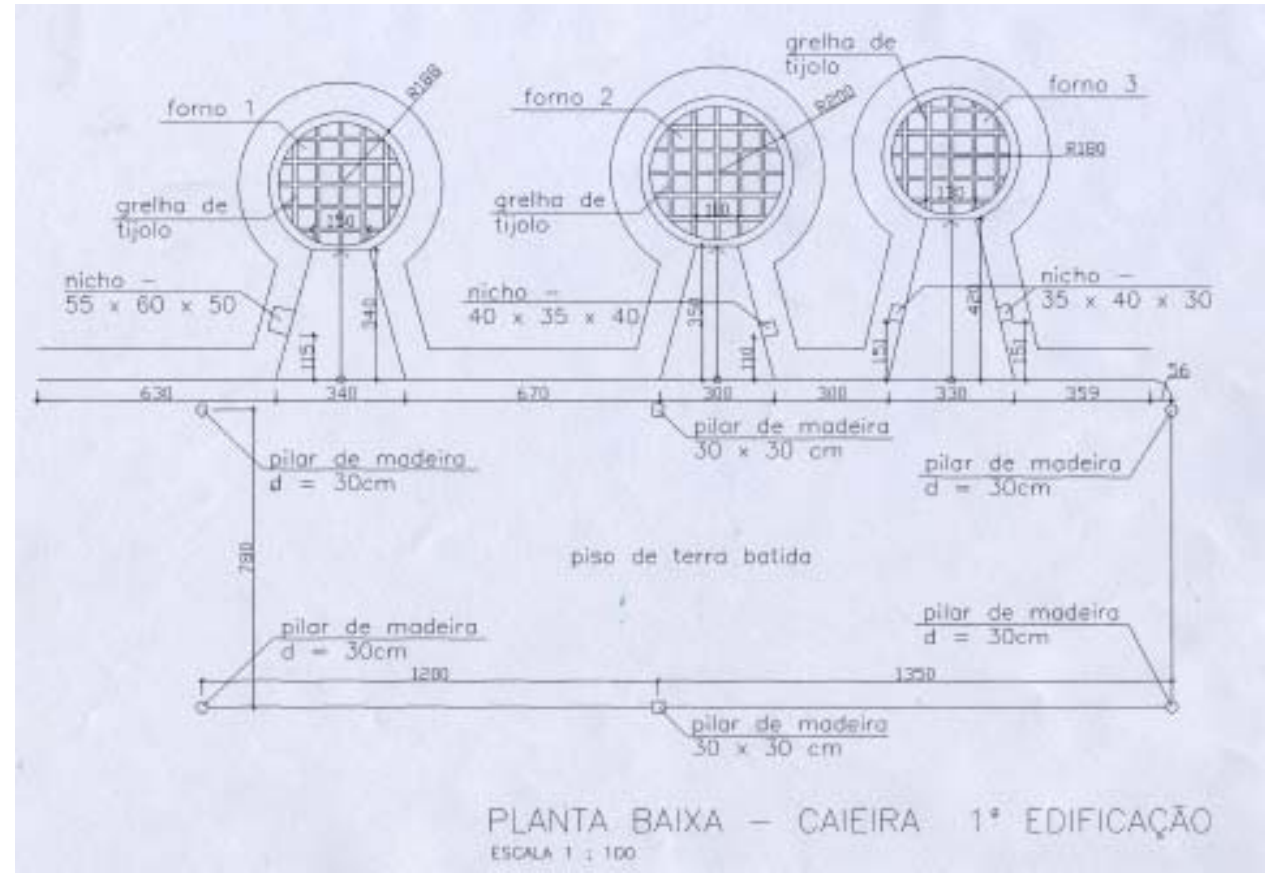

Figura 3.4 - Planta dos fornos - Caieira do Meio fonte: Arquivo Público Municipal, 1999

O telhado em madeira com telhas de zinco apresenta-se bastante danificado, conforme verificação visual “ in loco” ( Figuras 3.5 e 3.6). Uma armação em forma de grade, de vigas de alvenaria, sustenta o assoalho do forno sobre uma abertura, o carvoeiro. 


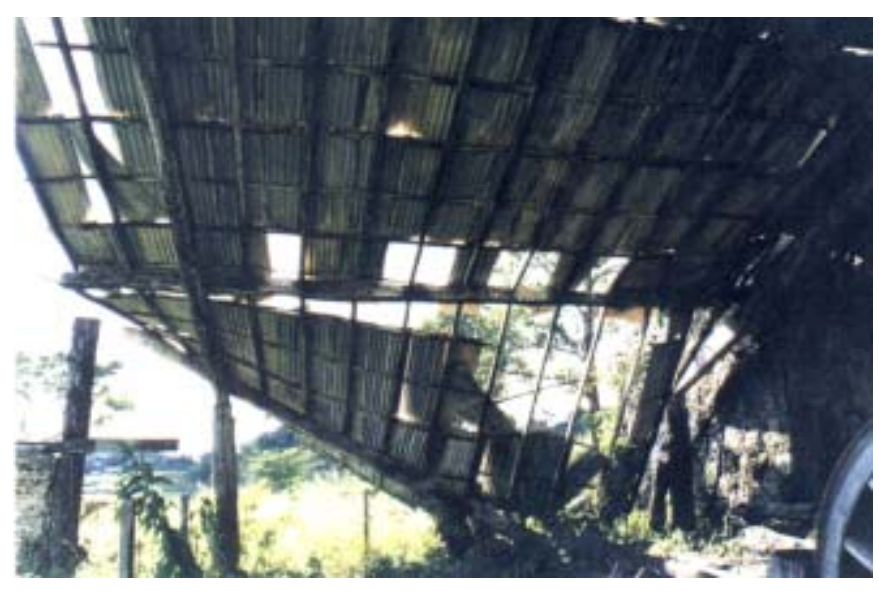

Figura 3.5 - Detalhe da cobertura danificada fonte: Arquivo Público Municipal

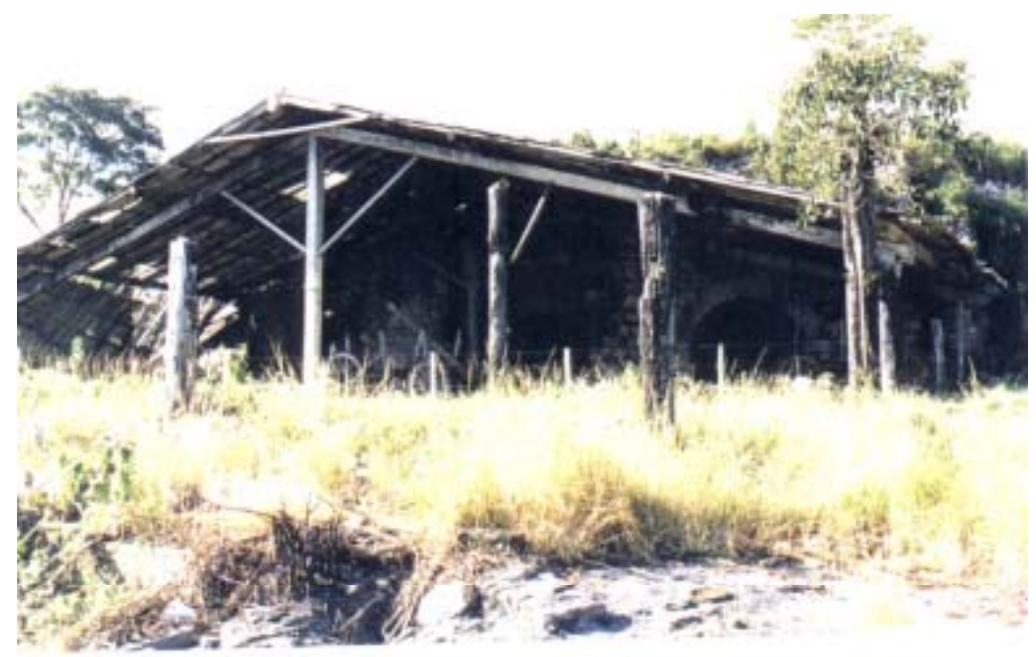

Figura 3.6 - Visão geral da cobertura danificada fonte: Arquivo Público Municipal, 1999

A segunda edificação bastante ampla, compõe-se de um galpão de duas águas, sendo que o corte na colina, estende-se em ângulo de $45^{\circ}$, até a metade de um dos lados do galpão, de forma a abrigar um fosso( Figuras 3.7 e 3.8). Uma construção, que parece ter sido uma marcenaria, ocupa parte do galpão coberto em telhas originais tipo capa e canal. 


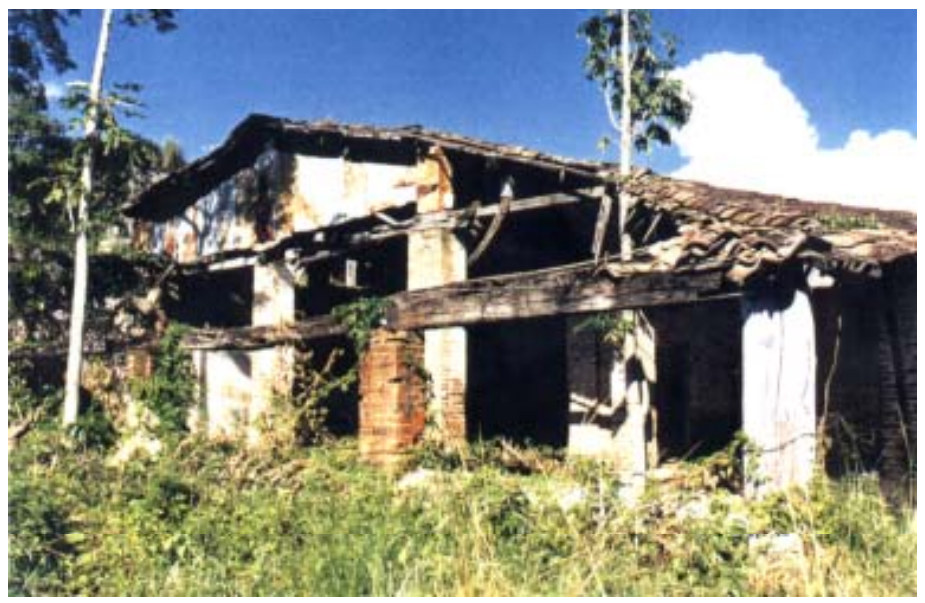

Figura 3.7 - Vista geral Edificação 2 . Caieira do Meio fonte: Arquivo Público Municipal

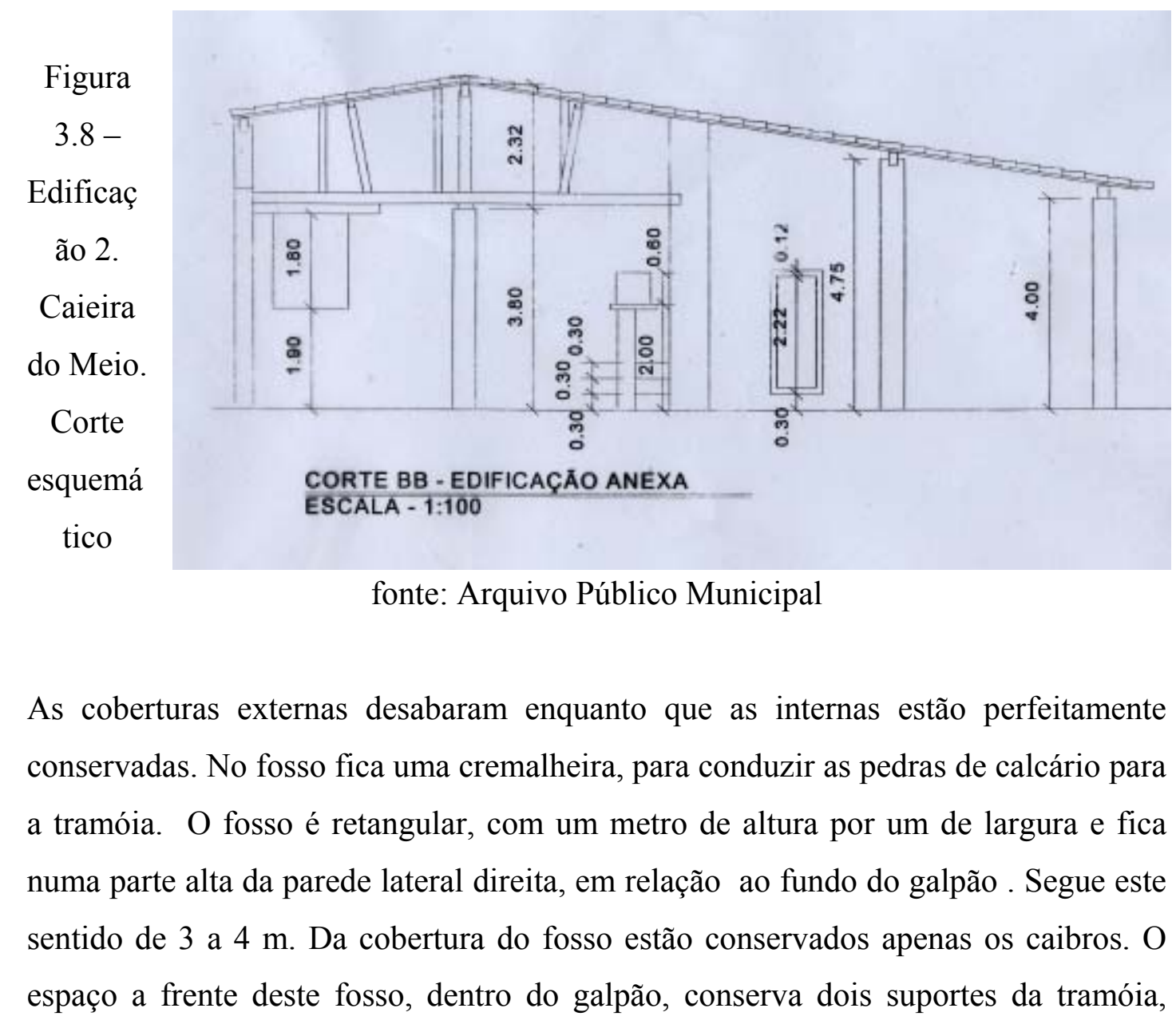


constituído por dois pilares de madeira vermelha, provavelmente jatobá, de cerca de dois metros de altura.

Na parte do galpão da fábrica, colunas de tijolos dão sustentação ao teto, com caibros de madeira (Figura 3.9).

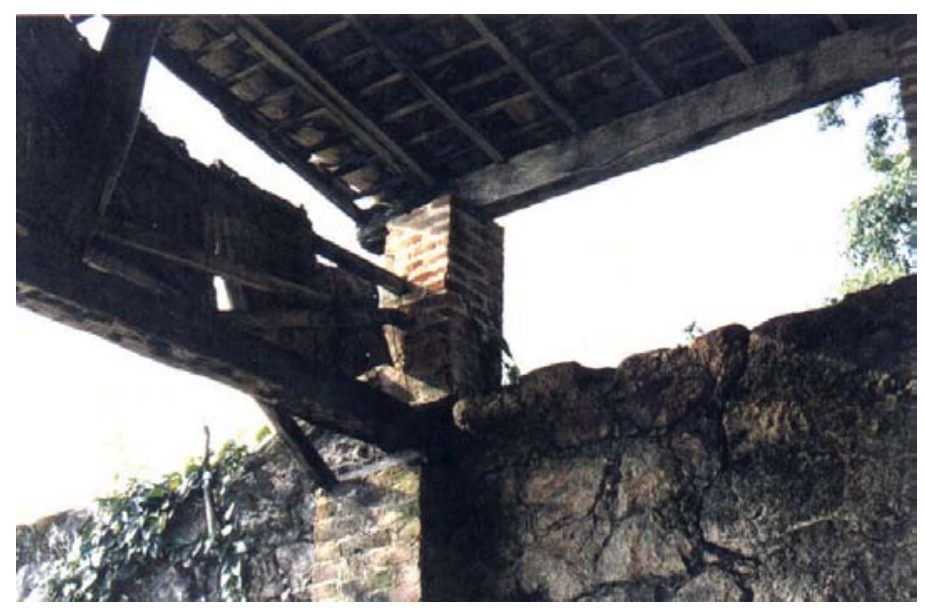

Figura 3.9 - Detalhe do pilar em alvenaria. fonte: Arquivo Público Municipal, 1999

Ao lado direito da segunda edificação, fica um forno de forma circular de 3 metros de diâmetro, por três metros de altura, construído em tijolões, tendo uma cúpula por cobertura. Uma abertura no arco abatido da acesso ao seu interior. A construção deste forno data de 1942.

Segundo laudo técnico parcial apresentado, ao Arquivo Público Municipal de Uberaba, pelo arquiteto Marcelo J. Temponi , CREA - MG 70199, o madeiramento que sustenta o telhado está em parte danificado e cedendo, a cobertura está em péssimo estado com comprometimento de aproximadamente $90 \%$, os pilares em tijolo queimado estão rompendo e toda a estrutura do forno para carvão está comprometida devido a fissuras e rachaduras. 
Após visitas no local constatou-se efetivamente que existe a necessidade de substituição e recuperação de algumas peças do telhado, principalmente das terças, a fim de se poder adequar a estrutura da edificação para utilização como atrativo á visitação ao parque paleontológico de Peirópolis.

\subsection{ELEMENTOS ESTRUTURAIS EM AÇO FORMADOS A FRIO}

\subsubsection{HISTÓRICO}

Segundo Yu (1991) o início da utilização de perfis formados a frio na construção civil data de 1850, na Inglaterra e Estados Unidos, tendo poucas informações técnicas e sendo seu uso restrito.

Através da iniciativa do AISI ( American Iron and Steel Institute), por volta de 1939, iniciam-se pesquisas orientadas pelo professor da Universidade Cornell, George Winter.

No ano de 1946, com o incentivo dos Estados Unidos, os perfis leves tornaram-se bastante utilizados tanto na construção como em outras áreas ligadas a estruturas de aço, sendo editadas várias edições da AISI. A de 1986, prescreveu o tradicional método das tensões admissíveis, tendo o método dos estados limites especificado na versão de 1991 e em uma segunda edição em 1996, que abordou também o método das tensões admissíveis.

No Brasil o uso destes perfis iniciou-se provavelmente na década de 60 . Foi publicada em 1967 a norma ABNT- NB 143 (Cálculo de estruturas de aço, constituídas por perfis leves), que devido a pouca divulgação e falta de revisões, se tornou um documento técnico desatualizado. Desta forma tornou-se comum o uso de normas estrangeiras para o cálculo e dimensionamento de perfis formados a frio. 
Tornou-se necessário então, a elaboração de uma Norma de perfis leves que viesse preencher essa lacuna existente no Brasil, propiciando um melhor uso do material, já que esses perfis são usados em larga escala, principalmente em obras leves, com custo menor que os perfis soldados e laminados e evitando incompatibilidade no uso simultâneo de normas estrangeiras e nacionais.

Elementos estruturais executados com perfis dobrados a frio estão sendo bastante utilizados no Brasil principalmente pelo seu baixo custo e falta ou preço elevado de outros produtos em aço. Em obras de grande porte são utilizados normalmente em elementos estruturais secundários, tais como contraventamentos, terças, vigas longarinas, entre outros. Utiliza-se também em edifícios de pequena altura e galpões de uso geral, sendo recomendados para situações de carregamentos de pequena intensidade.

\subsubsection{SEÇÕES USUAIS}

São diversas as seções que podem ser utilizadas na composição de elementos estruturais em perfis formados a frio, simples ou compostas. Perfis tipo U simples ou enrijecidos, cantoneiras, perfis Z, cartola, Duplo U aberto e duplo U Fechado, dentre outros, conforme figura 3.10.

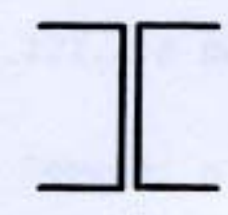

Perfil I

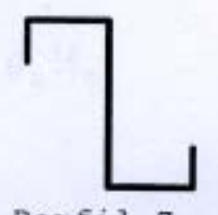

Perfil 2 enrijecido

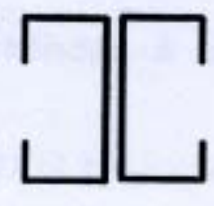

Perfil I enrijecido

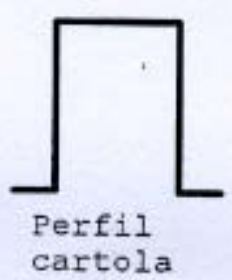

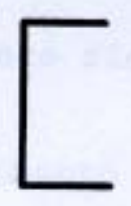
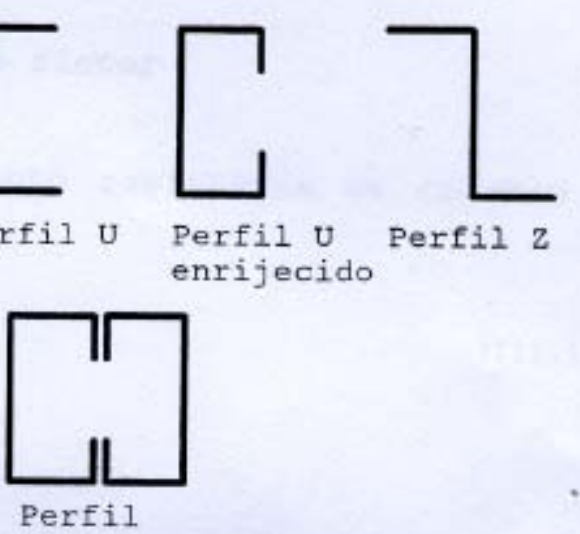

caixa
Figura 3.10 - Tipos de perfis formados a frio fonte: REIS, 1996.

3.2.3.

MATERIAIS

EMPREGADOS EM PERFIS

DE CHAPA DOBRADA 
De acordo com o projeto de norma de dimensionamento e cálculo de perfis formados a frio o uso de aços com qualificação estrutural e que possuam propriedades mecânicas adequadas para receber o trabalho a frio devem apresentar a relação entre a resistência à ruptura e a resistência ao escoamento $f_{u} / f_{y}$ maior ou igual a 1,08 , e o alongamento após ruptura não deve ser menor que $10 \%$ para base de medida igual a $50 \mathrm{~mm}$ ou $7 \%$ para base de medida igual a $200 \mathrm{~mm}$, tomando-se como referência os ensaios de tração conforme ASTM A370. A utilização de aços sem qualificação estrutural para perfis é tolerada se o aço possuir propriedades mecânicas adequadas para receber o trabalho a frio. Não devem ser adotados no projeto valores superiores à $180 \mathrm{MPa}$ e $300 \mathrm{MPa}$ para a resistência ao escoamento $f_{y}$ e a resistência à ruptura $f_{u}$, respectivamente. A AISI/86 especifica quatorze tipos de aço, sendo eles representados na tabela 2.1 .

Tabela 3.1 - Principais aços estruturais ASTM e sua utilização

\begin{tabular}{|c|l|l|}
\hline $\begin{array}{c}\text { ESPECIFICAÇÃO } \\
\text { ASTM }\end{array}$ & TIPOS DE PRODUTOS & \multicolumn{1}{|c|}{ UTILIZAÇÃO } \\
\hline A36 & $\begin{array}{l}\text { Perfis, chapas e barras de } \\
\text { aço-carbono. }\end{array}$ & $\begin{array}{l}\text { parafusada } \\
\text { edifícios, torres e uso } \\
\text { estrutural em geral. }\end{array}$ \\
\hline
\end{tabular}




\begin{tabular}{|c|c|c|}
\hline A53 & $\begin{array}{l}\text { Tubos soldados ou sem } \\
\text { costura, pretos } \\
\text { galvanizados. }\end{array}$ & $\begin{array}{l}\text { Construção soldada e } \\
\text { parafusada; especialmente } \\
\text { em pilares e barras de } \\
\text { treliças. }\end{array}$ \\
\hline A242 & $\begin{array}{l}\text { Perfis, chapas e barras de } \\
\text { aço de alta resistência e } \\
\text { baixa liga. }\end{array}$ & $\begin{array}{l}\text { Construção soldada e } \\
\text { parafusada; } \\
\text { edifícios, torres e ustes, } \\
\text { estrutural em } \\
\text { resistência à corrol A } \\
\text { atmosférica é cerca de } \\
\text { quatro vezes maior que a } \\
\text { do aço-carbono; aço } \\
\text { resistente ao intemperismo. }\end{array}$ \\
\hline A440 & $\begin{array}{l}\text { Perfis, chapas e barras de } \\
\text { aço de alta resistência. }\end{array}$ & $\begin{array}{l}\text { Construção parafusada; } \\
\text { pontes, edifícios, torres e } \\
\text { outras estruturas. A } \\
\text { resistência à corrosão } \\
\text { atmosférica é duas vezes } \\
\text { maior que a do aço- } \\
\text { carbono. }\end{array}$ \\
\hline A446 & $\begin{array}{l}\text { Chapas finas em bobinas } \\
\text { ou cortadas, galvanizadas. }\end{array}$ & $\begin{array}{llr}\text { Perfis formados } & \text { a } & \text { frio, } \\
\text { usados em } & \text { edifícios, } \\
\text { principalmente } & \text { do } & \text { tipo } \\
\text { padronizado, } & & \text { pré- }\end{array}$ \\
\hline
\end{tabular}




\begin{tabular}{|c|c|c|}
\hline & & $\begin{array}{l}\text { fabricado; construção } \\
\text { soldada, parafusada com } \\
\text { parafusos comuns ou auto } \\
\text { atarrachantes }\end{array}$ \\
\hline A500 & $\begin{array}{l}\text { Perfis tubulares formados } \\
\text { a frio, soldados ou sem } \\
\text { costura, redondos, } \\
\text { quadrados, retangulares ou } \\
\text { com formatos especiais. }\end{array}$ & $\begin{array}{l}\text { Construção } \quad \text { soldada ou } \\
\text { parafusada; }\end{array}$ \\
\hline A501 & $\begin{array}{l}\text { Perfis tubulares formados } \\
\text { a frio, soldados ou sem } \\
\text { costura, redondos, } \\
\text { quadrados, retangulares ou } \\
\text { com formatos especiais. }\end{array}$ & 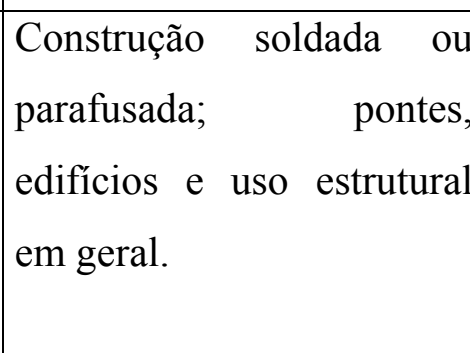 \\
\hline A514 & $\begin{array}{l}\text { Chapas temperadas, aço } \\
\text { de elevado limite de } \\
\text { escoamento. }\end{array}$ & $\begin{array}{l}\text { Usado principalmente em } \\
\text { pontes soldadas e outras } \\
\text { estruturas. A técnica de } \\
\text { soldagem não deve afetar } \\
\text { as propriedades da chapa, } \\
\text { especialmente na zona } \\
\text { afetada pelo calor. }\end{array}$ \\
\hline A529 & $\begin{array}{l}\text { Chapas e barras de aço- } \\
\text { carbono com espessura até } \\
13 \mathrm{~mm} .\end{array}$ & $\begin{array}{l}\text { Edifícios, principalmente } \\
\text { do tipo padronizado, pré- } \\
\text { fabricado; construção } \\
\text { soldada ou parafusada. }\end{array}$ \\
\hline & & Perfis soldados a frio \\
\hline
\end{tabular}




\begin{tabular}{|c|c|c|}
\hline A570 & $\begin{array}{l}\text { Chapas finas e tiras de } \\
\text { aço-carbono, laminadas a } \\
\text { quente, em bobinas ou } \\
\text { cortadas. }\end{array}$ & 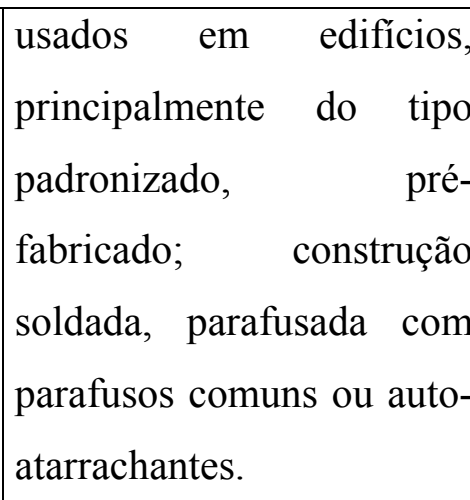 \\
\hline A572 & $\begin{array}{l}\text { Perfis, chapas, estacas } \\
\text { pranchas e barras de aço } \\
\text { de alta resistência e baixa } \\
\text { liga, contendo Colúmbio e } \\
\text { Vanádio. }\end{array}$ & $\begin{array}{l}\text { Construção soldada ou } \\
\text { parafusada em edifícios, } \\
\text { usando todos os graus de } \\
\text { resistência do aço: na } \\
\text { construção de pontes, } \\
\text { somente nas resistências } \\
300,320 \text { e } 350 \mathrm{MPa} \text {. }\end{array}$ \\
\hline A588 & $\begin{array}{l}\text { Perfis, chapas e barras de } \\
\text { alta resistência e baixa } \\
\text { liga. }\end{array}$ & $\begin{array}{l}\text { Usado principalmente em } \\
\text { pontes soldadas e em } \\
\text { edifícios. A resistência à } \\
\text { corrosão atmosférica é } \\
\text { cerca de quatro vezes } \\
\text { maior que a do aço- } \\
\text { carbono; aço resistente ao } \\
\text { intemperismo. }\end{array}$ \\
\hline A606 & $\begin{array}{l}\text { Chapas finas e tiras de aço } \\
\text { de alta resistência e baixa } \\
\text { liga, laminadas a quente e } \\
\text { a frio. }\end{array}$ & $\begin{array}{l}\text { Uso em estruturas e em } \\
\text { outras finalidades onde for } \\
\text { importante à economia de } \\
\text { peso e maior durabilidade. }\end{array}$ \\
\hline
\end{tabular}


No Brasil ainda é comum a fabricação de perfis formados a frio com aços de qualidade não estrutural. $\mathrm{Na}$ falta de especificações brasileiras (EB), serão adotadas as especificações ASTM A245, A303, A374, A375 e A446, até o limite máximo de $35 \mathrm{KN} / \mathrm{cm} 2$ para limite de escoamento dos vários aços estruturais.

\subsection{DIMENSIONAMENTO DAS PEÇAS A SEREM SUBSTITUÍDAS}

A proposta para recuperação de parte da estrutura da edificação1, foi a substituição das terças deterioradas de madeira, por perfis formados a frio. Para manter o aspecto de estético foi proposto perfil duplo U caixão, que será pintado de acordo com as normas técnicas.

\subsubsection{AÇO}

O aço utilizado para o cálculo das terças é o ASTM A-36. Este aço apresenta limite de escoamento nominal de $25 \mathrm{KN} / \mathrm{cm}^{2}$ e limite de resistência à tração de $40 \mathrm{KN} / \mathrm{cm}^{2}$.

\subsubsection{DISPOSIÇÃO DAS TERÇAS}

As terças deverão estar colocadas espaçadas de $3,5 \mathrm{~m}$ do lado direito e $4,5 \mathrm{~m}$ do lado esquerdo da cobertura. Estarão apoiadas sobre a estrutura de madeira já existente que apresenta bom estado, sendo reforçada em alguns pontos. $\mathrm{O}$ vão entre os apoios é de $7,8 \mathrm{~m}$ e serão colocadas duas correntes para o travamento lateral das terças.

\subsubsection{CARGAS ATUANTES}


Foram consideradas atuando sobre as terças as seguintes cargas:

a) Peso próprio

Foi considerado peso das terças e tirantes de acordo com valores práticos, no valor de $0,040 \mathrm{KN} / \mathrm{m}^{2}$ e peso da telha de aço galvanizado igual a $0,10 \mathrm{KN} / \mathrm{m}^{2}$, ficando o peso próprio total igual a $0,63 \mathrm{KN} / \mathrm{m}$.

b) Sobrecarga

Foi utilizado o valor definido pela Norma NBR 8800 (1986) no item B.3.6.1 do anexo B que específica que para coberturas comuns não sujeitas a acúmulo de quaisquer materiais, e na ausência de especificação em contrário, seja prevista uma sobrecarga nominal mínima de $0,25 \mathrm{KN} / \mathrm{m}^{2}$, em projeção horizontal. Neste caso o carregamento da terça devido a sobrecarga foi de $1,125 \mathrm{KN} / \mathrm{m}$.

c)Vento

A ação do vento sobre a estrutura foi determinada de acordo com os critérios da norma NBR 6123 (1988), sendo definidos os seguintes valores:

c.1) Velocidade básica do vento (Vo):

Foi definida por meio do gráfico das isopletas. Como o Município de Uberaba no qual está situada a edificação, localiza-se no estado de Minas Gerais no Triângulo Mineiro, o valor é de $\mathrm{Vo}=35 \mathrm{~m} / \mathrm{s}$.

c.2) Fator topográfico (S1): 
O terreno no qual situa-se a caieira do meio é fracamente acidentado, tomando-se para $\mathrm{S} 1$ o valor de 1,0 .

c.3) Fator rugosidade do terreno ( $\mathrm{S} 2$ ):Neste caso definiu-se $\mathrm{S} 2$ com valor de 0,98. A categoria considerada foi a II ( terrenos abertos em nível ou aproximadamente em nível, com poucos obstáculos isolados, tais com árvores e edificações baixas), Classe da edificação B ( toda edificação ou parte de edificação para a qual a maior dimensão horizontal ou vertical da superfície frontal esteja entre $20 \mathrm{~m}$ e $50 \mathrm{~m}$ ) e altura $7,0 \mathrm{~m}$.

c.4) Fator estatístico (S3):

Foi adotado o valor de 0,95 , relativo a construções rurais.

c.5) Velocidade Característica (Vk):

Através da equação VK= Vo.S1.S2.S3 determinou-se o valor da velocidade característica sendo o valor igual a $32,59 \mathrm{~m} / \mathrm{s}$.

c.6) Pressão dinâmica do vento (q):

Por meio da velocidade característica e da expressão $\mathrm{q}=0,613 \mathrm{Vk}^{2}$ determinou-se a pressão dinâmica do vento $\mathrm{q}=651,07 \mathrm{~N} / \mathrm{m}^{2}$ ou seja $\mathrm{q}=0,65 \mathrm{KN} / \mathrm{m}^{2}$.

c.7) Pressão efetiva do vento (p):

Analisando os coeficientes de pressão externos e internos, verificou-se na combinação entre Cpi e Cpe o valor crítico de $-1,0$. Portanto $p=-0,65 \mathrm{KN} / \mathrm{m}^{2}$.O valor da carga transmitida pelo vento às terças foi de - 2,93 KN/m (sucção).

\subsubsection{COMBINAÇÕES DAS AÇÕES}


Depois de definidas as ações, aplicou-se a expressão para combinações últimas normais de acordo com o Projeto de Norma de Dimensionamento de Estruturas Constituídas por Perfis Formados a Frio:

$$
F d=\sum_{i=1}^{m}\left(\gamma_{g i} F_{G i}\right)+\gamma_{q 1} F_{Q 1}+\sum_{j=2}^{n}\left(\gamma_{q j} \psi_{0 j} F_{Q j}\right)
$$

Onde:

$\mathrm{F}_{\mathrm{Gi}}$ são as ações permanentes;

$\mathrm{F}_{\mathrm{Q} 1}$ é a ação variável considerada como principal nas combinações normais, ou como principal para a situação transitória nas combinações especiais ou de construção;

$\mathrm{F}_{\mathrm{Qj}}$ são as demais ações variáveis;

$\gamma_{\mathrm{g}}$ é o coeficiente de ponderação das ações permanentes, conforme tabela 3.2;

$\gamma_{\mathrm{q}}$ é o coeficiente de ponderação das ações variáveis, conforme tabela 3.2;

$\psi_{0}$ é o fator de combinação, conforme tabela 3.3;

Tabela 3.2 - Coeficientes de ponderação das ações

\begin{tabular}{|l|l|l|l|l|l|}
\hline & \multicolumn{2}{|c|}{ Ações permanentes } & \multicolumn{3}{c|}{ Ações variáveis } \\
\hline $\begin{array}{l}\text { Combina- } \\
\text { ções }\end{array}$ & $\begin{array}{l}\text { Grande } \\
\text { Variabilida- } \\
\text { de }\end{array}$ & $\begin{array}{l}\text { Pequena } \\
\text { Variabilida- } \\
\text { de }\end{array}$ & $\begin{array}{l}\text { Recalques } \\
\text { Diferenciais }\end{array}$ & $\begin{array}{l}\text { Variação de } \\
\text { Temperatu- } \\
\text { ra }\end{array}$ & $\begin{array}{l}\text { Ações } \\
\text { variáveis em } \\
\text { geral, } \\
\text { incluindo as } \\
\text { decorrentes } \\
\text { do uso }\end{array}$ \\
\hline \multicolumn{1}{|c|}{$\gamma_{\mathrm{g}}{ }^{1)}$} & $\gamma_{\mathrm{g}}{ }^{1) 2)}$ & $\gamma_{\mathrm{q}}$ & $\gamma_{\mathrm{q}}{ }^{3)}$ & $\gamma_{\mathrm{q}}{ }^{4)}$ \\
\hline $\begin{array}{c}\text { Normais } \\
\text { Constru- } \\
\text { ção }\end{array}$ & $1,4(0,9)$ & $1,3(1,0)$ & 1,2 & 1,2 & 1,4 \\
\hline $\begin{array}{c}\text { Excepcio- } \\
\text { nais }\end{array}$ & $1,3(0,9)$ & $1,2(1,0)$ & 1,2 & 1,0 & 1,2 \\
\hline 1$)$ & $1,1(1,0)$ & 0 & 0 & 1,0 \\
\hline
\end{tabular}


permanentes favoráveis à segurança; ações variáveis e excepcionais favoráveis à segurança não devem ser incluídas nas combinações.

2) Todas as ações permanentes podem ser consideradas de pequena variabilidade quando o peso próprio da estrutura superar $75 \%$ da totalidade das ações permanentes. Também podem ser consideradas ações permanentes de pequena variabilidade os pesos próprios de elementos metálicos e pré-fabricados em geral, com controle rigoroso de peso. Excluem-se os revestimentos feitos in loco destes elementos.

3) A variação de temperatura citada não inclui a gerada por equipamentos, a qual deve ser considerada como ação decorrente do uso da edificação.

4) Ações decorrentes do uso da edificação incluem: sobrecargas em pisos e em coberturas, ações provenientes de monovias, pontes rolantes ou outros equipamentos, etc.

fonte: Projeto de Norma, 2001.

Tabela 3.3 - Fatores de combinação e fatores de utilização

\begin{tabular}{|c|c|c|c|}
\hline Ações & $\psi_{0}^{1)}$ & $\psi_{1}$ & $\psi_{2}$ \\
\hline $\begin{array}{l}\text { Variações uniformes de temperatura em relação à } \\
\text { média anual local }\end{array}$ & 0,6 & 0,5 & 0,3 \\
\hline - Pressão dinâmica do vento nas estruturas em geral & 0,4 & 0,2 & 0 \\
\hline $\begin{array}{l}\text { - Pressão dinâmica do vento nas estruturas em que a } \\
\text { ação variável principal tem pequena variabilidade } \\
\text { durante grandes intervalos de tempo (exemplo: } \\
\text { edifícios de habitação) }\end{array}$ & 0,6 & 0,2 & 0 \\
\hline \multicolumn{4}{|l|}{ Cargas acidentais (sobrecargas) nos edifícios: } \\
\hline $\begin{array}{l}\text { - Sem predominância de equipamentos que } \\
\text { permanecem fixos por longos períodos de tempo, nem } \\
\text { de elevadas concentrações de pessoas }\end{array}$ & 0,4 & 0,3 & 0,2 \\
\hline $\begin{array}{l}\text { - Com predominância de equipamentos que } \\
\text { permanecem fixos por longos períodos de tempo, ou } \\
\text { de elevadas concentracões de pessoas }\end{array}$ & 0,7 & 0,6 & 0,4 \\
\hline - $\quad$ Bibliotecas, arquivos, oficinas e garagens & 0,8 & 0,7 & 0,6 \\
\hline Cargas móveis e seus efeitos dinâmicos: & & & \\
\hline - Equipamentos de elevação e transporte & 0,6 & 0,4 & 0,2 \\
\hline - Passarelas de pedestres & 0,4 & 0,3 & 0,2 \\
\hline
\end{tabular}

fonte: Projeto de Norma, 2001. 
Nas terças em questão as seguintes combinações foram atribuídas:

- $1,3 . p p$

- $1,3 \cdot \mathrm{pp}+1,4 . \mathrm{sc}$

- $1,0 . \mathrm{pp}+1,4 \mathrm{v}$

- $1,3 . p p+1,4 \mathrm{sc}+0,84 . \mathrm{v}$

- $\quad 1,3 \cdot \mathrm{pp}+1,4 \mathrm{v}+0,98$. sc

Para as terças o peso próprio e a sobrecarga são cargas verticais e devem ser decompostas nas direções x e y, segundo um ângulo de $16,89^{\circ}$ e o vento com é uma carga perpendicular ao plano da terça é na direção y, conforme figura 3.11.

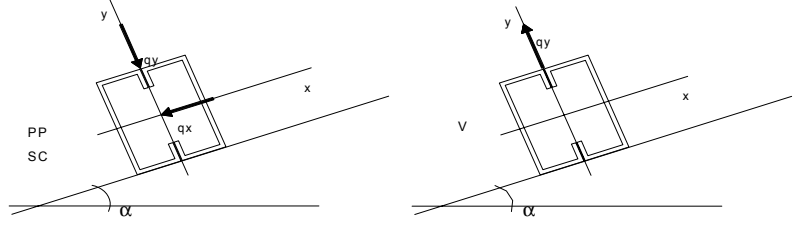

Figura 3.11 - Esquema de carregamento das terças

As ações foram combinadas sendo a situação crítica, vento (sucção), apresentada a seguir:

$\mathrm{qx}=1,0 \mathrm{x} 0,63 \mathrm{x} \cos 16,89^{\circ}+1,4 \mathrm{x}(-2,93)=-3,49 \mathrm{KN} / \mathrm{m}$

$\mathrm{qy}=1,0 \mathrm{x} 0,63 \mathrm{xsen} 16,89^{\circ}=0,18 \mathrm{KN} / \mathrm{m}$

As terças foram projetadas levando em consideração a flexão oblíqua, flexão em torno dos eixos $\mathrm{x}$ e $\mathrm{y}$, de acordo com o projeto da Norma Brasileira de 
Dimensionamento de Estruturas de Aço constituída por Perfis Formados a Frio, apresentado no anexo, através da expressão de iteração:

$\frac{N_{c, S d}}{N_{0, R d}}+\frac{M_{x, S d}}{M_{x, R d}}+\frac{M_{y, S d}}{M_{y, R d}} \leq 1,0$

Como o perfil não está sujeito à carga de compressão, o primeiro termo anula-se ficando apenas a expressão:

$\frac{M_{x, S d}}{M_{x, R d}}+\frac{M_{y, S d}}{M_{y, R d}} \leq 1,0$

onde:

$\mathrm{M}_{\mathrm{x}, \mathrm{Sd}} ; \mathrm{M}_{\mathrm{y}, \mathrm{Sd}}$ são os momentos fletores solicitantes de cálculo, na seção considerada, em relação aos eixos $x$ e $y$, respectivamente;

$\mathrm{M}_{\mathrm{x}, \mathrm{Rd}} ; \mathrm{M}_{\mathrm{y}, \mathrm{Rd}}$ são os momentos fletores resistentes de cálculo, em relação aos eixos $x$ e $y$, respectivamente, calculados conforme item 7.8.1, com $\mathrm{C}_{\mathrm{b}}=1,0$, apresentado no Anexo.

Foi ainda verificado o deslocamento da terça, considerando para isto os limites e combinação de ações, recomendados pelo projeto de norma, conforme tabela 3.4.

Tabela 3.4 - Deslocamentos limites recomendados

\begin{tabular}{|l|c|c|c|}
\hline \multicolumn{1}{|c|}{ Descrição } & $\mathbf{d}_{\mathbf{1}}$ & $\mathbf{d}_{\mathbf{2}}$ & $\begin{array}{l}\text { Exemplos de } \\
\text { Combinações 2) 3) }\end{array}$ \\
\hline $\begin{array}{l}\text {-Terças e longarinas de } \\
\text { fechamento em geral }{ }^{\text {) 5) }}\end{array}$ & $\mathrm{L} / 180$ & - & $\mathrm{F}_{\mathrm{G}}$ \\
\hline & & & $\mathrm{F}_{\mathrm{Q} 1}$ \\
\hline $\begin{array}{l}\text { Longarinas de fechamento em } \\
\text { geral }{ }^{6)}\end{array}$ & - & $\mathrm{L} / 120$ & $\mathrm{~F}_{\mathrm{Q} 1}$ \\
\hline $\begin{array}{l}\text { Longarinas suportando } \\
\text { fechamentos sujeitos à a }\end{array}$ & - & $\mathrm{L} / 180$ & \\
\hline
\end{tabular}




\begin{tabular}{|c|c|c|c|}
\hline \begin{tabular}{|llr} 
fissuração & e/ou componentes \\
sensíveis & a & deslocamentos \\
excessivos & &
\end{tabular} & & & \\
\hline $\begin{array}{ll}\text { 3) } & \text { Terças em geral } \\
\text { 5) }\end{array}$ & $\mathrm{L} / 180$ & - & $\mathrm{F}_{\mathrm{G}}+\mathrm{F}_{\mathrm{Q} 2}+0,2 \mathrm{~F}_{\mathrm{Q} 1}$ \\
\hline \begin{tabular}{lr}
-Terças & \multicolumn{2}{c}{ suportando } \\
fechamentos & sujeitos à \\
fissuração e/ou & componentes \\
sensíveis a & deslocamentos \\
excessivos 5) &
\end{tabular} & - & $\mathrm{L} / 250$ & $\begin{array}{l}\mathrm{F}_{\mathrm{Q} 1}+0,3 \mathrm{~F}_{\mathrm{Q} 2} \\
\mathrm{~F}_{\mathrm{Q} 2}+0,2 \mathrm{~F}_{\mathrm{Q} 1}\end{array}$ \\
\hline $\begin{array}{l}\text { - Treliças e vigas de cobertura } \\
\text { em geral }^{5)}\end{array}$ & $\mathrm{L} / 250$ & - & $\begin{array}{l}\mathrm{F}_{\mathrm{G}}+\mathrm{F}_{\mathrm{Q} 2}+0,4 \mathrm{~F}_{\mathrm{Q} 3}+0,2 \mathrm{~F}_{\mathrm{Q} 1} \\
\mathrm{~F}_{\mathrm{G}}+\mathrm{F}_{\mathrm{Q} 3}+0,3 \mathrm{~F}_{\mathrm{Q} 2}+0,2 \mathrm{~F}_{\mathrm{Q} 1}\end{array}$ \\
\hline & & $\mathrm{L} / 180$ & $\mathrm{~F}_{\mathrm{Q} 1}$ \\
\hline - Vigas de piso em geral & $\mathrm{L} / 300$ & - & $\begin{array}{c}\mathrm{F}_{\mathrm{G}}+\mathrm{F}_{\mathrm{Q} 2}+0,4 \mathrm{~F}_{\mathrm{Q} 3} \\
\mathrm{~F}_{\mathrm{G}}+\mathrm{F}_{\mathrm{Q} 3}+\psi_{1} \mathrm{~F}_{\mathrm{Q} 2}{ }^{7)}\end{array}$ \\
\hline & - & $\mathrm{L} / 350$ & $\begin{array}{c}\mathrm{F}_{\mathrm{Q} 2}+0,4 \mathrm{~F}_{\mathrm{Q} 3} \\
\mathrm{~F}_{\mathrm{Q} 3}+\psi_{1} \mathrm{~F}_{\mathrm{Q} 2}{ }^{7)}\end{array}$ \\
\hline $\begin{array}{l}\text { - Vigas de piso suportando } \\
\text { acabamentos sujeitos à } \\
\text { fissuração (alvenarias, painéis } \\
\text { rígidos, etc.) e esquadrias. }\end{array}$ & $\mathrm{L} / 350$ & - & $\begin{array}{c}\mathrm{F}_{\mathrm{G}}+\mathrm{F}_{\mathrm{Q} 2}+0,4 \mathrm{~F}_{\mathrm{Q} 3} \\
\mathrm{~F}_{\mathrm{G}}+\mathrm{F}_{\mathrm{Q} 3}+\psi_{1} \mathrm{~F}_{\mathrm{Q} 2}{ }^{7)}\end{array}$ \\
\hline & - & $\mathrm{L} / 400$ & $\begin{array}{c}\mathrm{F}_{\mathrm{Q} 2}+0,4 \mathrm{~F}_{\mathrm{Q} 3} \\
\mathrm{~F}_{\mathrm{Q} 3}+\psi_{1} \mathrm{~F}_{\mathrm{Q} 2}{ }^{7)}\end{array}$ \\
\hline $\begin{array}{l}\text { - Vigas de piso suportando } \\
\text { pilares }\end{array}$ & $\mathrm{L} / 400$ & - & $\begin{array}{c}\mathrm{F}_{\mathrm{G}}+\mathrm{F}_{\mathrm{Q} 2}+0,4 \mathrm{~F}_{\mathrm{Q} 3} \\
\mathrm{~F}_{\mathrm{G}}+\mathrm{F}_{\mathrm{Q} 3}+\psi_{1} \mathrm{~F}_{\mathrm{Q} 2}{ }^{7)}\end{array}$ \\
\hline & - & $\mathrm{L} / 500$ & $\mathrm{~F}_{\mathrm{Q} 2}+0,4 \mathrm{~F}_{\mathrm{Q} 3}$ \\
\hline
\end{tabular}




\begin{tabular}{|c|c|c|c|}
\hline & & & $\mathrm{F}_{\mathrm{Q} 3}+\psi_{1} \mathrm{~F}_{\mathrm{Q} 2}{ }^{7)}$ \\
\hline $\begin{array}{l}\text { Galpões em geral e edifícios de } \\
\text { um pavimento: } \\
\text { - Deslocamento horizontal do } \\
\text { topo em relação à base }{ }^{6)}\end{array}$ & - & $\mathrm{H} / 300$ & $\begin{array}{l}\mathrm{F}_{\mathrm{Q} 1}+0,3 \mathrm{~F}_{\mathrm{Q} 2}+0,4 \mathrm{~F}_{\mathrm{Q} 3} \\
\mathrm{~F}_{\mathrm{Q} 3}+0,2 \mathrm{~F}_{\mathrm{Q} 1}+0,3 \mathrm{~F}_{\mathrm{Q} 2}\end{array}$ \\
\hline $\begin{array}{r}\text { Edifícios de dois ou mais } \\
\text { pavimentos: } \\
\text { 4) } \\
\text { Deslocamento } \\
\text { horizontal do } \\
\text { topo em relação } \\
\text { à base }{ }^{6)} \\
\text { - Deslocamento horizontal } \\
\text { relativo entre dois pisos } \\
\text { consecutivos }\end{array}$ & - & $\begin{array}{l}\mathrm{H} / 400 \\
\mathrm{~h} / 300\end{array}$ & $\begin{array}{l}\mathrm{F}_{\mathrm{Q} 1}+\psi_{1} \mathrm{~F}_{\mathrm{Q} 2}{ }^{7)} \\
\mathrm{F}_{\mathrm{Q} 1}+\psi_{1} \mathrm{~F}_{\mathrm{Q} 2}{ }^{7)}\end{array}$ \\
\hline 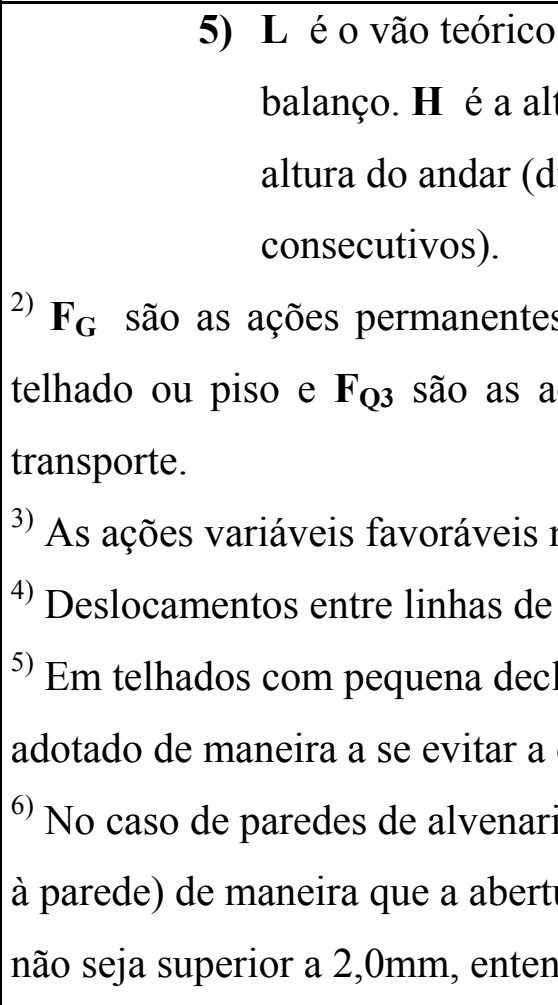 & orrêr & $\begin{array}{l}\text { ou o dob } \\
\text { ilar (dis } \\
\text { centros } \\
\text { ẽo do } \\
\text { entes de } \\
\text { conside } \\
\text { plano d } \\
\text { slocame } \\
\text { empoça } \\
\text { eslocame } \\
\text { que pos } \\
\text { como p }\end{array}$ & $\begin{array}{l}\text { o comprimento teórico do } \\
\text { la do topo à base) e } \mathbf{h} \text { é a } \\
\text { vigas de dois pisos } \\
\text {;ipamentos de elevação e } \\
\mathbf{F}_{\mathbf{Q} 2} \text { é a sobrecarga no } \\
\text { is na combinação. } \\
\text { esmas. } \\
\text { imite também deve ser } \\
\text { to. } \\
\text { horizontal (perpendicular } \\
\text { correr na base da parede } \\
1 \text { rígido (figura }{ }^{a} 1 \text { ). }\end{array}$ \\
\hline
\end{tabular}


${ }^{7)} \psi_{1}$ é o fator de utilização referente ao valor freqüente da sobrecarga, conforme tabela 2.

Fonte: Projeto de Norma, 2001.

Foi adotada a expressão referente a terças em geral:

$$
\mathrm{Fd}=\mathrm{F}_{\mathrm{G}}+\mathrm{F}_{\mathrm{Q} 2}+0,2 \mathrm{~F}_{\mathrm{Q} 1}
$$

Adotou-se no cálculo apenas a expressão: $\mathrm{Fd}=\mathrm{F}_{\mathrm{G}}+0,2 \mathrm{~F}_{\mathrm{Q} 1}$, devido a ação do vento (sucção) ser mais desfavorável.

\subsubsection{CÁLCULO DAS TERÇAS}

Adotou-se o perfil $2 \mathrm{U}$ enrijecido fechado $200 \times 150 \times 25 \times 4,75$ de acordo com tabela da TECNOFER S.A.

\subsubsection{FLEXÃO EM TORNO DO EIXO X.}

a) Propriedades Geométricas

Altura (mm): hw $=200$

Largura da mesa $(\mathrm{mm}): \mathrm{bf}=75$

Largura do enrijecedor (mm): $\quad D=25$

Espessura(mm): $\mathrm{t}=4,75, \quad$ Área $\left(\mathrm{cm}^{2}\right): A=28,39, \mathrm{Ix}=1716,19 \mathrm{~cm} 4, \mathrm{Iy}=969,5 \mathrm{~cm} 4$ $\mathrm{It}=1,331 \mathrm{~cm} 4, \mathrm{rx}=7,77 \mathrm{~cm}, \mathrm{Cw}=30678,3 \mathrm{~cm} 6, \mathrm{ry}=5,84 \mathrm{~cm} \mathrm{Wx}=171,6 \mathrm{~cm} 4$

$$
\begin{aligned}
& \mathrm{b}=\mathrm{bf}-4 \mathrm{t} \quad-\mathrm{b}=60 \mathrm{~mm} \\
& \mathrm{~h}=\mathrm{hw}-4 \mathrm{t} \quad-\mathrm{h}=185 \mathrm{~mm} \\
& \mathrm{~d}=\mathrm{D}-2 \mathrm{t} \quad-\mathrm{d}=17,5 \mathrm{~mm}
\end{aligned}
$$


b) Propriedades Mecânicas do Aço ASTM A-36

fy $=25 \mathrm{KN} / \mathrm{cm}^{2} \quad \mathrm{fu}=40 \mathrm{KN} / \mathrm{cm}^{2} \quad \mathrm{E}=20500 \mathrm{KN} / \mathrm{cm}^{2} \quad \mathrm{G}=8000 \mathrm{KN} / \mathrm{cm}^{2}$

c) Comprimentos e coeficientes de flambagem

$\mathrm{Kx}=1,0 \quad \mathrm{Ky}=1,0 \quad \mathrm{Kt}=1,0 \quad \mathrm{~L}=780 \mathrm{~cm} \quad \mathrm{Cb}=1,0 \quad \mathrm{Ly}=260 \mathrm{~cm}$

$\mathrm{Lx}=780 \mathrm{~cm} \quad \mathrm{Lt}=260 \mathrm{~cm}$

d) Determinação das propriedades efetivas

$\sigma=\mathrm{fy}=25 \mathrm{KN} / \mathrm{cm} 2$

d.1) Enrijecedor - largura efetiva

$\lambda_{p d}=\frac{b / t}{0,95\left(k E / \sigma_{n}\right)^{0,5}}$

$\lambda_{p d}=0,26$

$0,26<0,673$

$\mathrm{def}=\mathrm{h}=17,5 \mathrm{~mm}$

d.2) Largura efetiva da mesa

- eficiência do enrijecedor:

$$
\begin{aligned}
& \lambda_{p 0}=\frac{b / t}{0,623(E / \sigma)^{0,5}} \\
& \lambda_{p 0}=0,89 \\
& I a=400 \cdot 3,75^{4}\left(0,49 \cdot \lambda_{p_{0}}-0,33\right)^{3} \\
& I a=94,48 \mathrm{~mm}^{4} \\
& I s=\frac{t . d e f^{3}}{12}
\end{aligned}
$$




$$
\begin{gathered}
I s=1674,80 \mathrm{~mm}^{4} \\
K a=5,25-5 .(\mathrm{D} / \mathrm{b}) \\
K a=3,15 \\
K=\left(\frac{I s}{I a}\right)^{0,5} \cdot(\mathrm{Ka}-0,43)+0,43 \\
\left.d s=\left(\frac{I s}{I a}\right) \cdot d e f \quad d s\right\rangle d e f \quad d s=d e f=17,5 \mathrm{~mm} \\
\text { bef }=b . \frac{(1,88}{\lambda p} \quad \text { bef }=35,50 \mathrm{~mm} \\
\left(1-\frac{0,22}{\lambda p}\right)
\end{gathered}
$$

d.3) Largura efetiva da alma

Abaixamento da linha neutra

$$
\begin{array}{lll}
\Delta y=0 & h c=\frac{h}{2} & h c=92,5 \mathrm{~mm} \\
\sigma_{1}=f y & \sigma_{2}=-\sigma_{1} & \psi=\frac{\sigma_{2}}{\sigma_{1}}=-1 \\
K=1,7-5 . \psi+17,1 \psi^{2} & \mathrm{~K}=23,8
\end{array}
$$




$$
\begin{gathered}
\lambda p=\frac{\left(\frac{h}{t}\right)}{0,95 .\left(k \cdot \frac{E}{\sigma}\right)} \quad \lambda p=0,37 \\
h e f=h c \cdot \frac{\left(1-\frac{0,22}{\lambda p}\right)}{\lambda p} \quad h e f=92,5 \mathrm{~mm}
\end{gathered}
$$

d.4) Área efetiva

$$
\begin{gathered}
\text { Aef }=A-t \frac{(2 .(b-b e f)+2 \cdot(h c-h e f)+2 .(d-d s))}{100} \\
\text { Aef }=26,55 \mathrm{~cm}^{2}
\end{gathered}
$$

d.5) Inércia Efetiva

$$
\begin{aligned}
& I_{3}=2 \cdot(b-b e f)\left(\frac{h}{2}+\Delta y-t\right)^{2} \cdot t \\
& I_{3}=1447318,36 \mathrm{~mm}^{4} \\
& I_{4}=0 \\
& \text { Ief }=1571,37 \mathrm{~cm}^{4}
\end{aligned}
$$

d.6) Módulo Resistente efetivo 


$$
W e f c=W e f t=\frac{\text { Ief }}{\left(\frac{\frac{h w}{2}-\Delta y}{10}\right)} \quad W e f c=W e f t=157,13 \mathrm{~cm}^{3}
$$

e) Estado Limite de início do Escoamento

$$
M r d=\frac{\text { Wefc.fy }}{1,1} \quad M r d=3571,14 \mathrm{~cm}^{4}
$$

f) Estado Limite FLT

$$
\begin{aligned}
& \text { Ney }=\pi^{2} \cdot E \cdot \frac{I y}{(k y \cdot L y)} 2 \quad N e y=5131,35 K N \\
& r o=\left(r x^{2}+r y^{2}+x o^{2}+y o^{2}\right)^{0,5} \quad r o=9,72 \mathrm{~cm} \\
& \text { Net }=\left(\frac{1}{r o^{2}}\right) \cdot\left[\left[\frac{\pi^{2} \cdot E \cdot C w}{(K t \cdot L t)^{2}}\right]+\text { G.It }\right] \quad \text { Net }=1083,58 K N \\
& M e=C b \cdot r o \cdot \sqrt{\text { Ney.Net }} \quad \mathrm{Me}=22919,89 \mathrm{KN} \cdot \mathrm{cm}
\end{aligned}
$$




$$
\begin{aligned}
& \lambda o=\sqrt{\frac{W \cdot f y}{M e}} \quad \lambda o=0,43 \quad \rho f l t=1,0 \\
& M_{x, R d}=\frac{\rho f l t . W e f c . f y}{1,1} \quad M_{x, R d}=35,71 \mathrm{KN} \cdot \mathrm{m}
\end{aligned}
$$

\subsubsection{FLEXÃO EM TORNO DO EIXO Y}

Analogamente em relação ao eixo de menor inércia y, calculou-se o momento resistente, sendo o seu valor:

$M_{y, R d}=53,72 \mathrm{KN} . \mathrm{m}$

\subsubsection{VERIFICAÇÃO DOS DESLOCAMENTOS LIMITES}

$q=0,017 \mathrm{KN} / \mathrm{m}$
$\delta=\frac{5 \cdot q \cdot L^{4}}{384 \cdot E \cdot I}$
$\delta=0,02 \mathrm{~cm}$
$\delta m a ́ x=\frac{L}{180}$

$\delta m a ́ x=4,33 \mathrm{~cm}$ 
A utilização do projeto de Norma Brasileira de Dimensionamento de Perfis Formados a frio, permitiu a determinou perfil a ser utilizado na composição da terça a ser substituída na recuperação do telhado da edificação denominada Caieira do Meio, situada no município de Uberaba no distrito de Peirópolis. O perfil adotado foi um duplo U caixão 200x150x25x3,75.

Os momentos fletores solicitantes de cálculo em relação aos eixos principais x e y, encontrados, foram respectivamente: 
$M_{x, S d}=26,54 K N . m \quad$ e $\quad M_{y, S d}=0,13 K N . m$

Os momentos fletores resistentes de cálculo em relação aos eixos x e y, encontrados, foram respectivamente:

$M_{x, R d}=35,71 K N . m \quad$ e $\quad M_{y, R d}=53,72 K N . m$

Através da verificação da expressão de iteração prescrita pelo projeto de Norma, para terças, que são elementos sujeitos à flexão oblíqua, pode-se constatar que o perfil é satisfatório. $\mathrm{O}$ valor encontrado na iteração foi de 0,75 , portanto menor que 1 .

$\mathrm{Na}$ verificação do deslocamento da terça em torno do eixo x, constatou-se que $\delta=$ $0,02 \mathrm{~cm}$, sendo inferior a $\delta m a ́ x=4,33 \mathrm{~cm}$.

Com base nos resultados anteriormente apresentados, considera-se que as dimensões do perfil escolhido são viáveis para a estrutura analisada., demonstrando que os perfis formados a frio podem ser usados na recuperação estrutural de obras históricas.

Apesar da edificação ser executada em madeira existe a viabilidade técnica de se aplicar o perfil formado a frio. Na região de Uberaba -MG existe a facilidade de se obter os perfis formados a frio já que eles são bastante utilizados. A interferência no bem imóvel de grande valor histórico poderá ser feita sem prejuízo às características da edificação.

No processo de análise da estrutura de madeira observou-se que existiam algumas peças, que apesar do tempo apresentavam praticamente íntegras, caso dos pilares de aroeira, sendo apenas recomendado um tratamento através de técnicas específicas. As peças afetadas se subdividiram em duas situações: aquelas que não poderiam ser aproveitadas, o caso das terças, e aquelas que poderiam apesar de afetadas, caso da 
estrutura de apoio das terças, serem tratadas e reaproveitadas, além de serem reforçadas com perfis metálicos.

A substituição das terças de madeira por perfis formados a frio se deve principalmente ao tamanho do vão a ser vencido pela mesma. A substituição das terças atuais por outras também de madeira, indicariam seções maiores que as recomendadas quando se utiliza o perfil formado a frio, em função da deformabilidade da madeira. A madeira é um material muito deformável e necessitaria de uma grande altura. Ainda, as peças de apoio das terças receberão cargas menores. Não foi proposta aqui a substituição destas peças por elas apresentarem um bom estado de conservação, sendo recomendado apenas um tratamento específico para que a mesma resista por mais tempo.

A figura 4.1 apresenta o detalhe de com será feita a ligação da peça em aço com a madeira. Como pode ser observado essa ligação é muito simples, não apresentando nenhum inconveniente para execução. Os pilares de aroeira de diâmetro de $30 \mathrm{~cm}$ e seção de 30x30 não apresentam danificações graves, podendo permanecer na situação original. Para tanto será indicado um acompanhamento, para verificar danos futuros.

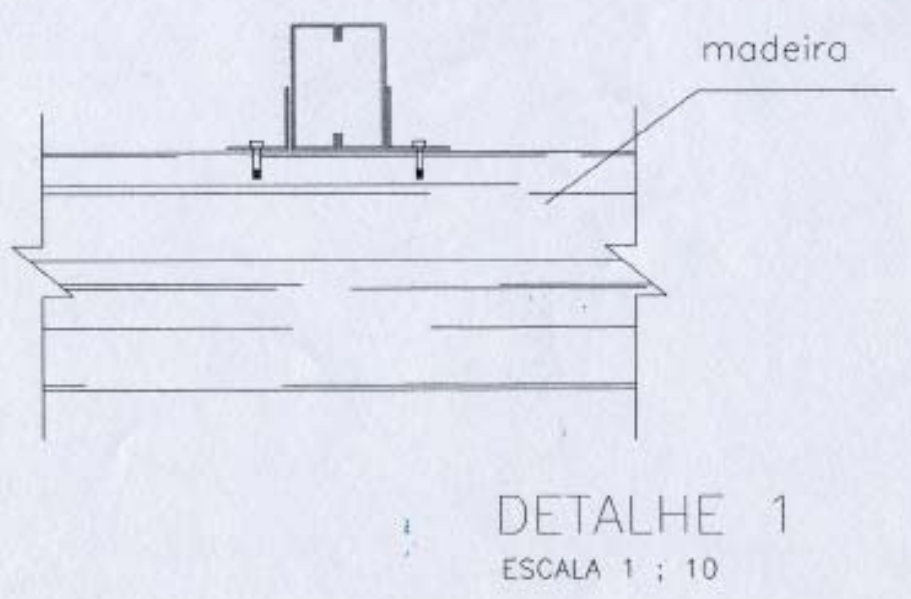


Figura 4.1 - Detalhe da ligação aço/madeira

O resultado encontrado atende os padrões de perfis encontrados no mercado do município de Uberaba, perfis estes produzidos pela empresa Tecnaço-S.A, com alto padrão de qualidade. As vantagens de se utilizar perfis formados a frio na recuperação de edificações históricas, , são:

- Mais exatidão nas medidas;

- Construção mais rápida;

- Maior grau de durabilidade;

- O aço não se deforma com o tempo como a madeira;

- Quase não existe perda na sua fabricação;

A utilização do texto da norma de dimensionamento de estruturas de aço constituídos de perfis formados a frio, neste trabalho propiciará uma discussão com o meio técnico sobre a viabilidade da utilização destes perfis não somente em recuperação de obras históricas mas também em edificações em geral.

Convém, ainda, comentar que todo o dimensionamento baseado no projeto de norma, deve contemplar para fins de comparação, o resultado final quando da publicação da norma. 


\section{CONSIDERACÕES FINAIS E CONCLUSÕES}

Procurou-se neste trabalho apresentar alguns aspectos para o dimensionamento e cálculo de perfis formados a frio, basicamente em terças, de acordo com o projeto de norma de dimensionamento de estruturas de aço com esses perfis, avaliando a viabilidade de se utilizá-los na recuperação estrutural de edificações históricas.

A utilização freqüente de perfis formados a frio em estruturas, no Brasil, e particularmente em Uberaba-MG, norteou o desenvolvimento desta pesquisa a fim de se divulgar o projeto de norma. 
Discutiram-se as metodologias empregadas para a elaboração de planos de intervenção em estruturas de caráter histórico, bem como a aplicação em uma específica, a "Caieira do Meio". Avaliou-se, por meio de exemplos de edificações nas quais foram feitas recuperações utilizando o aço, os procedimentos e processos que permitiram tal escolha.

Conclui-se que é viável a aplicação de perfis formados a frio considerando-se as condições apresentadas nesta pesquisa, leveza , facilidade no processo construtivo, custo, resistência e adaptação a outros materiais, como a madeira por exemplo.

Destaca-se, porém, que os aspectos construtivos apresentados estão fundamentados na observação e análise da obra da Caieira do Meio. O projeto de perfis deve atender as dimensões dimensionadas de acordo com as especificações do projeto de norma. Recomenda-se que a aplicação de perfis formados a frio em outras situações, deve ser analisada individualmente para cada caso específico.

Verificou-se ainda a tendência do crescimento do uso de perfis formados a frio em Uberaba, porém muitas das vezes sem amparo de norma, sendo este trabalho indicativo para o dimensionamento e uso correto destes perfis, esperando-se que seja útil para profissionais e pesquisadores. 
ANEXO - DIMENSIONAMENTO DE PERFIS FORMADOS A FRIO - PROJETO DE NORMA 


\section{Requisitos para o dimensionamento de barras}

\subsection{Valores máximos da relação largura-espessura}

A relação largura-espessura de um elemento, desconsiderando enrijecedores intermediários, não deve ultrapassar os valores estabelecidos na tabela 3.

Tabela 3 - Valores máximos da relação largura-espessura

\begin{tabular}{|c|c|}
\hline Caso a ser analisado & $\begin{array}{l}\text { Valor máximo } \\
\text { da relação } \\
\text { largura- } \\
\text { espessura } \\
\end{array}$ \\
\hline $\begin{array}{l}\text { Elemento comprimido AA, tendo uma borda vinculada a alma ou mesa, } \\
\text { e a outra a enrijecedor de borda simples }\end{array}$ & $(\mathrm{b} / \mathrm{t})_{\max }=60^{2)}$ \\
\hline $\begin{array}{l}\text { Elemento comprimido AA, tendo uma borda vinculada a alma, e a } \\
\text { outra a mesa ou outro tipo de enrijecedor de borda com } I_{s} \geq I_{a} \text { e } D / b \leq \\
0,8 \text { conforme } 7.2 .2\end{array}$ & $(\mathrm{~b} / \mathrm{t})_{\max }=90$ \\
\hline Alma de perfis U não enrijecidos sujeita à compressão uniforme & $(\mathrm{b} / \mathrm{t})_{\max }=90$ \\
\hline $\begin{array}{l}\text { Elemento comprimido com ambas as bordas vinculadas a elementos } \\
\text { AA }\end{array}$ & $(\mathrm{b} / \mathrm{t})_{\max }=500^{3)}$ \\
\hline $\begin{array}{l}\text { Elemento comprimido AL ou AA com enrijecedor de borda tendo } \mathrm{I}_{\mathrm{s}}< \\
\mathrm{I}_{\mathrm{a}} \text { e } \mathrm{D} / \mathrm{b} \leq 0,8 \text { conforme } 7.2 .2\end{array}$ & $(\mathrm{~b} / \mathrm{t})_{\max }=60^{2)}$ \\
\hline Alma de vigas sem enrijecedores transversais & $(\mathrm{b} / \mathrm{t})_{\max }=200$ \\
\hline $\begin{array}{l}\text { Alma de vigas com enrijecedores transversais apenas nos apoios e } \\
\text { satisfazendo as exigências de 7.5.1 }\end{array}$ & $(\mathrm{b} / \mathrm{t})_{\max }=260$ \\
\hline $\begin{array}{llllll}\text { Alma de vigas com enrijecedores transversais nos apoios } & \mathrm{e} \\
\text { intermediários, satisfazendo as exigências de 7.5.1 } & & & \\
\end{array}$ & $(\mathrm{b} / \mathrm{t})_{\max }=300$ \\
\hline \\
\hline
\end{tabular}

\subsection{Flambagem local}

\subsubsection{Elementos AA e AL}

A flambagem local de elementos totalmente ou parcialmente comprimidos deve ser considerada por meio de larguras efetivas, calculadas conforme a) e b).

\section{a) cálculo de resistência:}

Para o cálculo da resistência de perfis formados por elementos esbeltos, deve ser considerada a redução de sua resistência, provocada pela flambagem local. Para isto, devem ser calculadas as larguras efetivas $b_{\text {ef }}$ dos elementos da seção transversal que se encontrem total ou parcialmente submetidos a tensões normais de compressão, conforme descrito a seguir: 
- todos os elementos AA indicados na tabela 4 e os elementos AL indicados na tabela 5 sem inversão no sinal da tensão $(\psi \geq 0)$ :

$$
b_{e f}=b\left(1-0,22 / \lambda_{p}\right) / \lambda_{p} \leq b
$$

- elementos AL indicados na tabela 5 com inversão no sinal da tensão $(\psi<0)$ :

$$
b_{\text {ef }}=b_{c}\left(1-0,22 / \lambda_{p}\right) / \lambda_{p} \leq b_{c}
$$

Onde:

b é a largura do elemento;

$b_{c}$ é a largura da região comprimida do elemento, calculada com base na seção efetiva;

$\lambda_{\mathrm{p}}$ é o índice de esbeltez reduzido do elemento, definido como

$$
\lambda_{p}=\frac{b / t}{0,95(k E / \sigma)^{0,5}}
$$

Para $\lambda_{\mathrm{p}} \leq 0,673$ a largura efetiva é a própria largura do elemento;

t é a espessura do elemento;

$\mathrm{k}$ é o coeficiente de flambagem local, a ser calculado de acordo com a tabela 4 para elementos AA, ou de acordo com a tabela 5 para elementos AL;

$\sigma$ é a tensão normal de compressão, definida conforme descrito a seguir:

\section{1) Estado limite último de escoamento da seção}

Para cada elemento totalmente ou parcialmente comprimido, $\sigma$ é a máxima tensão de compressão, calculada para a seção efetiva, que ocorre quando a seção atinge o escoamento. Se a máxima tensão for de tração, $\sigma$ pode ser calculada admitindo-se distribuição linear de tensões. A seção efetiva, neste caso, deve ser determinada por aproximações sucessivas.

\section{2) Estado limite último de flambagem da barra}

Se a barra for submetida à compressão, $\sigma=\rho f_{y}$, sendo $\rho$ o fator de redução associado à flambagem conforme 7.7.1. Se a barra for submetida à flexão, $\sigma=\rho_{\text {FLT }} f_{y}$, sendo $\rho_{\text {FLT }} \mathrm{o}$ fator de redução associado à flambagem lateral com torção conforme 7.8.1.2. 
b) cálculo de deslocamentos:

O cálculo de deslocamentos em barras com seções transversais constituídas por elementos esbeltos deve ser feito por aproximações sucessivas, considerando a redução de sua rigidez provocada pela flambagem local. Para isto, devem ser calculadas as larguras efetivas $b_{\text {ef }}$ dos elementos da seção transversal que se encontrem total ou parcialmente submetidos a tensões normais de compressão, conforme 7.2.1a, substituindo $\lambda_{\mathrm{p}}$ por $\lambda_{\mathrm{pd}}$.

Onde:

$$
\lambda_{p d}=\frac{b / t}{0,95\left(k E / \sigma_{n}\right)^{0,5}}
$$

$\mathrm{k}$ é o coeficiente de flambagem local, a ser calculado de acordo com a tabela 4, para elementos AA, ou de acordo com a tabela 5 para elementos AL, e $\sigma_{\mathrm{n}}$ é a máxima tensão normal de compressão, calculada para a seção transversal efetiva e considerando as combinações de ações para os estados limite de utilização conforme 5.3.

Tabela 4 - Largura efetiva e coeficientes de flambagem local para elementos AA

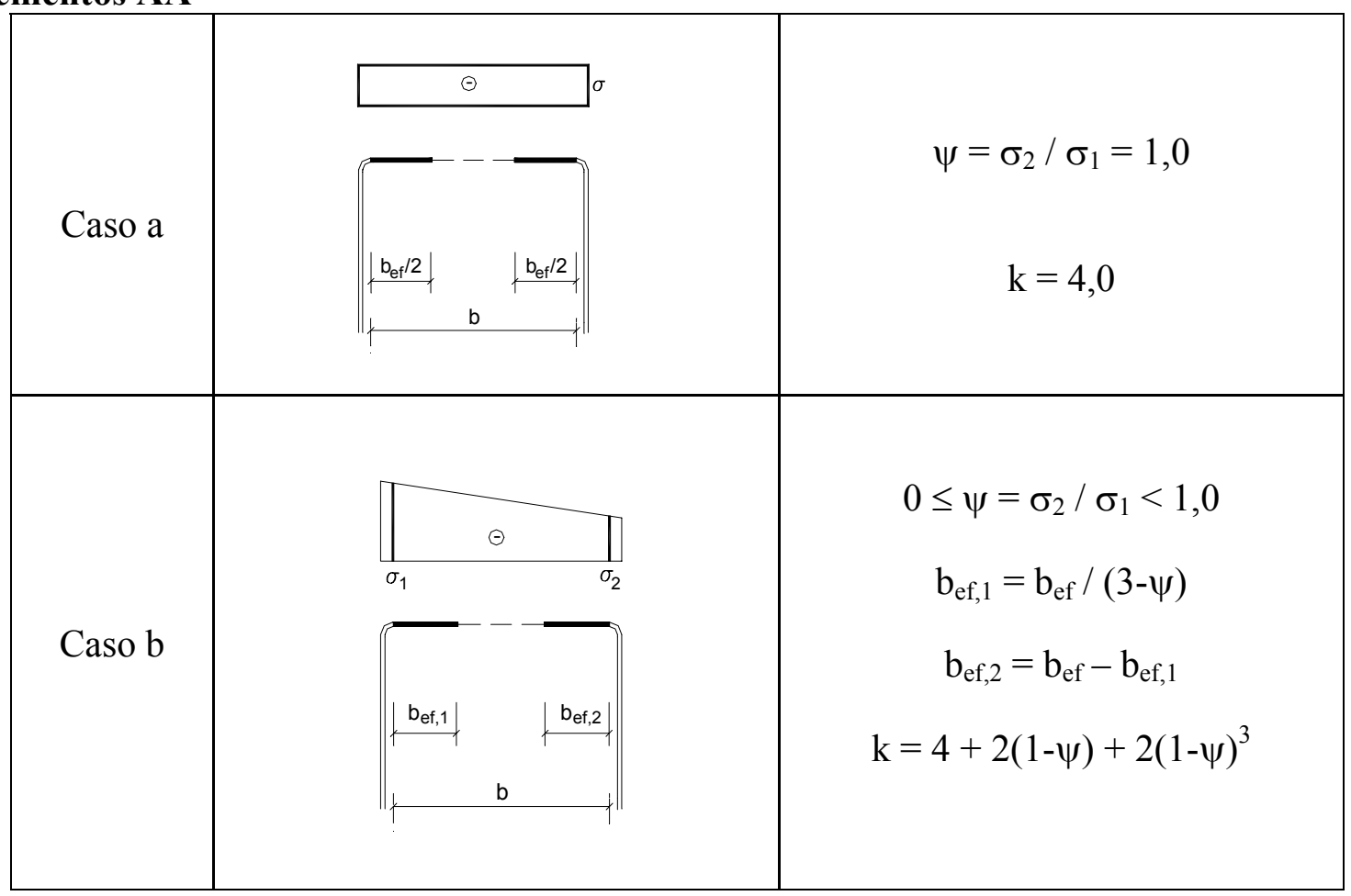




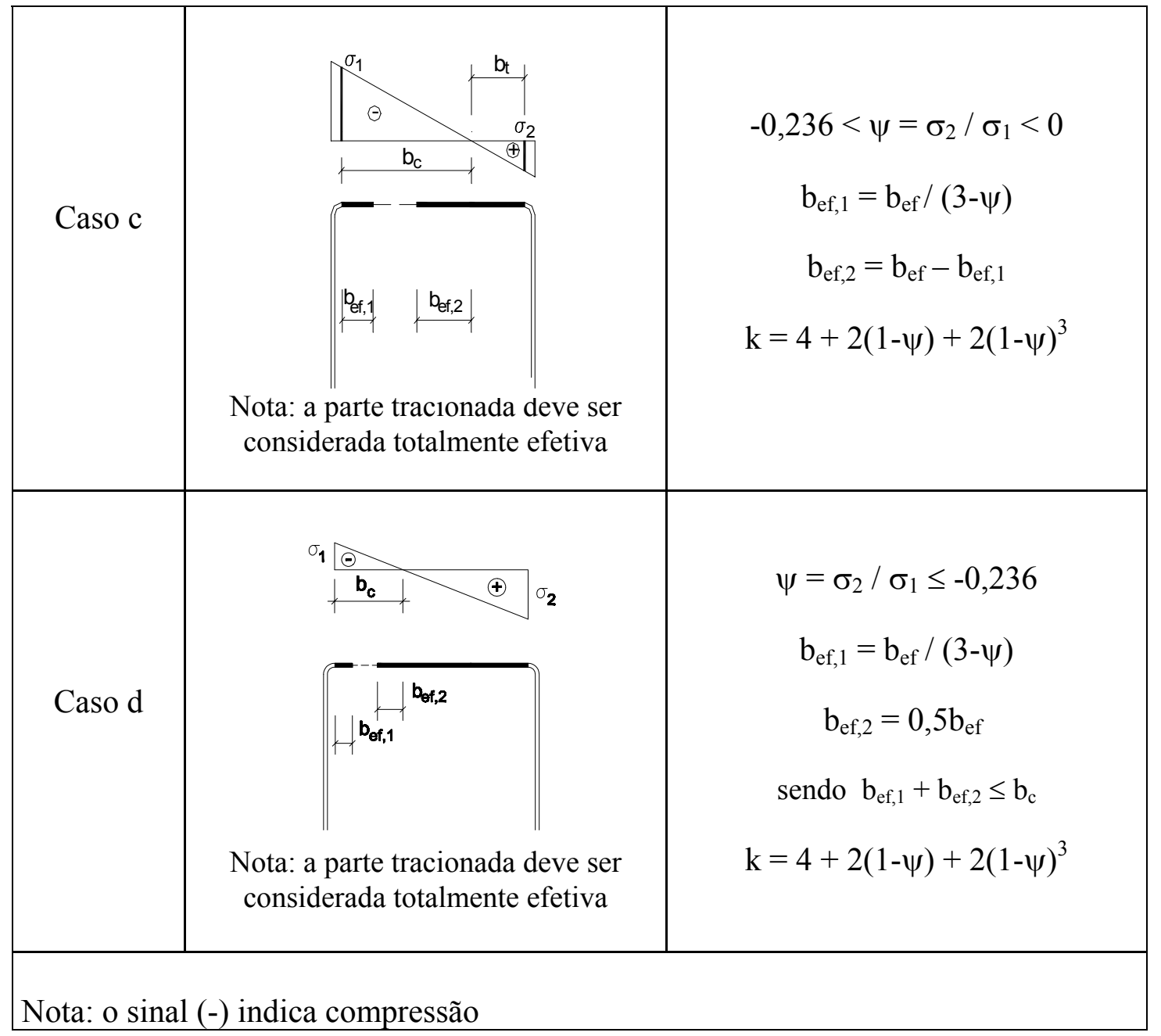

Tabela 5 - Largura efetiva e coeficientes de flambagem local para elementos AL

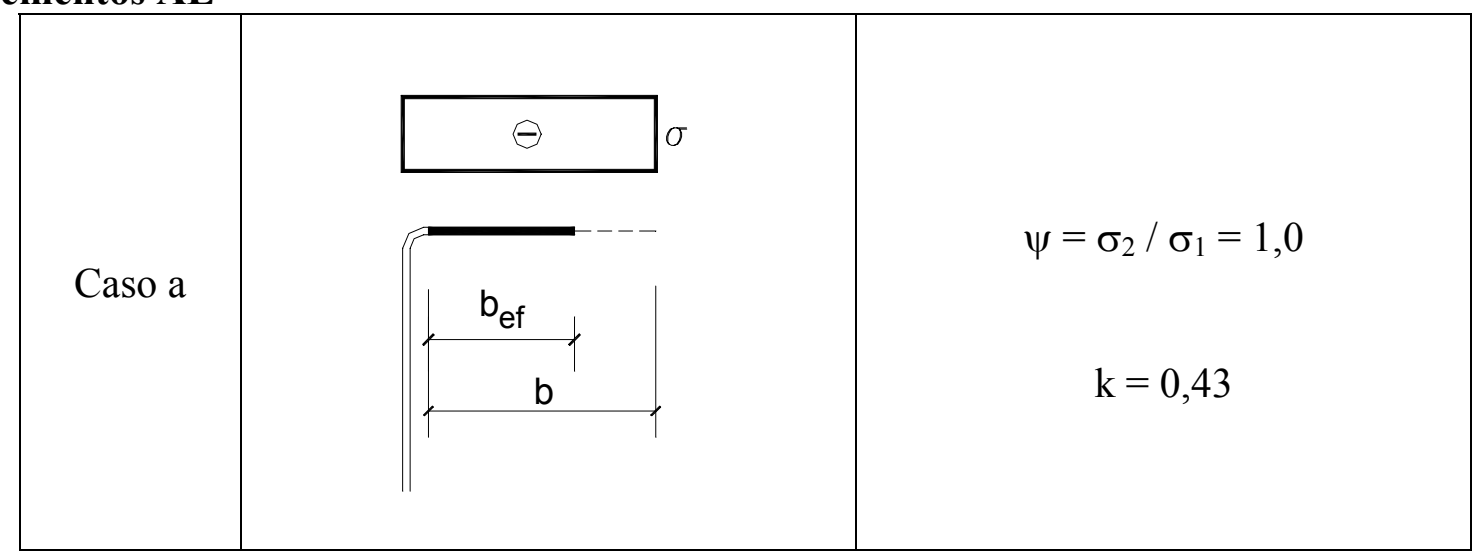

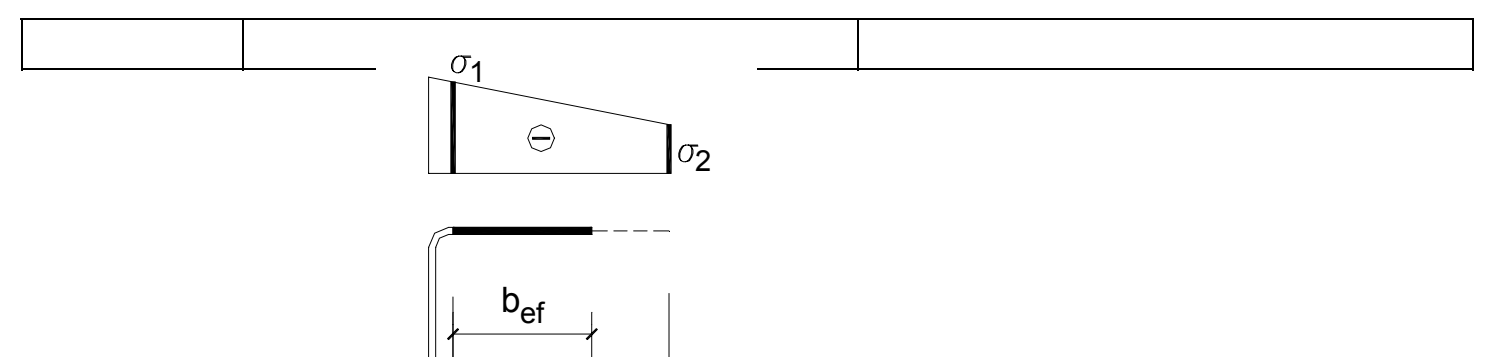




\begin{tabular}{|c|c|c|}
\hline & & \\
& & \\
Caso b & $\mathrm{k}=0,578 /(\psi+0,34)$ \\
& & \\
& & \\
\hline
\end{tabular}




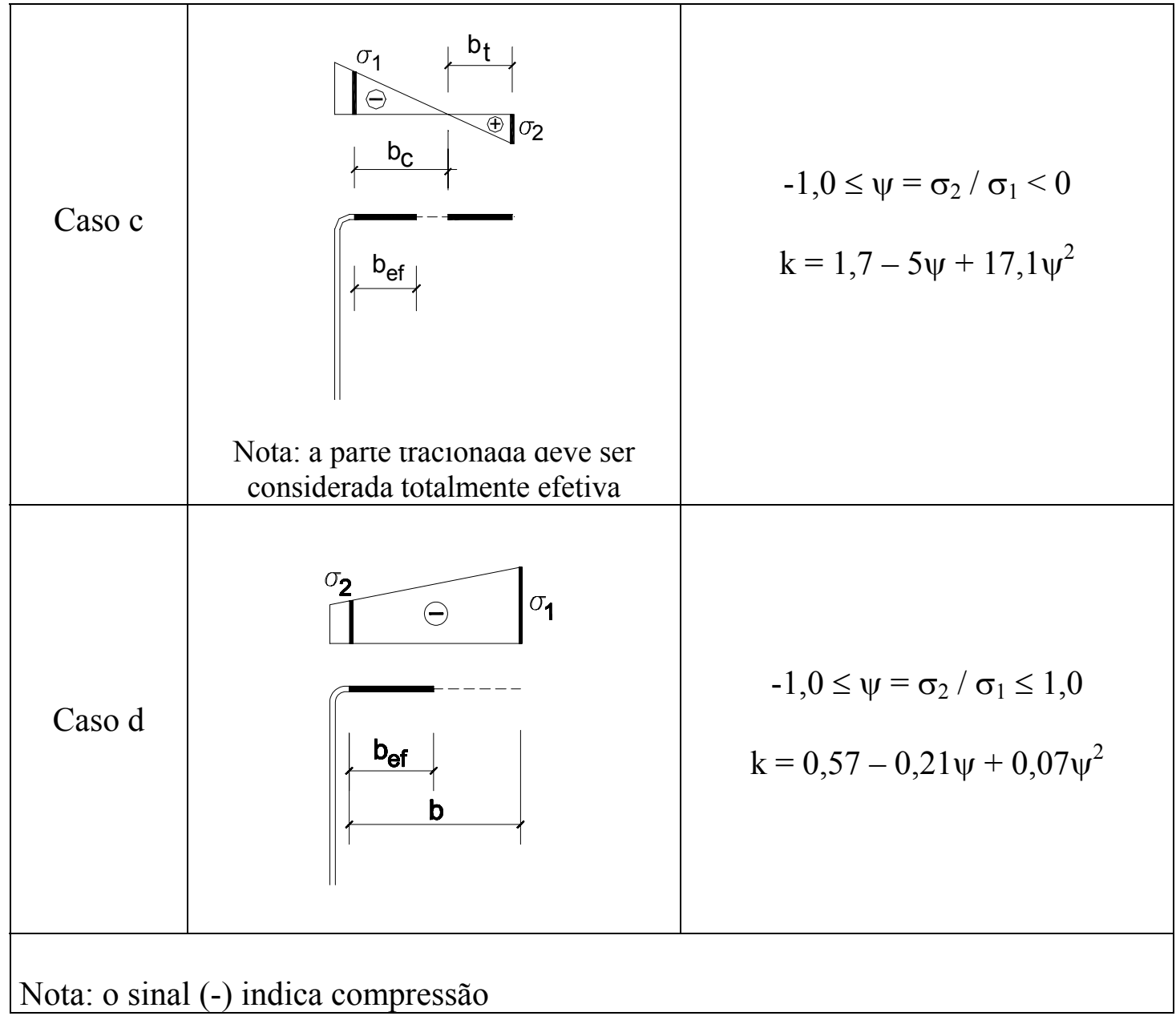

\subsubsection{Largura efetiva de elementos uniformemente comprimidos com um enrijecedor} intermediário ou com enrijecedor de borda

Nesta subseção os símbolos e seus respectivos significados são os seguintes:

$$
\begin{aligned}
\lambda_{p 0} & =\frac{b_{0} / t}{1,9(E / \sigma)^{0,5}} \quad \text { para 7.2.2.1 } \\
\lambda_{\mathrm{p} 0} & =\frac{\mathrm{b} / \mathrm{t}}{0,623(\mathrm{E} / \sigma)^{0,5}} \quad \text { para 7.2.2.2 }
\end{aligned}
$$

$\sigma$ é a tensão normal definida em 7.2.1a;

$\mathrm{b}_{0}$ é a largura do elemento com enrijecedor intermediário (ver figura 2);

$\mathrm{k}$ é o coeficiente de flambagem local;

$\mathrm{D}, \mathrm{b}, \mathrm{d}$ são as dimensões indicadas na figura 3; 
$\mathrm{d}_{\mathrm{ef}}$ é a largura efetiva do enrijecedor calculada conforme 7.2.1a;

$\mathrm{d}_{\mathrm{s}}$ é a largura efetiva reduzida do enrijecedor e adotada no cálculo das propriedades da seção

efetiva do perfil;

$\mathrm{A}_{\mathrm{s}}$ é a área reduzida do enrijecedor calculada conforme indicado nesta seção, e adotada

no cálculo das propriedades da seção efetiva do perfil. O centróide e os momentos de

inércia do enrijecedor devem ser assumidos em relação à sua seção bruta;

$I_{a}$ é o momento de inércia de referência do enrijecedor intermediário ou de borda;

$\mathrm{I}_{\mathrm{s}}, \mathrm{A}_{\mathrm{ef}}$ são o momento de inércia da seção bruta do enrijecedor em relação ao seu eixo principal paralelo ao elemento a ser enrijecido e área efetiva do enrijecedor, respectivamente.

Para enrijecedor de borda, a região das dobras entre o enrijecedor e o elemento a ser enrijecido não deve ser considerada como parte integrante do enrijecedor.

Para o enrijecedor representado na figura 3:

$$
\begin{gathered}
I_{s}=\left(d^{3} t \operatorname{sen}^{2} \theta\right) / 12 \\
A_{e f}=d_{e f} t
\end{gathered}
$$

\subsubsection{Largura efetiva de elementos uniformemente comprimidos com um enrijecedor intermediário}

A largura efetiva de elementos uniformemente comprimidos com um enrijecedor intermediário deve ser calculada conforme a) e b), para os casos de cálculo de resistência e deslocamentos, respectivamente.

\section{a) cálculo de resistência:}

Para o cálculo da resistência de perfis formados por elementos com um enrijecedor intermediário, deve ser considerada a redução de sua resistência, provocada pela flambagem local. Para isto, deve ser calculada a largura 
efetiva do elemento e a área efetiva do enrijecedor, conforme descrito a seguir:

Caso I: $\quad \lambda_{\mathrm{p} 0} \leq 0,673$

enrijecedor intermediário não é necessário

$$
\begin{gathered}
\mathrm{b}_{\mathrm{ef}}=\mathrm{b} \\
\mathrm{A}_{\mathrm{s}}=\mathrm{A}_{\mathrm{ef}}
\end{gathered}
$$

Caso II: $0,673<\lambda_{\mathrm{p} 0}<2,03$

$$
\mathrm{I}_{\mathrm{a}}=50 \mathrm{t}^{4}\left[1,484 \lambda_{\mathrm{p} 0}-1\right]
$$

$b_{\text {ef }}$ e $A_{\text {ef }}$ devem ser calculadas conforme 7.2.1a, onde:

$$
\begin{aligned}
& \mathrm{k}=3\left(\mathrm{I}_{\mathrm{s}} / \mathrm{I}_{\mathrm{a}}\right)^{0,5}+1 \leq 4 \\
& \mathrm{~A}_{\mathrm{s}}=\mathrm{A}_{\mathrm{ef}}\left(\mathrm{I}_{\mathrm{s}} / \mathrm{I}_{\mathrm{a}}\right) \leq \mathrm{A}_{\mathrm{ef}}
\end{aligned}
$$

Caso III: $\lambda_{\mathrm{p} 0} \geq 2,03$

$$
I_{a}=\left[190 \lambda_{p 0}-285\right] \mathrm{t}^{4}
$$

$b_{\text {ef }}$ e $A_{e f}$ devem ser calculadas conforme 7.2.1a, onde:

$$
\begin{aligned}
& \mathrm{k}=3\left(\mathrm{I}_{\mathrm{s}} / \mathrm{I}_{\mathrm{a}}\right)^{0,33}+1 \leq 4 \\
& \mathrm{~A}_{\mathrm{s}}=\mathrm{A}_{\mathrm{ef}}\left(\mathrm{I}_{\mathrm{s}} / \mathrm{I}_{\mathrm{a}}\right) \leq \mathrm{A}_{\mathrm{ef}}
\end{aligned}
$$




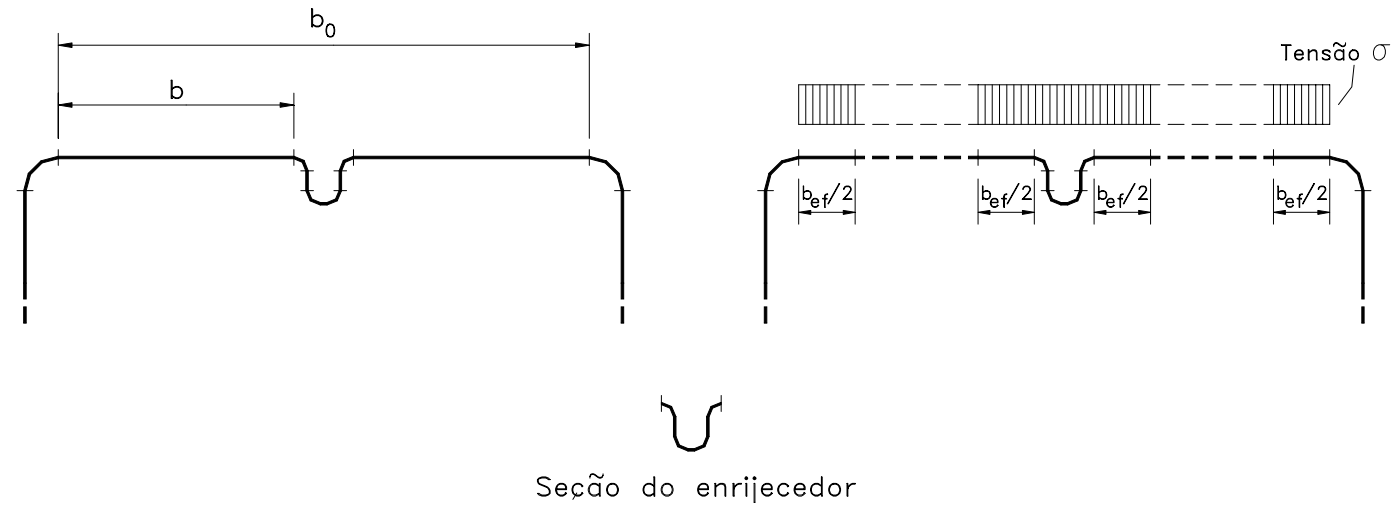

Figura 2 - Elemento uniformemente comprimido com enrijecedor intermediário

b) cálculo de deslocamentos:

Deve ser adotado o mesmo procedimento estabelecido em 7.2.2.1a, substituindo $\sigma$ por $\sigma_{\mathrm{n}}$, que é a tensão calculada considerando as combinações de ações para os estados limite de utilização conforme 5.3.

\subsubsection{Elementos uniformemente comprimidos com enrijecedor de borda}

A largura efetiva de elementos uniformemente comprimidos com enrijecedor de borda deve ser calculada conforme a) e b), para os casos de cálculo de resistência e deslocamentos, respectivamente.

\section{a) cálculo de resistência:}

Para o cálculo da resistência de perfis formados por elementos com enrijecedor de borda, deve ser considerada a redução de sua resistência, provocada pela flambagem local. Para isto, devem ser calculadas as larguras efetivas do elemento e do enrijecedor, conforme descrito a seguir:

Caso I: : $\lambda_{\mathrm{p} 0} \leq 0,673$

enrijecedor de borda não é necessário 


$$
\mathrm{b}_{\mathrm{ef}}=\mathrm{b}
$$

$\mathrm{d}_{\mathrm{s}}=\mathrm{d}_{\mathrm{ef}}$ (para enrijecedor de borda simples)

$A_{s}=A_{e f}$ (para outros tipos de enrijecedor)

Caso II: $0,673<\lambda_{\mathrm{p} 0}<2,03$

$$
\begin{gathered}
\mathrm{I}_{\mathrm{a}}=400 \mathrm{t}^{4}\left[0,49 \lambda_{\mathrm{p} 0}-0,33\right]^{3} \\
\mathrm{~b}_{\mathrm{ef}, 2}=\left(\mathrm{I}_{\mathrm{s}} / \mathrm{I}_{\mathrm{a}}\right)\left(\mathrm{b}_{\mathrm{ef}} / 2\right) \leq\left(\mathrm{b}_{\mathrm{ef}} / 2\right) \\
\mathrm{b}_{\mathrm{ef}, 1}=\mathrm{b}_{\mathrm{ef}}-\mathrm{b}_{\mathrm{ef}, 2}
\end{gathered}
$$

$b_{\text {ef }}$ deve ser calculada conforme 7.2.1a, onde:

$$
\mathrm{k}=\left(\mathrm{I}_{\mathrm{s}} / \mathrm{I}_{\mathrm{a}}\right)^{1 / 2}\left(\mathrm{k}_{\mathrm{a}}-0,43\right)+0,43 \leq \mathrm{k}_{\mathrm{a}}
$$

$k_{a}=5,25-5(D / b) \leq 4,0 \quad$ para enrijecedor de borda simples com $40^{\circ} \leq \theta \leq$ $140^{\circ} \mathrm{e}$

$\mathrm{D} / \mathrm{b} \leq 0,8$, onde $\theta$ é indicado na figura 3

$$
\mathrm{d}_{\mathrm{s}}=\left(\mathrm{I}_{\mathrm{s}} / \mathrm{I}_{\mathrm{a}}\right) \mathrm{d}_{\mathrm{ef}} \leq \mathrm{d}_{\mathrm{ef}}
$$

$\mathrm{k}_{\mathrm{a}}=4,0 \quad$ para outros tipos de enrijecedor

$$
A_{s}=\left(I_{s} / I_{a}\right) A_{e f} \leq A_{e f}
$$

Caso III: $\lambda_{\mathrm{p} 0} \geq 2,03$

$$
\begin{gathered}
\mathrm{I}_{\mathrm{a}}=\left[56 \lambda_{\mathrm{p} 0}+5\right] \mathrm{t}^{4} \\
\mathrm{k}=\left(\mathrm{I}_{\mathrm{s}} / \mathrm{I}_{\mathrm{a}}\right)^{1 / 3}\left(\mathrm{k}_{\mathrm{a}}-0,43\right)+0,43 \leq \mathrm{k}_{\mathrm{a}}
\end{gathered}
$$

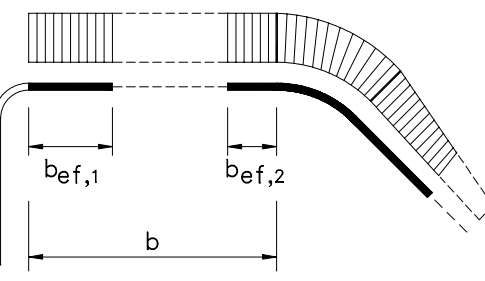


Figura 3 - Elemento uniformemente comprimido com enrijecedor de borda b) cálculo de deslocamentos:

Deve ser adotado o mesmo procedimento estabelecido em 7.2.2.2a, substituindo $\sigma$ por $\sigma_{\mathrm{n}}$, que é a tensão calculada considerando as combinações de ações para os estados limite de utilização conforme 5.3.

\subsubsection{Perfis tubulares com seção transversal circular}

A flambagem local de perfis tubulares com seção transversal circular deve ser considerada por meio das propriedades efetivas da seção, conforme a) e b).

\section{a) cálculo de resistência:}

Para os perfis tubulares com seção transversal circular submetidos à compressão, deve ser considerada a redução de sua resistência, provocada pela flambagem local, mediante o cálculo da área efetiva da seção $\mathrm{A}_{\mathrm{ef}}$, conforme descrito a seguir:

Onde:

$$
A_{\text {ef }}=\left[1-\left(1-0,5 \mathrm{Af}_{\mathrm{y}} / \mathrm{N}_{\mathrm{e}}\right)\left(1-\mathrm{A}_{0} / \mathrm{A}\right)\right] \mathrm{A} \leq \mathrm{A}
$$

A é a área bruta da seção transversal do tubo;

$\mathrm{A}_{\mathrm{o}}=\left(0,037 \mathrm{tE} / \mathrm{Df}_{\mathrm{y}}+0,667\right) \mathrm{A} \leq \mathrm{A} \quad$ para $\mathrm{D} / \mathrm{t} \leq 0,44\left(\mathrm{E} / \mathrm{f}_{\mathrm{y}}\right) ;$

D é o diâmetro externo do tubo;

$\mathrm{N}_{\mathrm{e}}$ é a força normal de flambagem elástica da barra;

té a espessura da parede do tubo.

b) cálculo de deslocamentos:

O cálculo de deslocamentos em barras tubulares com seção transversal circular pode ser feito com as propriedades geométricas da seção transversal bruta.

\subsection{Efeito "shear lag"}

Para vigas cujo comprimento $L$ é inferior a $30 b_{f}$, submetidas a uma força concentrada, ou várias forças concentradas com espaçamento superior a $2 b_{f}$, as propriedades geométricas da seção devem ser determinadas tomando-se como larguras efetivas das mesas tracionada e comprimida, a largura real multiplicada pelos fatores de redução estabelecidos na tabela 6. Para a mesa comprimida, tal largura efetiva não pode ultrapassar a determinada com base na flambagem local conforme 7.2. 
Tabela 6 - Fatores de redução da largura da mesa

\begin{tabular}{|c|c|c|c|}
\hline $\mathbf{L} / \mathbf{b}_{\mathbf{f}}$ & Fatores de redução & $\mathbf{L} / \mathbf{b}_{\mathbf{f}}$ & Fatores de redução \\
\hline 30 & 1,00 & 14 & 0,82 \\
\hline 25 & 0,96 & 12 & 0,78 \\
\hline 20 & 0,91 & 10 & 0,73 \\
\hline 18 & 0,89 & 8 & 0,67 \\
\hline 16 & 0,86 & 6 & 0,55 \\
\hline
\end{tabular}

Onde:

L é o vão das vigas simplesmente apoiadas, ou a distância entre pontos de inflexão para as vigas contínuas, ou duas vezes o comprimento dos balanços;

$b_{f}$ é a largura de referência, tomada como a largura livre da mesa (distância entre a face da alma e a borda livre) para seções I, U e Z; ou a metade da distância livre entre as almas para seções caixão, cartola e similares. Para mesas de seção $\mathrm{I}, \mathrm{U}$ e $\mathrm{Z}$ enrijecidas nas bordas, $\mathrm{b}_{\mathrm{f}}$ deve ser tomada como a largura livre da mesa mais a largura nominal do enrijecedor de borda.

\subsection{Flambagem por distorção da seção transversal}

As seções transversais de barras submetidas à compressão centrada ou à flexão, principalmente as constituídas por elementos com enrijecedores de borda, podem apresentar flambagem por distorção, conforme ilustrado na figura 4. Dependendo da forma da seção e das dimensões dos elementos, o modo de flambagem por distorção pode corresponder ao modo crítico, devendo portanto ser considerado no dimensionamento, conforme 7.7 .3 para barras submetidas à compressão centrada ou 7.8.1.3 para barras submetidas à flexão.

O cálculo do valor da tensão convencional de flambagem elástica por distorção pode ser feito com base na teoria da estabilidade elástica, ou conforme o procedimento apresentado no anexo D.

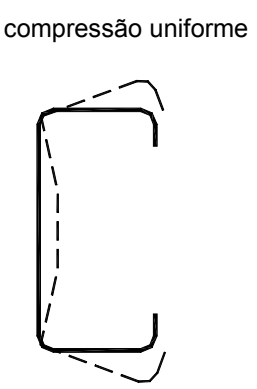

a) Seção tipo U enrijecido flexão

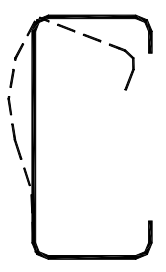

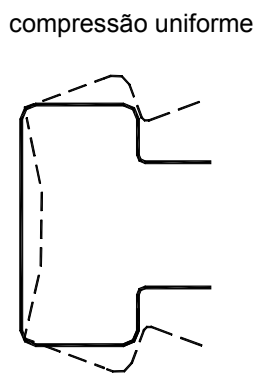

b) Seção tipo rack flexão

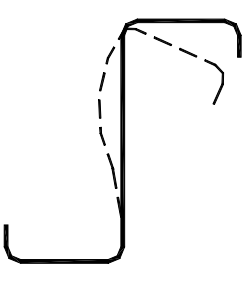

c) Seção tipo Z enrijecido 
Figura 4 - Flambagem por distorção da seção transversal

\subsection{Enrijecedores transversais}

\subsubsection{Enrijecedores transversais em seções com força concentrada}

Devem ser previstos enrijecedores transversais nas seções dos apoios e nas seções intermediárias sujeitas à forças concentradas, exceto nos casos em que se demonstre que tais enrijecedores não sejam necessários (ver anexo E), ou ainda nos casos onde as almas sejam ligadas a outras vigas ou pilares. A força normal resistente de cálculo de enrijecedores transversais $N_{s, R d}$ deve ser calculada por:
a) enrijecedores tracionados: $\mathrm{N}_{\mathrm{s}, \mathrm{Rd}}=\mathrm{Af}_{\mathrm{y}} / \gamma$
$(\gamma=1,1)$
b) enrijecedores comprimidos: $\mathrm{N}_{\mathrm{s}, \mathrm{Rd}}=\rho \mathrm{Af}_{\mathrm{y}} / \gamma \quad(\gamma=1,1)$

Onde:

$\rho$ é o fator de redução associado à flambagem por flexão de uma barra hipotética, com comprimento efetivo de flambagem $K L$ igual a altura da viga e a seção transversal a ser considerada é a formada pelo enrijecedor mais uma faixa de alma de largura igual a $10 t$, se o enrijecedor for de extremidade, ou igual a $18 t$ se o enrijecedor for intermediário. Deve ser admitida flambagem por flexão em relação a um eixo no plano médio da alma, adotando-se curva de resistência à compressão "d" conforme 7.7.2;

$\mathrm{A}=18 \mathrm{t}^{2}+\mathrm{A}_{\mathrm{s}}$ para enrijecedores posicionados em seções intermediárias da barra, ou

$A=10 t^{2}+A_{s}$ para enrijecedores posicionados em seções de extremidade da barra;

$\mathrm{A}_{\mathrm{s}}$ é a área da seção transversal do enrijecedor;

té a espessura da alma da viga.

A relação largura-espessura do enrijecedor $b / t_{s}$ não deve ultrapassar os seguintes valores:

$$
\begin{aligned}
& 1,28\left(E / f_{y}\right)^{0,5} \text { para enrijecedores AA } \\
& 0,42\left(E / f_{y}\right)^{0,5} \text { para enrijecedores AL }
\end{aligned}
$$

\subsubsection{Enrijecedores transversais para força cortante}

Os enrijecedores transversais para força cortante previstos em 7.8.2, devem atender às seguintes exigências: 
- a relação $a / h$ não deve exceder a 3,0 e nem a $[260 /(\mathrm{h} / \mathrm{t})]^{2}$;

- o momento de inércia $I_{s}$ de um enrijecedor simples ou duplo, em relação ao eixo contido no plano médio da alma, não deve ser inferior a:

$$
\mathrm{I}_{\mathrm{s}, \min }=5 \mathrm{ht}^{3}(\mathrm{~h} / \mathrm{a}-0,7 \mathrm{a} / \mathrm{h}) \geq(\mathrm{h} / 50)^{4}
$$

\subsection{Barras submetidas à tração}

7.6.1 A força normal de tração resistente de cálculo $N_{t, R d}$ deve ser tomada como o menor valor entre:

$$
\begin{array}{r}
\mathrm{N}_{\mathrm{t}, \mathrm{Rd}}=\mathrm{Af}_{\mathrm{y}} / \gamma \quad(\gamma=1,1) \\
\mathrm{N}_{\mathrm{t}, \mathrm{Rd}}=\mathrm{C}_{\mathrm{t}} \mathrm{A}_{\mathrm{n}} \mathrm{f}_{\mathrm{u}} / \gamma \quad(\gamma=1,35)
\end{array}
$$

Onde:

A é a área bruta da seção transversal da barra;

$\mathrm{A}_{\mathrm{n}}$ é a área líquida da seção transversal da barra, dada por:

Para ligações parafusadas, devem ser analisadas as prováveis linhas de ruptura (figura 5a), sendo a seção crítica aquela correspondente ao menor valor da área líquida. A área líquida da seção de ruptura analisada deve ser calculada por:

$$
A_{n}=0,9\left(A-n_{f} d_{f} t+\Sigma t s^{2} / 4 g\right)
$$

Para ligações soldadas, considerar $A_{n}=A$. Nos casos em que houver apenas soldas transversais (soldas de topo), $\mathrm{A}_{\mathrm{n}}$ deve ser considerada igual à área bruta $\mathrm{da}(\mathrm{s})$ parte(s) conectada(s) apenas.

$d_{f}$ é a dimensão do furo, conforme tabela 9.

$\mathrm{n}_{\mathrm{f}}$ é a quantidade de furos contidos na linha de ruptura analisada.

s é o espaçamento dos furos na direção da solicitação (figura 5a);

g é o espaçamento dos furos na direção perpendicular à solicitação (figura 5a).

t é a espessura da parte conectada analisada.

$\mathrm{C}_{\mathrm{t}}$ é o coeficiente de redução da área líquida, dado por: 


\section{a) chapas com ligações parafusadas:}

- todos os parafusos da ligação contidos em uma única seção transversal:

$$
\mathrm{C}_{\mathrm{t}}=2,5(\mathrm{~d} / \mathrm{g}) \leq 1,0
$$

- dois parafusos na direção da solicitação, alinhados ou em zig-zag:

$$
\mathrm{C}_{\mathrm{t}}=0,5+1,25(\mathrm{~d} / \mathrm{g}) \leq 1,0
$$

- três parafusos na direção da solicitação, alinhados ou em zig-zag:

$$
\mathrm{C}_{\mathrm{t}}=0,67+0,83(\mathrm{~d} / \mathrm{g}) \leq 1,0
$$

- quatro ou mais parafusos na direção da solicitação, alinhados ou em zigzag:

$$
\mathrm{C}_{\mathrm{t}}=0,75+0,625(\mathrm{~d} / \mathrm{g}) \leq 1,0
$$

d é o diâmetro nominal do parafuso;

Em casos de espaçamentos diferentes, tomar sempre o maior valor de $g$ para cálculo de $\mathrm{C}_{\mathrm{t}}$;

Nos casos em que o espaçamento entre furos $g$ for inferior à soma das distâncias entre os centros dos furos de extremidade às respectivas bordas, na direção perpendicular à solicitação $\left(e_{1}+e_{2}\right), \quad \mathrm{C}_{\mathrm{t}}$ deve ser calculado substituindo $g$ por $e_{1}+e_{2}$.

Havendo um único parafuso na seção analisada, $C_{t}$ deve ser calculado tomando-se $g$ como a própria largura bruta da chapa.

Nos casos de furos com disposição em zig-zag, com $g$ inferior a $3 d, \mathrm{C}_{\mathrm{t}}$ deve ser calculado tomando-se $g$ igual ao maior valor entre $3 d$ e a soma $e_{1}+e_{2}$.

\section{b) perfis com ligações parafusadas:}

- todos os elementos conectados, com dois ou mais parafusos na direção da solicitação:

$$
\mathrm{C}_{\mathrm{t}}=1,0
$$

$5 c)$ :

- cantoneiras com dois ou mais parafusos na direção da solicitação (figura 


$$
\left.\mathrm{C}_{\mathrm{t}}=1-1,2(\mathrm{x} / \mathrm{L})<0,9 \text { (porém, não inferior a } 0,4\right)
$$

- perfis U com dois ou mais parafusos na direção da solicitação (figura $5 c)$ :

$$
\mathrm{C}_{\mathrm{t}}=1-0,36(\mathrm{x} / \mathrm{L})<0,9 \text { (porém, não inferior a } 0,5 \text { ) }
$$

Nos casos onde todos os parafusos estão contidos em uma única seção transversal, o perfil deve ser tratado como chapa equivalente (figura $5 \mathrm{~b}$ ), conforme a), com $\mathrm{C}_{t}$ dado por:

$$
\mathrm{C}_{\mathrm{t}}=2,5(\mathrm{~d} / \mathrm{g}) \leq 1,0
$$

\section{c) chapas com ligações soldadas:}

- soldas longitudinais associadas a soldas transversais:

$$
\mathrm{C}_{\mathrm{t}}=1,0
$$

- somente soldas longitudinais ao longo de ambas as bordas:

$$
\begin{aligned}
& \text { para } b \leq L<1,5 b: C_{t}=0,75 \\
& \text { para } 1,5 b \leq L<2 b: C_{t}=0,87 \\
& \text { para } L \geq 2 b: C_{t}=1,0
\end{aligned}
$$

\section{d) perfis com ligações soldadas:}

- todos os elementos conectados:

$$
\mathrm{C}_{\mathrm{t}}=1,0
$$

- cantoneiras com soldas longitudinais (figura 5d):

$$
\mathrm{C}_{\mathrm{t}}=1-1,2(\mathrm{x} / \mathrm{L})<0,9 \text { (porém, não inferior a } 0,4 \text { ) }
$$

- perfis U com soldas longitudinais (figura 5d):

$$
\mathrm{C}_{\mathrm{t}}=1-0,36(\mathrm{x} / \mathrm{L})<0,9 \text { (porém, não inferior a } 0,5 \text { ) }
$$

b é a largura da chapa;

L é o comprimento da ligação parafusada (figura 5c) ou o comprimento da solda (figura 5d); 
x é a excentricidade da ligação, tomada como a distância entre o plano da ligação e o centróide da seção transversal do perfil (figuras 5c e 5d). 


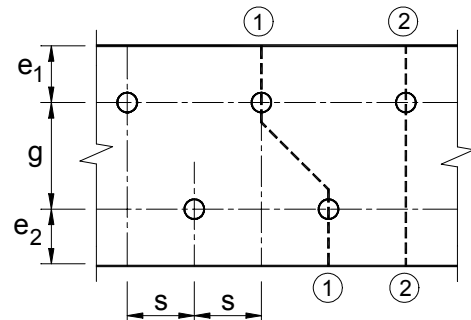

5a) Prováveis linhas de ruptura

1-1: linha de ruptura com segmento inclinado

2-2: linha de ruptura perpendicular à solicitação
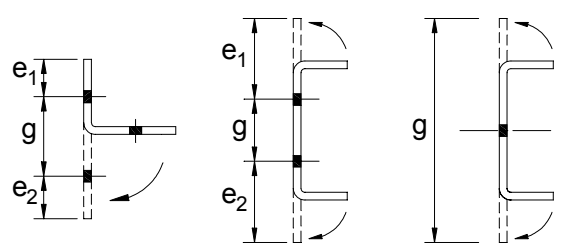

5b) Perfis tratados como chapa (todos os parafusos contidos em uma única seção )

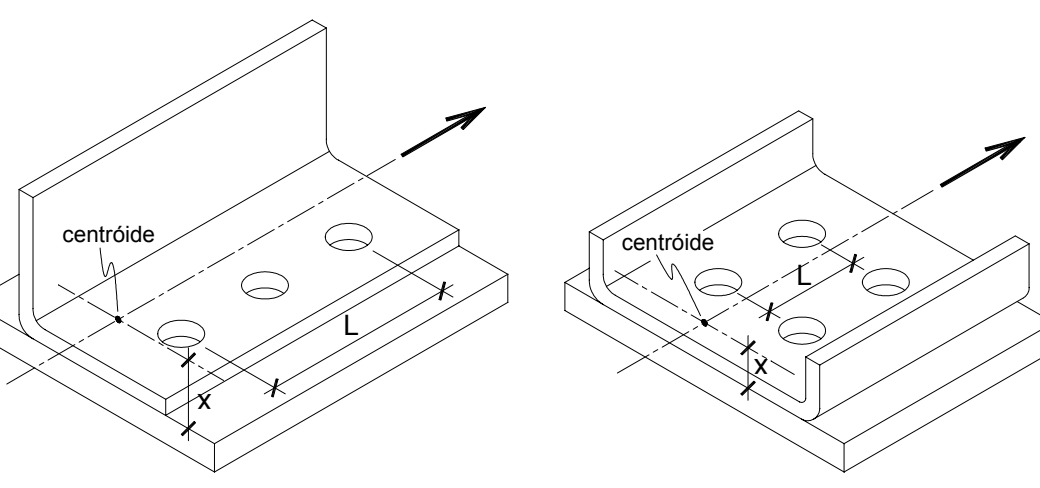

5c) Ligação parafusada em perfis
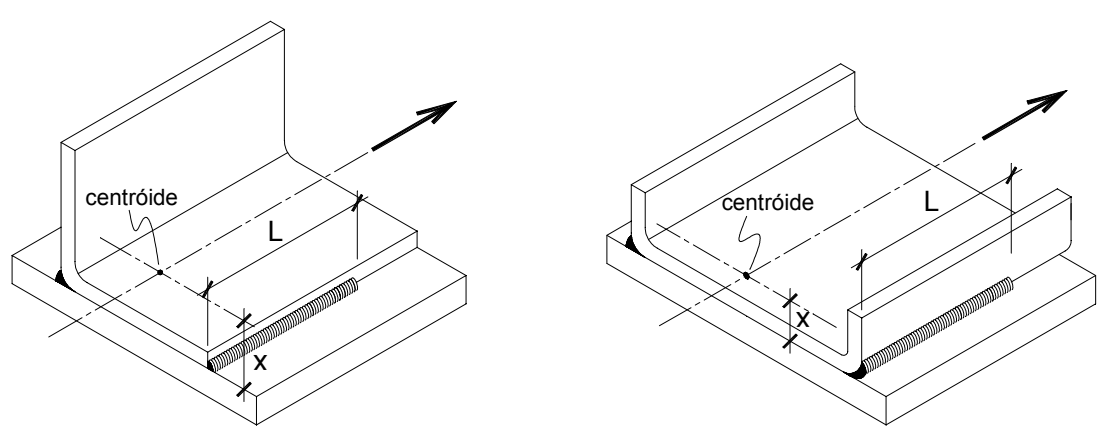

5d) Ligação soldada em perfis

Figura 5 - Linhas de ruptura e grandezas para cálculo do coeficiente $C_{t}$

7.6.2 É recomendado que o índice de esbeltez $K L / r$ das barras tracionadas não exceda 300. Para as barras compostas tracionadas, ou seja, aquelas constituídas por um ou mais perfis associados, é também recomendado que o índice de esbeltez de cada perfil componente da barra não exceda 300 .

\subsection{Barras submetidas à compressão centrada}




\subsubsection{Generalidades}

A força normal de compressão resistente de cálculo $N_{c, R d}$ deve ser tomada como o menor valor calculado em 7.7.2 e 7.7.3.

\subsubsection{Flambagem da barra por flexão, por torção ou por flexo-torção}

A força normal de compressão resistente de cálculo $N_{c, R d}$ deve ser calculada por:

$$
\mathrm{N}_{\mathrm{c}, \mathrm{Rd}}=\rho \mathrm{A}_{\mathrm{ef}} \mathrm{f}_{\mathrm{y}} / \gamma \quad(\gamma=1,1)
$$

Onde:

$\rho$ é o fator de redução associado à flambagem, apresentado na tabela $8 \mathrm{ou}$ calculado por:

$$
\begin{aligned}
& \rho=\frac{1}{\beta+\left(\beta^{2}-\lambda_{0}^{2}\right)^{0,5}} \leq 1,0 \\
& \beta=0,5\left[1+\alpha\left(\lambda_{0}-0,2\right)+\lambda_{0}^{2}\right]
\end{aligned}
$$

$\alpha$ é o fator de imperfeição inicial. Nos casos de flambagem por flexão, os valores de $\alpha$ variam de acordo com o tipo de seção e eixo de flambagem, conforme tabela 7, sendo:

$$
\begin{aligned}
& \text { curva a: } \alpha=0,21 \\
& \text { curva b: } \alpha=0,34 \\
& \text { curva c: } \alpha=0,49
\end{aligned}
$$

Nos casos de flambagem por torção ou por flexo-torção, deve-se tomar a curva $b$.

$\lambda_{0}$ é o índice de esbeltez reduzido para barras comprimidas, dado por:

$$
\lambda_{0}=\left[\frac{A_{e f} f_{y}}{N_{e}}\right]^{0,5}
$$

$\mathrm{A}_{\mathrm{ef}}$ é a área efetiva da seção transversal da barra, calculada com base nas larguras efetivas dos elementos, conforme 7.2, adotando $\sigma=\rho f_{\mathrm{y}}$. Nesse caso $\rho$ pode ser determinado de forma aproximada, tomando-se diretamente $\mathrm{A}_{\mathrm{ef}}=\mathrm{A}$ para o cálculo de $\lambda_{0}$, dispensando processo iterativo. 
$\mathrm{N}_{\mathrm{e}}$ é a força normal de flambagem elástica da barra, conforme 7.7.2.1, 7.7.2.2 ou 7.7.2.3.

\subsubsection{Perfis com dupla simetria ou simétricos em relação a um ponto}

A força normal de flambagem elástica $\mathrm{N}_{\mathrm{e}}$ é o menor valor dentre os obtidos por a), b) e c):

a) força normal de flambagem elástica por flexão em relação ao eixo principal x:

$$
N_{e x}=\frac{\pi^{2} E I_{x}}{\left(K_{x} L_{x}\right)^{2}}
$$

b) força normal de flambagem elástica por flexão em relação ao eixo principal y:

$$
N_{e y}=\frac{\pi^{2} E I_{y}}{\left(K_{y} L_{y}\right)^{2}}
$$

c) força normal de flambagem elástica por torção:

$$
N_{e t}=\frac{1}{r_{0}^{2}}\left[\frac{\pi^{2} E C_{w}}{\left(K_{t} L_{t}\right)^{2}}+G I_{t}\right]
$$

Onde:

$\mathrm{C}_{\mathrm{w}}$ é a constante de empenamento da seção;

E é o módulo de elasticidade;

G é o módulo de elasticidade transversal;

$\mathrm{I}_{\mathrm{t}}$ é o momento de inércia à torção uniforme;

$K_{x} L_{x}$ é o comprimento efetivo de flambagem por flexão em relação ao eixo x;

$K_{y} L_{y}$ é o comprimento efetivo de flambagem por flexão em relação ao eixo y;

$\mathrm{K}_{\mathrm{t}} \mathrm{L}_{\mathrm{t}}$ é o comprimento efetivo de flambagem por torção. Quando não houver garantia de impedimento ao empenamento, deve-se tomar $\mathrm{K}_{\mathrm{t}}$ igual a 1,0.

$\mathrm{r}_{0}$ é o raio de giração polar da seção bruta em relação ao centro de torção, dado por: 


$$
\mathrm{r}_{0}=\left[\mathrm{r}_{\mathrm{x}}^{2}+\mathrm{r}_{\mathrm{y}}^{2}+\mathrm{x}_{0}^{2}+\mathrm{y}_{0}^{2}\right]^{0,5}
$$

$\mathrm{r}_{\mathrm{x}} ; \mathrm{r}_{\mathrm{y}}$ são os raios de giração da seção bruta em relação aos eixos principais de inércia $x$ e $y$,

respectivamente;

$\mathrm{x}_{0} ; \mathrm{y}_{0}$ são as coordenadas do centro de torção na direção dos eixos principais $x$ e $y$,

respectivamente, em relação ao centróide da seção.

\subsubsection{Perfis monossimétricos}

A força normal de flambagem elástica $\mathrm{N}_{\mathrm{e}}$ de um perfil com seção monossimétrica, cujo eixo $x$ é o eixo de simetria, é o menor valor dentre os obtidos por a) e b) seguintes:

a) força normal de flambagem elástica por flexão em relação ao eixo $y$ :

$$
N_{e y}=\frac{\pi^{2} E I_{y}}{\left(K_{y} L_{y}\right)^{2}}
$$

b) força normal de flambagem elástica por flexo-torção:

$$
N_{e x t}=\frac{N_{e x}+N_{e t}}{2\left[1-\left(x_{0} / r_{0}\right)^{2}\right]}\left[1-\sqrt{1-\frac{4 N_{e x} N_{e t}\left[1-\left(x_{0} / r_{0}\right)^{2}\right]}{\left(N_{e x}+N_{e t}\right)^{2}}}\right]
$$

Onde:

$\mathrm{N}_{\mathrm{ex}} ; \mathrm{N}_{\mathrm{et}}$ são as forças normais de flambagem elástica conforme 7.7.2.1a e 7.7.2.1c, respectivamente;

$\mathrm{r}_{0} ; \mathrm{x}_{0}$ conforme definidos em 7.7.2.1

Caso o eixo $y$ seja o eixo de simetria, basta substituir $y$ por $x$ em a); $x$ por $y$ e $x_{0}$ por $\left.y_{0} \mathrm{em} \mathrm{b}\right)$

\subsubsection{Perfis assimétricos}

A força normal de flambagem elástica $\mathrm{N}_{\mathrm{e}}$ de um perfil com seção assimétrica é dada pela menor das raízes da seguinte equação cúbica:

Onde:

$$
r_{0}^{2}\left(N_{e}-N_{e x}\right)\left(N_{e}-N_{e y}\right)\left(N_{e}-N_{e t}\right)-N_{e}^{2}\left(N_{e}-N_{e y}\right) x_{0}^{2}-N_{e}^{2}\left(N_{e}-N_{e x}\right) y_{0}^{2}=0
$$

$\mathrm{N}_{\mathrm{ex}} ; \mathrm{N}_{\mathrm{ey}} ; \mathrm{N}_{\mathrm{et}} ; \mathrm{x}_{0} ; \mathrm{y}_{0} ; \mathrm{r}_{0}$ conforme definidos em 7.7.2.1. 
Tabela 7 - Classificação de seções e respectivas curvas de resistência à compressão associadas à flambagem por flexão

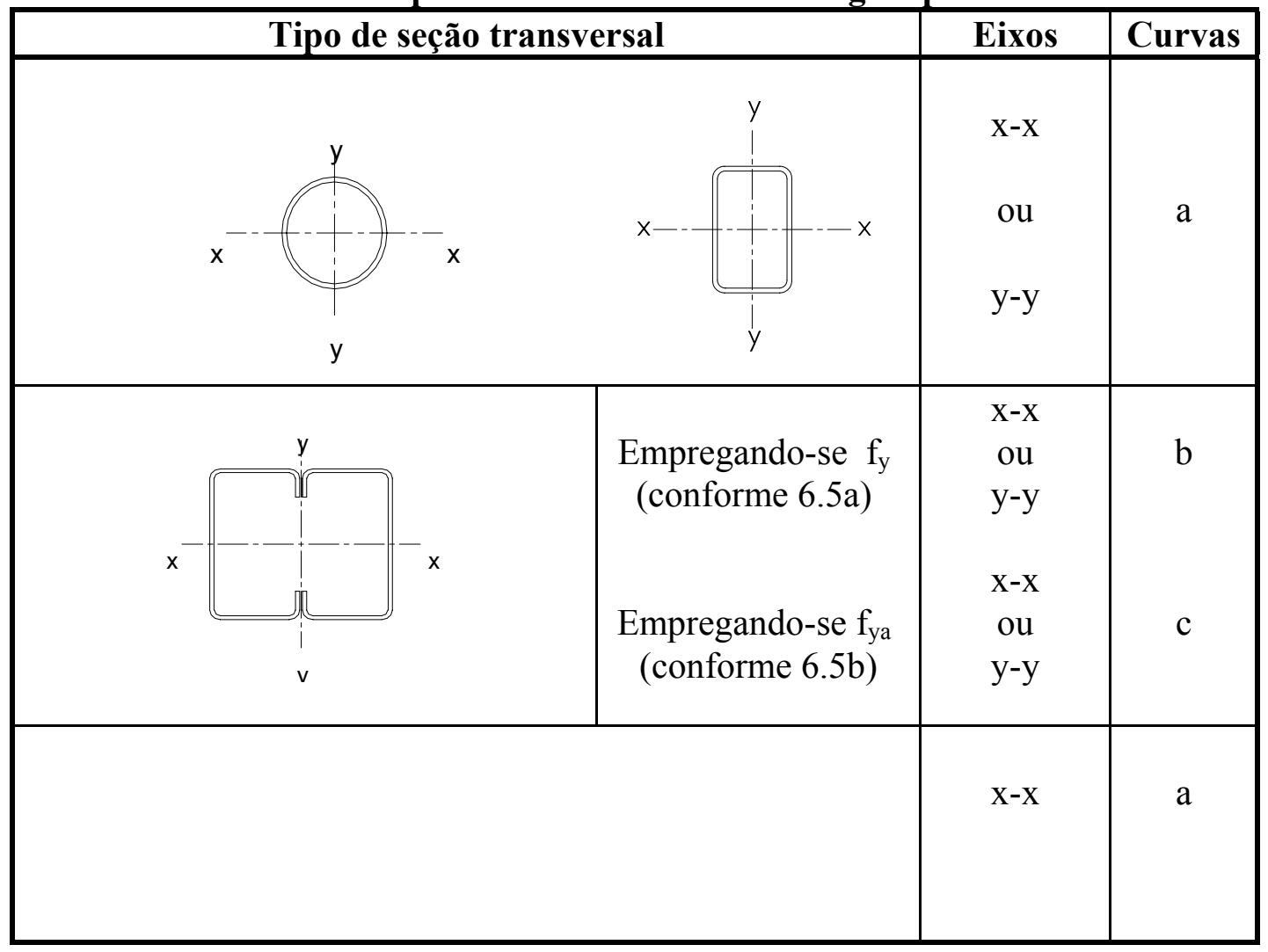




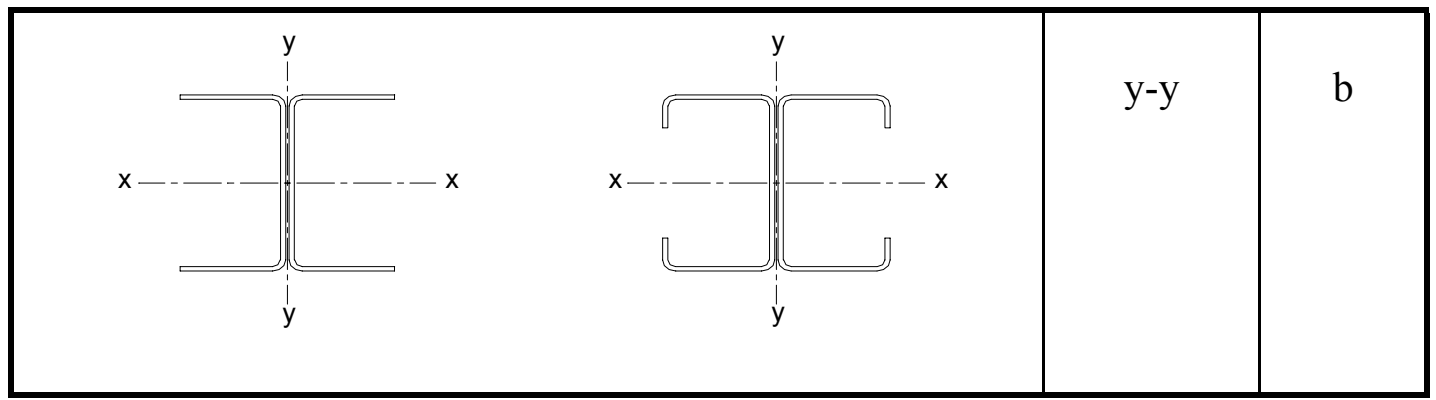




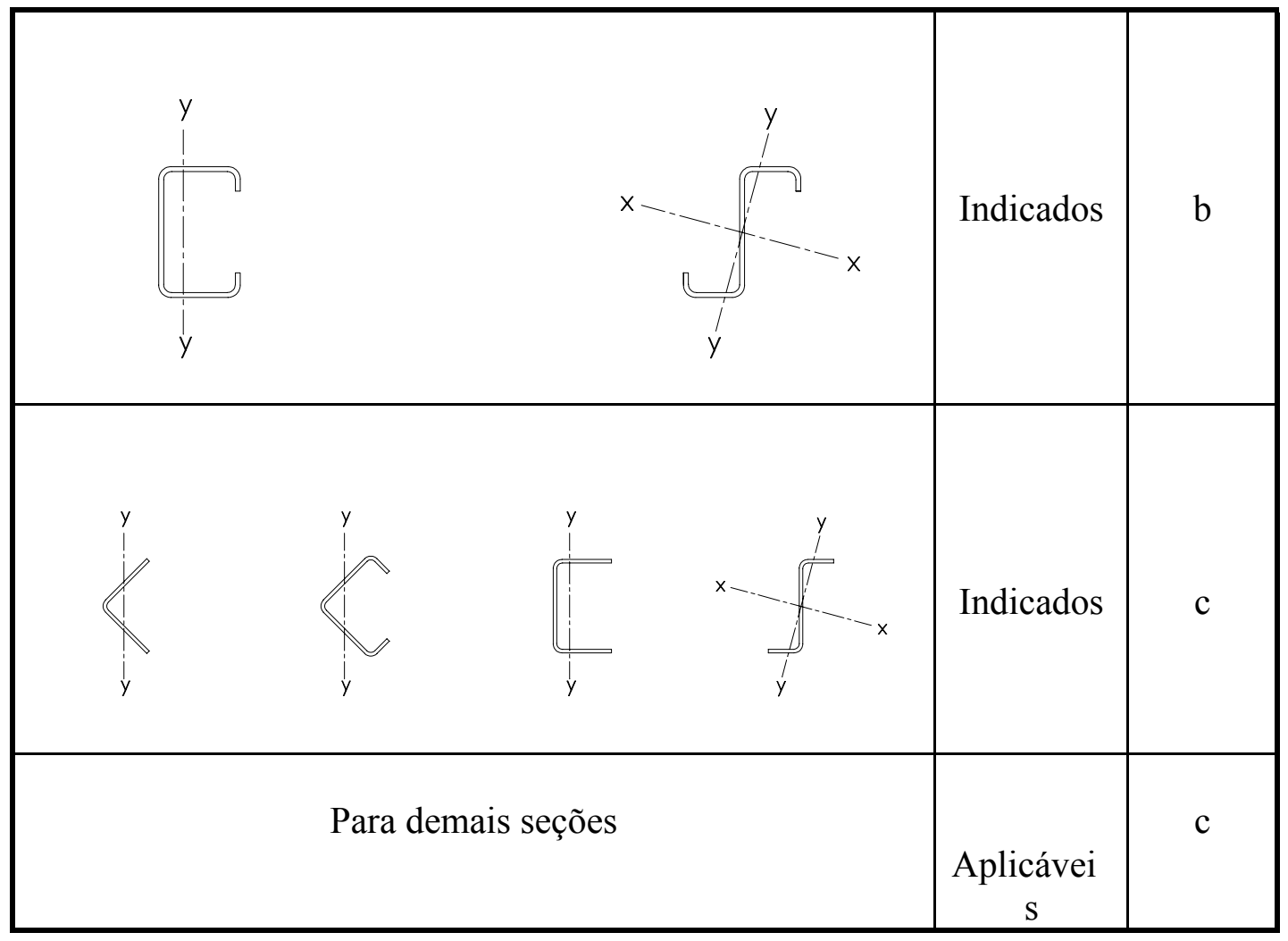

Tabela 8a - Valores de $\rho$ para curva $a(\alpha=0,21)$

\begin{tabular}{|c|c|c|c|c|c|c|c|c|c|c|c|}
\hline $\boldsymbol{\lambda}_{\mathbf{0}}$ & $\mathbf{0 , 0 0}$ & $\mathbf{0 , 0 1}$ & $\mathbf{0 , 0 2}$ & $\mathbf{0 , 0 3}$ & $\mathbf{0 , 0 4}$ & $\mathbf{0 , 0 5}$ & $\mathbf{0 , 0 6}$ & $\mathbf{0 , 0 7}$ & $\mathbf{0 , 0 8}$ & $\mathbf{0 , 0 9}$ & $\boldsymbol{\lambda}_{\mathbf{0}}$ \\
\hline $\mathbf{0 , 0}$ & 1,000 & 1,000 & 1,000 & 1,000 & 1,000 & 1,000 & 1,000 & 1,000 & 1,000 & 1,000 & $\mathbf{0 , 0}$ \\
\hline $\mathbf{0 , 1}$ & 1,000 & 1,000 & 1,000 & 1,000 & 1,000 & 1,000 & 1,000 & 1,000 & 1,000 & 1,000 & $\mathbf{0 , 1}$ \\
\hline $\mathbf{0 , 2}$ & 1,000 & 0,998 & 0,996 & 0,993 & 0,991 & 0,989 & 0,987 & 0,984 & 0,982 & 0,980 & $\mathbf{0 , 2}$ \\
\hline $\mathbf{0 , 3}$ & 0,977 & 0,975 & 0,973 & 0,970 & 0,968 & 0,965 & 0,963 & 0,960 & 0,958 & 0,955 & $\mathbf{0 , 3}$ \\
\hline $\mathbf{0 , 4}$ & 0,953 & 0,950 & 0,947 & 0,945 & 0,942 & 0,939 & 0,936 & 0,933 & 0,930 & 0,927 & $\mathbf{0 , 4}$ \\
\hline $\mathbf{0 , 5}$ & 0,924 & 0,921 & 0,918 & 0,915 & 0,911 & 0,908 & 0,905 & 0,901 & 0,897 & 0,894 & $\mathbf{0 , 5}$ \\
\hline $\mathbf{0 , 6}$ & 0,890 & 0,886 & 0,882 & 0,878 & 0,874 & 0,870 & 0,866 & 0,861 & 0,857 & 0,852 & $\mathbf{0 , 6}$ \\
\hline $\mathbf{0 , 7}$ & 0,848 & 0,843 & 0,838 & 0,833 & 0,828 & 0,823 & 0,818 & 0,812 & 0,807 & 0,801 & $\mathbf{0 , 7}$ \\
\hline $\mathbf{0 , 8}$ & 0,796 & 0,790 & 0,784 & 0,778 & 0,772 & 0,766 & 0,760 & 0,753 & 0,747 & 0,740 & $\mathbf{0 , 8}$ \\
\hline $\mathbf{0 , 9}$ & 0,734 & 0,727 & 0,721 & 0,714 & 0,707 & 0,700 & 0,693 & 0,686 & 0,679 & 0,672 & $\mathbf{0 , 9}$ \\
\hline $\mathbf{1 , 0}$ & 0,666 & 0,659 & 0,652 & 0,645 & 0,638 & 0,631 & 0,624 & 0,617 & 0,610 & 0,603 & $\mathbf{1 , 0}$ \\
\hline $\mathbf{1 , 1}$ & 0,596 & 0,589 & 0,582 & 0,576 & 0,569 & 0,562 & 0,556 & 0,549 & 0,543 & 0,536 & $\mathbf{1 , 1}$ \\
\hline $\mathbf{1 , 2}$ & 0,530 & 0,524 & 0,517 & 0,511 & 0,505 & 0,499 & 0,493 & 0,487 & 0,482 & 0,476 & $\mathbf{1 , 2}$ \\
\hline $\mathbf{1 , 3}$ & 0,470 & 0,465 & 0,459 & 0,454 & 0,448 & 0,443 & 0,438 & 0,433 & 0,428 & 0,423 & $\mathbf{1 , 3}$ \\
\hline $\mathbf{1 , 4}$ & 0,418 & 0,413 & 0,408 & 0,403 & 0,399 & 0,394 & 0,390 & 0,385 & 0,381 & 0,377 & $\mathbf{1 , 4}$ \\
\hline $\mathbf{1 , 5}$ & 0,372 & 0,368 & 0,364 & 0,360 & 0,356 & 0,352 & 0,348 & 0,344 & 0,341 & 0,337 & $\mathbf{1 , 5}$ \\
\hline $\mathbf{1 , 6}$ & 0,333 & 0,330 & 0,326 & 0,322 & 0,319 & 0,316 & 0,312 & 0,309 & 0,306 & 0,302 & $\mathbf{1 , 6}$ \\
\hline $\mathbf{1 , 7}$ & 0,299 & 0,296 & 0,293 & 0,290 & 0,287 & 0,284 & 0,281 & 0,278 & 0,276 & 0,273 & $\mathbf{1 , 7}$ \\
\hline $\mathbf{1 , 8}$ & 0,270 & 0,267 & 0,265 & 0,262 & 0,260 & 0,257 & 0,255 & 0,252 & 0,250 & 0,247 & $\mathbf{1 , 8}$ \\
\hline $\mathbf{1 , 9}$ & 0,245 & 0,242 & 0,240 & 0,238 & 0,236 & 0,233 & 0,231 & 0,229 & 0,227 & 0,225 & $\mathbf{1 , 9}$ \\
\hline $\mathbf{2 , 0}$ & 0,223 & 0,220 & 0,219 & 0,217 & 0,215 & 0,213 & 0,211 & 0,209 & 0,207 & 0,205 & $\mathbf{2 , 0}$ \\
\hline $\mathbf{2 , 1}$ & 0,204 & 0,202 & 0,200 & 0,198 & 0,196 & 0,195 & 0,193 & 0,191 & 0,190 & 0,188 & $\mathbf{2 , 1}$
\end{tabular}


\begin{tabular}{|l|l|l|l|l|l|l|l|l|l|l|l|}
$\mathbf{2 , 2}$ & 0,187 & 0,185 & 0,183 & 0,182 & 0,180 & 0,179 & 0,177 & 0,176 & 0,174 & 0,173 & $\mathbf{2 , 2}$ \\
\hline
\end{tabular}

Tabela 8b - Valores de $\rho$ para curva $b(\alpha=0,34)$

\begin{tabular}{|c|c|c|c|c|c|c|c|c|c|c|c|}
\hline $\boldsymbol{\lambda}_{\mathbf{0}}$ & $\mathbf{0 , 0 0}$ & $\mathbf{0 , 0 1}$ & $\mathbf{0 , 0 2}$ & $\mathbf{0 , 0 3}$ & $\mathbf{0 , 0 4}$ & $\mathbf{0 , 0 5}$ & $\mathbf{0 , 0 6}$ & $\mathbf{0 , 0 7}$ & $\mathbf{0 , 0 8}$ & $\mathbf{0 , 0 9}$ & $\boldsymbol{\lambda}_{\mathbf{0}}$ \\
\hline $\mathbf{0 , 0}$ & 1,000 & 1,000 & 1,000 & 1,000 & 1,000 & 1,000 & 1,000 & 1,000 & 1,000 & 1,000 & $\mathbf{0 , 0}$ \\
\hline $\mathbf{0 , 1}$ & 1,000 & 1,000 & 1,000 & 1,000 & 1,000 & 1,000 & 1,000 & 1,000 & 1,000 & 1,000 & $\mathbf{0 , 1}$ \\
\hline $\mathbf{0 , 2}$ & 1,000 & 0,996 & 0,993 & 0,989 & 0,986 & 0,982 & 0,979 & 0,975 & 0,971 & 0,968 & $\mathbf{0 , 2}$ \\
\hline $\mathbf{0 , 3}$ & 0,964 & 0,960 & 0,957 & 0,953 & 0,949 & 0,945 & 0,942 & 0,938 & 0,934 & 0,930 & $\mathbf{0 , 3}$ \\
\hline $\mathbf{0 , 4}$ & 0,926 & 0,922 & 0,918 & 0,914 & 0,910 & 0,906 & 0,902 & 0,897 & 0,893 & 0,889 & $\mathbf{0 , 4}$ \\
\hline $\mathbf{0 , 5}$ & 0,884 & 0,880 & 0,875 & 0,871 & 0,866 & 0,861 & 0,857 & 0,852 & 0,847 & 0,842 & $\mathbf{0 , 5}$ \\
\hline $\mathbf{0 , 6}$ & 0,837 & 0,832 & 0,827 & 0,822 & 0,816 & 0,811 & 0,806 & 0,800 & 0,795 & 0,789 & $\mathbf{0 , 6}$ \\
\hline $\mathbf{0 , 7}$ & 0,784 & 0,778 & 0,772 & 0,766 & 0,761 & 0,755 & 0,749 & 0,743 & 0,737 & 0,731 & $\mathbf{0 , 7}$ \\
\hline $\mathbf{0 , 8}$ & 0,724 & 0,718 & 0,712 & 0,706 & 0,699 & 0,693 & 0,687 & 0,680 & 0,674 & 0,668 & $\mathbf{0 , 8}$ \\
\hline $\mathbf{0 , 9}$ & 0,661 & 0,655 & 0,648 & 0,642 & 0,635 & 0,629 & 0,623 & 0,616 & 0,610 & 0,603 & $\mathbf{0 , 9}$ \\
\hline $\mathbf{1 , 0}$ & 0,597 & 0,591 & 0,584 & 0,578 & 0,572 & 0,566 & 0,559 & 0,553 & 0,547 & 0,541 & $\mathbf{1 , 0}$ \\
\hline $\mathbf{1 , 1}$ & 0,535 & 0,529 & 0,523 & 0,518 & 0,512 & 0,506 & 0,500 & 0,495 & 0,489 & 0,484 & $\mathbf{1 , 1}$ \\
\hline $\mathbf{1 , 2}$ & 0,478 & 0,473 & 0,467 & 0,462 & 0,457 & 0,452 & 0,447 & 0,442 & 0,437 & 0,432 & $\mathbf{1 , 2}$ \\
\hline $\mathbf{1 , 3}$ & 0,427 & 0,422 & 0,417 & 0,413 & 0,408 & 0,404 & 0,399 & 0,395 & 0,390 & 0,386 & $\mathbf{1 , 3}$ \\
\hline $\mathbf{1 , 4}$ & 0,382 & 0,378 & 0,373 & 0,369 & 0,365 & 0,361 & 0,357 & 0,354 & 0,350 & 0,346 & $\mathbf{1 , 4}$ \\
\hline $\mathbf{1 , 5}$ & 0,342 & 0,339 & 0,335 & 0,331 & 0,328 & 0,324 & 0,321 & 0,318 & 0,314 & 0,311 & $\mathbf{1 , 5}$ \\
\hline $\mathbf{1 , 6}$ & 0,308 & 0,305 & 0,302 & 0,299 & 0,295 & 0,292 & 0,289 & 0,287 & 0,284 & 0,281 & $\mathbf{1 , 6}$ \\
\hline $\mathbf{1 , 7}$ & 0,278 & 0,275 & 0,273 & 0,270 & 0,267 & 0,265 & 0,262 & 0,259 & 0,257 & 0,255 & $\mathbf{1 , 7}$ \\
\hline $\mathbf{1 , 8}$ & 0,252 & 0,250 & 0,247 & 0,245 & 0,243 & 0,240 & 0,238 & 0,236 & 0,234 & 0,231 & $\mathbf{1 , 8}$ \\
\hline $\mathbf{1 , 9}$ & 0,229 & 0,227 & 0,225 & 0,223 & 0,221 & 0,219 & 0,217 & 0,215 & 0,213 & 0,211 & $\mathbf{1 , 9}$ \\
\hline $\mathbf{2 , 0}$ & 0,209 & 0,208 & 0,206 & 0,204 & 0,202 & 0,200 & 0,199 & 0,197 & 0,195 & 0,194 & $\mathbf{2 , 0}$ \\
\hline $\mathbf{2 , 1}$ & 0,192 & 0,190 & 0,189 & 0,187 & 0,186 & 0,184 & 0,182 & 0,181 & 0,179 & 0,178 & $\mathbf{2 , 1}$ \\
\hline $\mathbf{2 , 2}$ & 0,176 & 0,175 & 0,174 & 0,172 & 0,171 & 0,169 & 0,168 & 0,167 & 0,165 & 0,164 & $\mathbf{2 , 2}$ \\
\hline
\end{tabular}

Tabela 8c - Valores de $\rho$ para curva c $(\alpha=0,49)$

\begin{tabular}{|c|c|c|c|c|c|c|c|c|c|c|c|}
\hline$\lambda_{\mathbf{0}}$ & $\mathbf{0 , 0 0}$ & $\mathbf{0 , 0 1}$ & $\mathbf{0 , 0 2}$ & $\mathbf{0 , 0 3}$ & $\mathbf{0 , 0 4}$ & $\mathbf{0 , 0 5}$ & $\mathbf{0 , 0 6}$ & $\mathbf{0 , 0 7}$ & $\mathbf{0 , 0 8}$ & $\mathbf{0 , 0 9}$ & $\lambda_{\mathbf{0}}$ \\
\hline $\mathbf{0 , 0}$ & 1,000 & 1,000 & 1,000 & 1,000 & 1,000 & 1,000 & 1,000 & 1,000 & 1,000 & 1,000 & $\mathbf{0 , 0}$ \\
\hline $\mathbf{0 , 1}$ & 1,000 & 1,000 & 1,000 & 1,000 & 1,000 & 1,000 & 1,000 & 1,000 & 1,000 & 1,000 & $\mathbf{0 , 1}$ \\
\hline $\mathbf{0 , 2}$ & 1,000 & 0,995 & 0,990 & 0,985 & 0,980 & 0,975 & 0,969 & 0,964 & 0,959 & 0,954 & $\mathbf{0 , 2}$ \\
\hline $\mathbf{0 , 3}$ & 0,949 & 0,944 & 0,939 & 0,934 & 0,929 & 0,923 & 0,918 & 0,913 & 0,908 & 0,903 & $\mathbf{0 , 3}$ \\
\hline $\mathbf{0 , 4}$ & 0,897 & 0,892 & 0,887 & 0,881 & 0,876 & 0,871 & 0,865 & 0,860 & 0,854 & 0,849 & $\mathbf{0 , 4}$ \\
\hline $\mathbf{0 , 5}$ & 0,843 & 0,837 & 0,832 & 0,826 & 0,820 & 0,815 & 0,809 & 0,803 & 0,797 & 0,791 & $\mathbf{0 , 5}$ \\
\hline $\mathbf{0 , 6}$ & 0,785 & 0,779 & 0,773 & 0,767 & 0,761 & 0,755 & 0,749 & 0,743 & 0,737 & 0,731 & $\mathbf{0 , 6}$ \\
\hline $\mathbf{0 , 7}$ & 0,725 & 0,718 & 0,712 & 0,706 & 0,700 & 0,694 & 0,687 & 0,681 & 0,675 & 0,668 & $\mathbf{0 , 7}$ \\
\hline $\mathbf{0 , 8}$ & 0,662 & 0,656 & 0,650 & 0,643 & 0,637 & 0,631 & 0,625 & 0,618 & 0,612 & 0,606 & $\mathbf{0 , 8}$ \\
\hline $\mathbf{0 , 9}$ & 0,600 & 0,594 & 0,588 & 0,582 & 0,575 & 0,569 & 0,563 & 0,558 & 0,552 & 0,546 & $\mathbf{0 , 9}$ \\
\hline $\mathbf{1 , 0}$ & 0,540 & 0,534 & 0,528 & 0,523 & 0,517 & 0,511 & 0,506 & 0,500 & 0,495 & 0,490 & $\mathbf{1 , 0}$ \\
\hline $\mathbf{1 , 1}$ & 0,484 & 0,479 & 0,474 & 0,469 & 0,463 & 0,458 & 0,453 & 0,448 & 0,443 & 0,439 & $\mathbf{1 , 1}$ \\
\hline $\mathbf{1 , 2}$ & 0,434 & 0,429 & 0,424 & 0,420 & 0,415 & 0,411 & 0,406 & 0,402 & 0,397 & 0,393 & $\mathbf{1 , 2}$ \\
\hline $\mathbf{1 , 3}$ & 0,389 & 0,385 & 0,380 & 0,376 & 0,372 & 0,368 & 0,364 & 0,361 & 0,357 & 0,353 & $\mathbf{1 , 3}$ \\
\hline $\mathbf{1 , 4}$ & 0,349 & 0,346 & 0,342 & 0,338 & 0,335 & 0,331 & 0,328 & 0,324 & 0,321 & 0,318 & $\mathbf{1 , 4}$ \\
\hline $\mathbf{1 , 5}$ & 0,315 & 0,311 & 0,308 & 0,305 & 0,302 & 0,299 & 0,296 & 0,293 & 0,290 & 0,287 & $\mathbf{1 , 5}$ \\
\hline $\mathbf{1 , 6}$ & 0,284 & 0,281 & 0,279 & 0,276 & 0,273 & 0,271 & 0,268 & 0,265 & 0,263 & 0,260 & $\mathbf{1 , 6}$ \\
\hline $\mathbf{1 , 7}$ & 0,258 & 0,255 & 0,253 & 0,250 & 0,248 & 0,246 & 0,243 & 0,241 & 0,239 & 0,237 & $\mathbf{1 , 7}$ \\
\hline $\mathbf{1 , 8}$ & 0,235 & 0,232 & 0,230 & 0,228 & 0,226 & 0,224 & 0,222 & 0,220 & 0,218 & 0,216 & $\mathbf{1 , 8}$ \\
\hline $\mathbf{1 , 9}$ & 0,214 & 0,212 & 0,210 & 0,209 & 0,207 & 0,205 & 0,203 & 0,201 & 0,200 & 0,198 & $\mathbf{1 , 9}$ \\
\hline
\end{tabular}




\begin{tabular}{|l|l|l|l|l|l|l|l|l|l|l|l|}
\hline $\mathbf{2 , 0}$ & 0,196 & 0,195 & 0,193 & 0,191 & 0,190 & 0,188 & 0,186 & 0,185 & 0,183 & 0,182 & $\mathbf{2 , 0}$ \\
\hline $\mathbf{2 , 1}$ & 0,180 & 0,179 & 0,177 & 0,176 & 0,174 & 0,173 & 0,172 & 0,170 & 0,169 & 0,168 & $\mathbf{2 , 1}$ \\
\hline $\mathbf{2 , 2}$ & 0,166 & 0,165 & 0,164 & 0,162 & 0,161 & 0,160 & 0,159 & 0,157 & 0,156 & 0,155 & $\mathbf{2 , 2}$ \\
\hline
\end{tabular}

\subsubsection{Flambagem por distorção da seção transversal}

Para as barras com seção transversal aberta sujeitas à flambagem por distorção, a força normal de compressão resistente de cálculo $N_{c, R d}$ deve ser calculada pelas expressões seguintes:

$$
\begin{gathered}
\mathrm{N}_{\mathrm{c}, \mathrm{Rd}}=\operatorname{Af}_{\mathrm{y}}\left(1-0,25 \lambda_{\text {dist }}^{2}\right) / \gamma \quad \text { para } \lambda_{\text {dist }}<1,414 \\
\mathrm{~N}_{\mathrm{c}, \mathrm{Rd}}=\operatorname{Af}_{\mathrm{y}}\left\{0,055\left[\lambda_{\text {dist }}-3,6\right]^{2}+0,237\right\} / \gamma \quad \text { para } 1,414 \leq \lambda_{\text {dist }} \leq 3,6
\end{gathered}
$$

Onde:

$$
\gamma=1,1
$$

A é área bruta da seção transversal da barra;

$\lambda_{\text {dist }}$ é o índice de esbeltez reduzido referente à flambagem por distorção, dado por:

$$
\lambda_{\text {dist }}=\left(f_{\mathrm{y}} / \sigma_{\text {dist }}\right)^{0,5}
$$

$\sigma_{\text {dist }}$ é a tensão convencional de flambagem elástica por distorção, calculada pela teoria da estabilidade elástica ou conforme anexo D.

\subsubsection{Limitação de esbeltez}

O índice de esbeltez $K L / r$ das barras comprimidas não deve exceder 200.

\subsubsection{Barras compostas comprimidas}

Para barras compostas comprimidas, ou seja, aquelas constituídas por um ou mais perfis associados, além de atender o disposto em 7.7.4, o índice de esbeltez de cada perfil componente da barra deve ser inferior:

a) à metade do índice de esbeltez máximo do conjunto, para o caso de presilhas (chapas separadoras);

b) ao índice de esbeltez máximo do conjunto, para o caso de travejamento em treliça. Neste caso, o índice de esbeltez das barras do travejamento deve ser inferior a 140 . 
A substituição de travejamento em treliça por chapas regularmente espaçadas (talas), formando travejamento em quadro, não é prevista nesta Norma. Neste caso, a redução da força normal de compressão resistente de cálculo devida à deformação por cisalhamento não deve ser desprezada.

\subsection{Barras submetidas à flexão simples}

\subsubsection{Momento fletor}

O momento fletor resistente de cálculo $M_{R d}$ deve ser tomado como o menor valor calculado em 7.8.1.1, 7.8.1.2, 7.8.1.3 e 7.8.1.4 onde aplicável:

\subsubsection{Início de escoamento da seção efetiva}

$$
\mathrm{M}_{\mathrm{Rd}}=\mathrm{W}_{\mathrm{ef}} \mathrm{f}_{\mathrm{y}} / \gamma \quad(\gamma=1,1)
$$

Onde:

$\mathrm{W}_{\text {ef }}$ é o módulo de resistência elástico da seção efetiva calculado com base nas larguras efetivas dos elementos, conforme 7.2, com $\sigma$ calculada para 0 estado limite último de escoamento da seção;

\subsubsection{Flambagem lateral com torção}

O momento fletor resistente de cálculo referente à flambagem lateral com torção, tomando-se um trecho compreendido entre seções contidas lateralmente, deve ser calculado por:

$$
\mathrm{M}_{\mathrm{Rd}}=\left[\rho_{\mathrm{FLT}} \mathrm{W}_{\mathrm{c}, \text { ef }} \mathrm{f}_{\mathrm{y}}\right] / \gamma \quad(\gamma=1,1)
$$

Onde:

$\mathrm{W}_{\mathrm{c}, \mathrm{ef}}$ é o módulo de resistência elástico da seção efetiva em relação à fibra comprimida, calculado com base nas larguras efetivas dos elementos, conforme 7.2 , adotando $\sigma=\rho_{\mathrm{FLT}} \mathrm{f}_{\mathrm{y}}$;

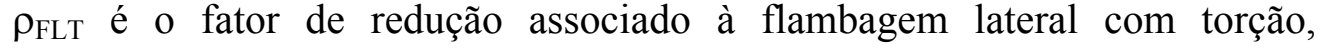
calculado por:

- para $\lambda_{0} \leq 0,6: \rho_{\mathrm{FLT}}=1,0$

- para $0,6<\lambda_{0}<1,336: \rho_{\mathrm{FLT}}=1,11\left(1-0,278 \lambda_{0}{ }^{2}\right)$

- para $\lambda_{0} \geq 1,336: \quad \rho_{\mathrm{FLT}}=1 / \lambda_{0}^{2}$

$\lambda_{0}=\left(\mathrm{W}_{\mathrm{c}} \mathrm{f}_{\mathrm{y}} / \mathrm{M}_{\mathrm{e}}\right)^{0,5}$ 
$\mathrm{W}_{\mathrm{c}}$ é o módulo de resistência elástico da seção bruta em relação à fibra comprimida;

$\mathrm{M}_{\mathrm{e}}$ é o momento fletor de flambagem lateral com torção, em regime elástico, que pode ser calculado pelas expressões seguintes, deduzidas para carregamento aplicado na posição do centro de torção. A favor da segurança, também podem ser empregadas nos casos de carregamento aplicado em posição estabilizante, isto é, que tende a restaurar a posição original da barra (por exemplo, carregamento gravitacional aplicado na parte inferior da barra). Em casos de carregamento aplicado em posição desestabilizante, consultar bibliografia especializada.

- barras com seção duplamente simétrica ou monossimétrica sujeitas à flexão em torno do eixo de simetria (eixo x):

$$
\mathrm{M}_{\mathrm{e}}=\mathrm{C}_{\mathrm{b}} \mathrm{r}_{0}\left(\mathrm{~N}_{\mathrm{ey}} \mathrm{N}_{\mathrm{et}}\right)^{0,5}
$$

Em barras com seção monossimétrica, sujeitas à flexão em torno do eixo perpendicular ao eixo de simetria, consultar bibliografia especializada.

- barras com seção Z ponto-simétrica, com carregamento no plano da alma:

$$
\mathrm{M}_{\mathrm{e}}=0,5 \mathrm{C}_{\mathrm{b}} \mathrm{r}_{0}\left(\mathrm{~N}_{\mathrm{ey}} \mathrm{N}_{\mathrm{et}}\right)^{0,5}
$$

- barras com seção fechada (caixão), sujeitas à flexão em torno do eixo x:

$$
\mathrm{M}_{\mathrm{e}}=\mathrm{C}_{\mathrm{b}}\left(\mathrm{N}_{\mathrm{ey}} \mathrm{GI}_{\mathrm{t}}\right)^{0,5}
$$

$\mathrm{N}_{\text {ey }} ; \mathrm{N}_{\mathrm{et}} ; \mathrm{r}_{0}$ conforme 7.7.2.1, considerando $\mathrm{K}_{\mathrm{y}} \mathrm{L}_{\mathrm{y}}=\mathrm{L}_{\mathrm{y}}$ e $\mathrm{K}_{\mathrm{t}} \mathrm{L}_{\mathrm{t}}=\mathrm{L}_{\mathrm{t}}$. Valores de $\mathrm{K}_{\mathrm{y}} \mathrm{L}_{\mathrm{y}}$ e $\mathrm{K}_{\mathrm{t}} \mathrm{L}_{\mathrm{t}}$ inferiores a $\mathrm{L}_{\mathrm{y}}$ e $\mathrm{L}_{\mathrm{t}}$, respectivamente, podem ser adotados desde que justificados com base em bibliografia especializada.

Para os balanços com a extremidade livre sem contenção lateral, $\mathrm{K}_{\mathrm{y}} \mathrm{L}_{\mathrm{y}}$ e $\mathrm{K}_{\mathrm{t}} \mathrm{L}_{\mathrm{t}}$ podem resultar maiores que $\mathrm{L}_{\mathrm{y}} \mathrm{e} \mathrm{L}_{\mathrm{t}}$, respectivamente, em função das condições de vínculo, por exemplo, em barras contínuas conectadas apenas pela mesa tracionada, portanto com deslocamentos laterais, rotação em torno do eixo longitudinal e empenamento parcialmente impedidos no apoio. Nesse caso deve-se consultar bibliografia especializada.

$\mathrm{C}_{\mathrm{b}}$ é o coeficiente de equivalência de momento na flexão, que a favor da segurança pode ser tomado igual a 1,0 ou calculado pela seguinte expressão:

$$
C_{b}=\frac{12,5 M_{\max }}{2,5 M_{\max }+3 M_{A}+4 M_{B}+3 M_{C}}
$$


Para balanços com a extremidade livre sem contenção lateral e para barras submetidas à flexão composta, $\mathrm{C}_{\mathrm{b}}$ deve ser tomado igual a 1,0.

$\mathrm{M}_{\max }$ é o máximo valor do momento fletor solicitante de cálculo, em módulo, no trecho analisado;

$\mathrm{M}_{\mathrm{A}}$ é o valor do momento fletor solicitante de cálculo, em módulo, no $1^{\mathrm{O}}$. quarto do trecho analisado;

$\mathrm{M}_{\mathrm{B}}$ é o valor do momento fletor solicitante de cálculo, em módulo, no centro do trecho analisado;

$\mathrm{M}_{\mathrm{C}}$ é o valor do momento fletor solicitante de cálculo, em módulo, no $3^{\circ}$. quarto do trecho analisado;

\subsubsection{Flambagem por distorção da seção transversal}

Para as barras com seção transversal aberta sujeitas à flambagem por distorção, submetidas à flexão em torno do eixo perpendicular à alma, o momento fletor resistente de cálculo deve ser calculado pela seguinte expressão:

$$
\mathrm{M}_{\mathrm{Rd}}=\mathrm{M}_{\mathrm{dist}} / \gamma \quad(\gamma=1,1)
$$

Onde:

$\mathrm{M}_{\text {dist }}$ é o momento fletor de flambagem por distorção, dado por:

$$
\begin{array}{ll}
\text { - para } \lambda_{\text {dist }}<1,414: & \mathrm{M}_{\text {dist }}=\mathrm{W}_{\mathrm{c}} \mathrm{f}_{\mathrm{y}}\left(1-0,25 \lambda_{\text {dist }}{ }^{2}\right) \\
\text { - para } \lambda_{\text {dist }} \geq 1,414: & \mathrm{M}_{\text {dist }}=\mathrm{W}_{\mathrm{c}} \mathrm{f}_{\mathrm{y}} / \lambda_{\text {dist }}{ }^{2}
\end{array}
$$

$\mathrm{W}_{\mathrm{c}}$ conforme definido em 7.8.1.2;

$\lambda_{\text {dist }}$ é o índice de esbeltez reduzido referente à flambagem por distorção, dado por:

$$
\lambda_{\text {dist }}=\left(f_{\mathrm{y}} / \sigma_{\text {dist }}\right)^{0,5}
$$

$\sigma_{\text {dist }}$ é a tensão convencional de flambagem elástica por distorção, calculada pela teoria da estabilidade elástica ou conforme anexo D.

\subsubsection{Barras com painel conectado à mesa tracionada}

A contenção lateral proveniente do painel conectado à mesa tracionada pode ser desprezada. O momento fletor resistente de cálculo, considerando o efeito da referida contenção lateral, pode ser calculado conforme anexo F. 


\subsubsection{Força cortante}

A força cortante resistente de cálculo $V_{R d}$ deve ser calculada por:

- para $\mathrm{h} / \mathrm{t} \leq 1,08\left(\mathrm{Ek}_{\mathrm{v}} / \mathrm{f}_{\mathrm{y}}\right)^{0,5}$

$$
\begin{gathered}
\mathrm{V}_{\mathrm{Rd}}=0,6 \mathrm{f}_{\mathrm{y}} \mathrm{ht} / \gamma \quad(\gamma=1,1) \\
\text { - para } 1,08\left(\mathrm{Ek}_{\mathrm{v}} / \mathrm{f}_{\mathrm{y}}\right)^{0,5}<\mathrm{h} / \mathrm{t} \leq 1,4\left(\mathrm{Ek}_{\mathrm{v}} / \mathrm{f}_{\mathrm{y}}\right)^{0,5} \\
\mathrm{~V}_{\mathrm{Rd}}=0,65 \mathrm{t}^{2}\left(\mathrm{k}_{\mathrm{v}} \mathrm{f}_{\mathrm{y}} \mathrm{E}\right)^{0,5} / \gamma \quad(\gamma=1,1) \\
\text { - para } \mathrm{h} / \mathrm{t}>1,4\left(\mathrm{Ek}_{\mathrm{v}} / \mathrm{f}_{\mathrm{y}}\right)^{0,5} \\
\mathrm{~V}_{\mathrm{Rd}}=\left[0,905 \mathrm{Ek}_{\mathrm{v}} \mathrm{t}^{3} / \mathrm{h}\right] / \gamma \quad(\gamma=1,1)
\end{gathered}
$$

Onde:

t é a espessura da alma;

h é a largura da alma (altura da parte plana da alma);

$\mathrm{k}_{\mathrm{v}}$ é o coeficiente de flambagem local por cisalhamento, dado por:

- para alma sem enrijecedores transversais:

$$
\mathrm{k}_{\mathrm{v}}=5,34
$$

- para alma com enrijecedores transversais satisfazendo as exigências de 7.5 .

$$
\begin{aligned}
& k_{v}=4,0+\frac{5,34}{(a / h)^{2}} \quad \text { para } \mathrm{a} / \mathrm{h} \leq 1,0 \\
& k_{v}=5,34+\frac{4,0}{(a / h)^{2}} \quad \text { para } \mathrm{a} / \mathrm{h}>1,0
\end{aligned}
$$

a é a distância entre enrijecedores transversais de alma.

Para seções com duas ou mais almas, cada alma deve ser analisada como um elemento separado resistindo à sua parcela de força cortante.

\subsubsection{Momento fletor e força cortante combinados}


Para barras sem enrijecedores transversais de alma, o momento fletor solicitante de cálculo e a força cortante solicitante de cálculo na mesma seção, devem satisfazer à seguinte expressão de interação:

$$
\left(\mathrm{M}_{\mathrm{Sd}} / \mathrm{M}_{0, \mathrm{Rd}}\right)^{2}+\left(\mathrm{V}_{\mathrm{Sd}} / \mathrm{V}_{\mathrm{Rd}}\right)^{2} \leq 1,0
$$

Para barras com enrijecedores transversais de alma, além de serem atendidas as exigências de 7.8.1.1 e 7.8.2, quando $\mathrm{M}_{\mathrm{Sd}} / \mathrm{M}_{0, \mathrm{Rd}}>0,5$ e $\mathrm{V}_{\mathrm{Sd}} / \mathrm{V}_{\mathrm{Rd}}>0,7$ deve ser satisfeita a seguinte expressão de interação:

$$
0,6\left(\mathrm{M}_{\mathrm{Sd}} / \mathrm{M}_{0, \mathrm{Rd}}\right)+\left(\mathrm{V}_{\mathrm{Sd}} / \mathrm{V}_{\mathrm{Rd}}\right) \leq 1,3
$$

Onde:

$\mathrm{M}_{\mathrm{Sd}}$ é o momento fletor solicitante de cálculo;

$\mathrm{M}_{0, \mathrm{Rd}}$ é o momento fletor resistente de cálculo conforme 7.8.1.1;

$\mathrm{V}_{\mathrm{Sd}}$ é a força cortante solicitante de cálculo;

$\mathrm{V}_{\mathrm{Rd}}$ é a força cortante resistente de cálculo conforme 7.8.2.

\subsubsection{Barras compostas submetidas à flexão}

O espaçamento $s$, na direção do eixo da barra, entre os parafusos ou soldas de ligação de dois perfis $\mathrm{U}$, para formar um perfil $\mathrm{I}$, não deve ser maior que o seguinte valor:

$$
\mathrm{S}_{\max }=\left(2 \mathrm{gF}_{\mathrm{Rd}}\right) /(\mathrm{mq}) \leq \mathrm{L} / 6
$$

Onde:

L é o comprimento da barra;

g é a distância entre os parafusos ou soldas na direção perpendicular ao eixo da barra (ver figura 6). Se a ligação for executada junto às mesas dos perfis, $g$ é igual à altura da barra;

$F_{R d}$ é a força resistente de cálculo do parafuso ou solda, correspondente ao tipo de esforço solicitante previsto no respectivo meio de ligação, conforme seção 8;

$m$ é a distância do centro de torção de um perfil $U$ ao plano médio da sua alma (ver figura 6); 
q é o valor de cálculo da força uniformemente distribuída de referência, igual a três vezes o valor de cálculo da força uniformemente distribuída na barra; ou igual ao valor de cálculo da força concentrada dividido pelo comprimento de atuação desta força. Se o comprimento de atuação da força concentrada for inferior ao espaçamento dos parafusos ou soldas na direção do eixo da barra $(s)$, a força resistente de cálculo do parafuso ou solda, junto à força concentrada, deve ser, no mínimo, $\mathrm{F}_{\mathrm{Rd}}=0,5 \mathrm{mF}_{\mathrm{Sd}} / \mathrm{g}$;

$F_{S d}$ é o valor de cálculo da força concentrada que atua na barra.

Se for adotado espaçamento uniforme da conexão em toda a barra, o espaçamento máximo $\left(s_{\max }\right)$ deve ser determinado com base no maior valor da força concentrada atuante na barra. Caso contrário, o espaçamento da conexão deve ser determinado considerando-se a variação do carregamento ao longo da barra. Nas seções onde atuam elevadas forças concentradas, recomenda-se que a ligação seja feita por meio de chapas conectadas às mesas dos perfis.

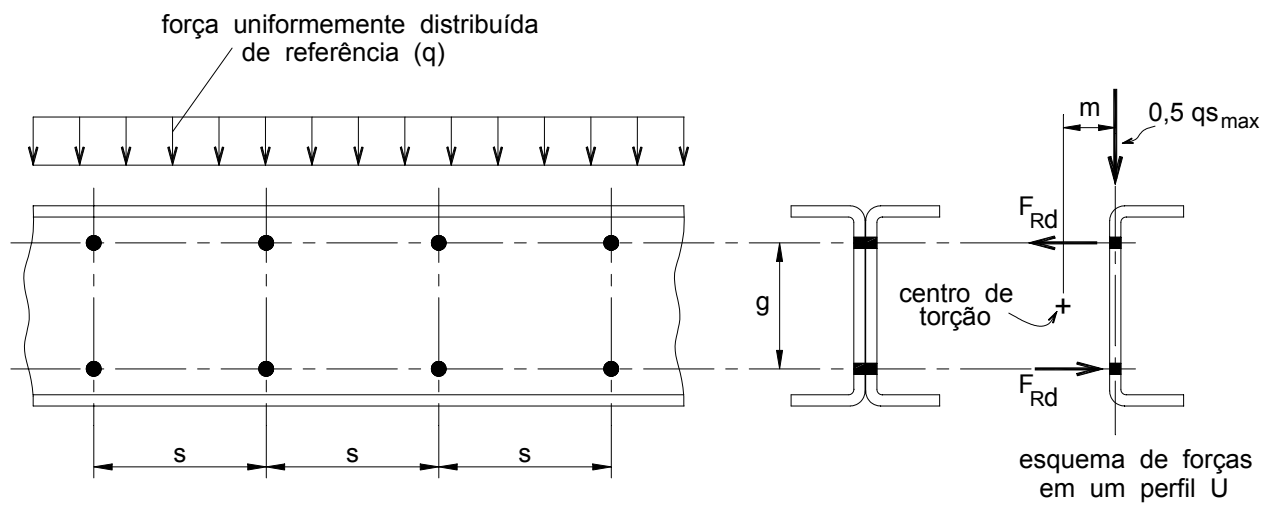

Figura 6 - Perfil I obtido pela composição de dois perfis U

\subsection{Barras submetidas à flexão composta}

\subsubsection{Generalidades}

A força normal solicitante de cálculo e os momentos fletores solicitantes de cálculo devem satisfazer as expressões de interação de 7.9.2 e 7.9.3. 


\subsubsection{Flexo-compressão}

$$
\begin{gathered}
\frac{N_{c, S d}}{N_{c, R d}}+\frac{C_{m x} M_{x, S d}}{\left(1-\frac{N_{c, S d}}{N_{e x}}\right) M_{x, R d}}+\frac{C_{m y} M_{y, S d}}{\left(1-\frac{N_{c, S d}}{N_{e y}}\right) M_{y, R d}} \leq 1,0 \\
e \\
\frac{N_{c, S d}}{N_{0, R d}}+\frac{M_{x, S d}}{M_{x, R d}}+\frac{M_{y, S d}}{M_{y, R d}} \leq 1,0
\end{gathered}
$$

Quando $\mathrm{N}_{\mathrm{c}, \mathrm{Sd}} / \mathrm{N}_{\mathrm{c}, \mathrm{Rd}} \leq 0,15$ as duas expressões anteriores podem ser substituídas por:

$$
\frac{N_{c, S d}}{N_{c, R d}}+\frac{M_{x, S d}}{M_{x, R d}}+\frac{M_{y, S d}}{M_{y, R d}} \leq 1,0
$$

Onde:

$\mathrm{N}_{\mathrm{c}, \mathrm{Sd}}$ é a força normal de compressão solicitante de cálculo, considerada constante na barra;

$\mathrm{M}_{\mathrm{x}, \mathrm{Sd}} ; \mathrm{M}_{\mathrm{y}, \mathrm{Sd}}$ são os momentos fletores solicitantes de cálculo, na seção considerada, em relação aos eixos $x$ e $y$, respectivamente;

$\mathrm{N}_{c, R d}$ é a força normal de compressão resistente de cálculo, conforme 7.7;

$\mathrm{N}_{0, \mathrm{Rd}}$ é a força normal de compressão resistente de cálculo, calculada conforme 7.7, tomando-se $\rho=1,0$;

$\mathrm{M}_{\mathrm{x}, \mathrm{Rd}} ; \mathrm{M}_{\mathrm{y}, \mathrm{Rd}}$ são os momentos fletores resistentes de cálculo, em relação aos eixos $x$ e $y$, respectivamente, calculados conforme 7.8.1 com $\mathrm{C}_{\mathrm{b}}=1,0$.

$\mathrm{N}_{\mathrm{ex}} ; \mathrm{N}_{\mathrm{ey}}$ são as forças normais de flambagem elástica, em relação aos eixos $x$ e $y$, respectivamente, calculadas por:

$$
\mathrm{N}_{\mathrm{ex}}=\pi^{2} \mathrm{EI}_{\mathrm{x}} /\left(\mathrm{K}_{\mathrm{x}} \mathrm{L}_{\mathrm{x}}\right)^{2} \quad ; \quad \mathrm{N}_{\mathrm{ey}}=\pi^{2} \mathrm{EI}_{\mathrm{y}} /\left(\mathrm{K}_{\mathrm{y}} \mathrm{L}_{\mathrm{y}}\right)^{2}
$$

$\mathrm{I}_{\mathrm{x}} ; \mathrm{I}_{\mathrm{y}}$ são os momentos de inércia da seção bruta em relação aos eixos $x$ e $y$, respectivamente;

$\left(\mathrm{K}_{\mathrm{x}} \mathrm{L}_{\mathrm{x}}\right) ;\left(\mathrm{K}_{\mathrm{y}} \mathrm{L}_{\mathrm{y}}\right)$ são os comprimentos efetivos de flambagem em relação aos eixos $x$ e $y$, respectivamente; 
$\mathrm{C}_{\mathrm{mx}} ; \mathrm{C}_{\mathrm{my}}$ são os coeficientes de equivalência de momento na flexão composta, em relação aos eixos $x$ e $y$, respectivamente, determinados conforme a), b) ou c) seguintes:

a) barras de estruturas indeslocáveis, sem ações transversais entre as extremidades:

$$
\mathrm{C}_{\mathrm{m}}=0,6-0,4\left(\mathrm{M}_{1} / \mathrm{M}_{2}\right)
$$

$\mathrm{M}_{1}$ é o menor e $\mathrm{M}_{2}$ o maior dos dois momentos fletores solicitantes de cálculo nas extremidades do trecho sem travamento lateral. A relação $\mathrm{M}_{1} / \mathrm{M}_{2}$ é positiva quando esses momentos provocarem curvatura reversa e negativa em caso de curvatura simples.

b) barras de estruturas indeslocáveis, sujeitas à ações transversais entre as extremidades:

Caso não sejam determinados de maneira mais precisa, os seguintes valores de $\mathrm{C}_{\mathrm{m}}$ podem ser adotados:

1) para ambas as extremidades da barra engastadas: $\mathrm{C}_{m}=0,85$

2) para os demais casos: $C_{m}=1,0$

c) barras de estruturas deslocáveis: $\mathrm{C}_{\mathrm{m}}=1,0$

Valores de $\mathrm{C}_{\mathrm{m}}$ inferiores a 1,0 podem ser adotados, desde que justificados com base em bibliografia especializada.

\subsubsection{Flexo-tração}

$$
\begin{gathered}
\frac{M_{x, S d}}{M_{x t, R d}}+\frac{M_{y, S d}}{M_{y t, R d}}+\frac{N_{t, S d}}{N_{t, R d}} \leq 1,0 \\
e \\
\frac{M_{x, S d}}{M_{x, R d}}+\frac{M_{y, S d}}{M_{y, R d}}-\frac{N_{t, S d}}{N_{t, R d}} \leq 1,0
\end{gathered}
$$

Onde:

$\mathrm{N}_{\mathrm{t}, \mathrm{Sd}}$ é a força normal de tração solicitante de cálculo, considerada constante na barra;

$\mathrm{M}_{\mathrm{x}, \mathrm{Sd}} ; \mathrm{M}_{\mathrm{y}, \mathrm{Sd}}$ são os momentos fletores solicitantes de cálculo, na seção considerada, em relação aos eixos $x$ e $y$, respectivamente; 
$\mathrm{N}_{\mathrm{t}, \mathrm{Rd}}$ é a força normal de tração resistente de cálculo, conforme 7.6;

$\mathrm{M}_{\mathrm{xt}, \mathrm{Rd}} ; \mathrm{M}_{\mathrm{yt} \text {,Rd }}$ são os momentos fletores resistentes de cálculo, na seção considerada, em relação aos eixos $x$ e $y$, respectivamente, calculados com base no escoamento da fibra tracionada da seção bruta, dados por $\mathrm{M}_{\mathrm{xt}, \mathrm{Rd}}=$ $\mathrm{W}_{\mathrm{xt}} \mathrm{f}_{\mathrm{y}} / \gamma$ e $\mathrm{M}_{\mathrm{yt}, \mathrm{Rd}}=\mathrm{W}_{\mathrm{yt}} \mathrm{f}_{\mathrm{y}} / \gamma \operatorname{com} \gamma=1,1$;

$\mathrm{W}_{\mathrm{xt}} ; \mathrm{W}_{\mathrm{yt}}$ são os módulos de resistência elásticos da seção bruta em relação aos eixos $x$ e $y$, respectivamente, referentes à fibra tracionada;

$\mathrm{M}_{\mathrm{x}, \mathrm{Rd}} ; \mathrm{M}_{\mathrm{y}, \mathrm{Rd}}$ são os momentos fletores resistentes de cálculo, em relação aos eixos $x$ e $y$, respectivamente, conforme 7.8.1. 


\section{REFERÊNCIASBIBUOGRÁFICAS}

ARENDT, C. (1997). O exaustivo caminho da recuperação. Sobre a abordagem técnica das edificações históricas. IV CONGRESSO IBEROAMERICANO DE PATOLOGÍA DAS CONSTRUÇÕES. Porto Alegre, 1997. v.2, p. 110-112.

AMERICAN IRON AND STEEL INSTITUTE ( 1996). Load and resistance factor design specification for cold-formed steel structural members. Washington, AISI.

ASSOCIAÇÃO BRASILEIRA DE NORMAS TÉCNICAS (1967). NB 143 Cálculo de estruturas de aço, constituídas por perfis leves. Rio de Janeiro. ABNT.

ASSOCIAÇÃO BRASILEIRA DE NORMAS TÉCNICAS (1980). NBR 6355 Perfis Estruturais de aço formados a frio. Rio de Janeiro. ABNT

ASSOCIAÇÃO BRASILEIRA DE NORMAS TÉCNICAS (1984). NBR 8681 Ações e segurança nas Estruturas. Rio de Janeiro. ABNT.

ASSOCIAÇÃO BRASILEIRA DE NORMAS TÉCNICAS (1986). NBR 8800 Projeto e execução de estruturas de aço de edifícios. Rio de Janeiro. ABNT

BATISTA, E.M.\& RODRIGUES, F.C. (1997). Bases para um projeto de norma brasileira para dimensionamento de perfis estruturais de chapa dobrada. In: JORNADAS SUL-AMERICANAS DE ENGENHARIA ESTRUTURAL, 28., São Carlos, 1-5 set. 1997. Departamento de Estruturas - EESC - USP/ Associação Sul-americana de engenharia Estrutural, 1997. V.6, p.2323-2332. 
CAlAVERA, J. Et al. (1987). Curso de Rehabilitacion. La Estructura. Colégio Oficial de Arquitectos., Madrid.

CALIL JUNIOR, C. ; BARALDI, L. T. ; STAMATO, G. C. ; FERREIRA, N.S.S. (2001). Estruturas de Madeira (Notas de aula). São Carlos, EESC, USP.

CARTA DE VENEZA (1964). Documento de Restauro.Veneza,. 1964.

CORDOVIL, F. A.; LORIGGIO,D.D. (1992). Recuperação de uma estrutura de madeira. In: IV ENCONTRO BRASILEIRO EM MADEIRA E EM ESTRUTURAS DE MADEIRA. São Carlos, 1992. v.3, p. 201-208.

DIMENSIONAMENTO de estruturas de aço constituídas por perfis formados a frio: projeto de norma brasileira. São Carlos. 2001.

EUROPEAN COMMITTEE FOR STANDARDISATION (1996). Eurocode 3 Design of steel structures: part 1.3 - general rules: supplementary rules for cold-formed thin gauge members and sheeting. Brussels.

KLEIN, D. L. ; MUNIZ, A. R. ; MORO, A. M. (1999). Metodología para a recuperação de obras históricas. In: V CONGRESSO IBEROAMERICANO DE PATOLOGIA DE LAS CONSTRUCIONES. Montevideo, 1999. v.2, p. 16011605.

MAZZOLANI, F. M. (1996). Strengthening options in rehabilitation by means of steelworks. In: $5^{\text {th }}$ INTERNATIONAL COLLOQUIUM ON STRUCTURAL STABILITY. Rio de Janeiro, 1996. v.1, p. 275-287.

PIZZI, C. O. ; GUEVARA, M. B. (1997). Proyecto de recuperacíon estructural de lãs torres - Tanques Del Edificio Central de la administración nacional de Aduana. In: IV CONGRESSO IBEROAMERICANO DE PATOLOGÍA DAS CONSTRUÇÕES. Porto Alegre, 1997. v.2, p. 717-718.

PUCCIONI , S. (1997). Restauração Estrutural, uma metodologia de diagnóstico. Rio de Janeiro. 163p. Dissertação (Mestrado). FAU-UFRJ. 
REIS, M. V. M. (1996). Uma proposta de padronização de telhados coloniais em estruturas metálicas. Ouro Preto. Dissertação (Mestrado). UFOP.

RIBEIRO, R.T.M. (1997). Recuperação de obras históricas- Restauração da Casa França-Brasil(RJ). In: IV CONGRESSO IBEROAMERICANO DE PATOLOGÍA DAS CONSTRUÇÕES. Porto Alegre, 1997. v.2. p. 681-683.

STANDARDS AUSTRALIA/STANDARDS NEW ZEALAND (1996) . AS/NZS 4600 - Cold-formed steel structures. Australia/New Zealand.

YU, W.W. (1991). Cold-formed steel design.2 ${ }^{\mathrm{a}}$ ed. New York, John Wiley \& Sons. 